\title{
Electrically Heated Ex-Reactor Pellet-Cladding Interaction (PCI) Simulations Utilizing Irradiated Zircaloy Cladding
}

\section{MICPUL!: : COVER}

Prepared by J. O. Barner, D. E. Fitzsimmons

Pacific Northwest Laboratory

Operated by

Battelle Memorial Institute

Prepared for

U.S. Nuclear Regulatory

Commission 


\section{DISCLAIMER}

This report was prepared as an account of work sponsored by an agency of the United States Government. Neither the United States Government nor any agency Thereof, nor any of their employees, makes any warranty, express or implied, or assumes any legal liability or responsibility for the accuracy, completeness, or usefulness of any information, apparatus, product, or process disclosed, or represents that its use would not infringe privately owned rights. Reference herein to any specific commercial product, process, or service by trade name, trademark, manufacturer, or otherwise does not necessarily constitute or imply its endorsement, recommendation, or favoring by the United States Government or any agency thereof. The views and opinions of authors expressed herein do not necessarily state or reflect those of the United States Government or any agency thereof. 


\section{DISCLAIMER}

Portions of this document may be illegible in electronic image products. Images are produced from the best available original document. 


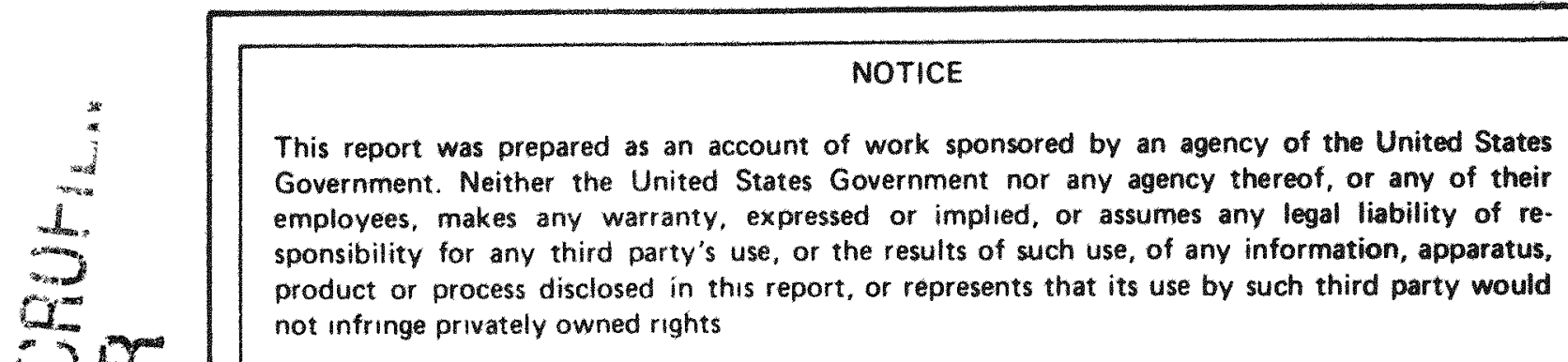

\section{NOTICE}

Availability of Reference Materials Cited in NRC Publications

Most documents cited in NRC publications will be available from one of the following sources:

1. The NRC Public Document Room, 1717 H Street, N.W. Washington, DC 20555

2. The NRC/GPO Sales Program, U.S. Nuclear Regulatory Commission, Washington, DC 20555

3. The National Technical Information Service, Springfield, VA 22161

Although the listing that follows represents the majority of documents cited in NRC publications, it is not intended to be exhaustive.

Referenced documents avalable for inspection and copying for a fee from the NRC Public Document Room include NRC correspondence and internal NRC memoranda; NRC Office of Inspection and Enforcement bulletins, circulars, information notices, inspection and investigation notices; Licensee Event Reports, vendor reports and correspondence; Commission papers; and applicant and ilcensee documents and correspondence.

The following documents in the NUREG series are avallable for purchase from the NRC/GPO Sales Program. formal NRC staff and contractor reports, NRC-sponsored conference proceedings, and NRC booklets and brochures. Also available are Regulatory Guides, NRC regulations in the Code of Federal Regulations, and Nuclear Regulatory Commıssion /ssuances.

Documents avallable from the National Technical Information Service include NUREG series reports and technical reports prepared by other federal agencies and reports prepared by the Atomic Energy Commission, forerunner agency to the Nuclear Regulatory Commission.

Documents avalable from public and special technical librarres include all open literature iterns, such as books, fournal and periodical articles, and transactions. Federal Register notices, federal and state legislation, and congressional reports can usually be obtained from these libraries.

Documents such as theses, dissertations, foreign reports and translations, and non-NRC conference proceedings are avallable for purchase from the organizatıon sponsoring the publication cited.

Single coptes of NRC draft reports are avarlable free, to the extent of supply, upon written request to the Division of Technical Information and Document Control, US Nuclear Regulatory Com. mission, Washington, DC 20555

Copies of industry codes and standards used in a substantive manner in the NRC regulatory process are maintained at the NRC Library, 7920 Norfolk Avenue, Bethesda, Maryland, and are available there for reference use by the public. Codes an'd standards are usually copyrighted and may be purchased from the originating orqanization or, if they are American National Standards, from the American National Standards Institute, 1430 Broadway, New York, NY 10018. 


\section{Electrically Heated Ex-Reactor Pellet-Cladding Interaction (PCI) Simulations Utilizing Irradiated Zircaloy Cladding}

Manuscript Completed: December 1984

Date Published: February 1985

Prepared by

J. O. Barner, D. E. Fitzsimmons

Pacific Northwest Laboratory

Richland, WA 99352

\section{Prepared for}

Division of Accident Evaluation

Office of Nuclear Regulatory Research

U.S. Nuclear Regulatory Commission

Washington, D.C. 20555

NRC FIN B2043

\section{NOTICE}

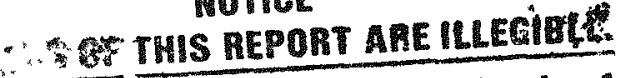

5 Den reproduced from the best

in'sle. conv to permit the broadest

ande avallability.

\section{DISCLAIMER}

This report was prepared as an account of work sponsored by an agency of the United States Government. Neither the United States Government nor any agency thereof, nor any of their employees, makes any warranty, express or implied, or assumes any legal liability or responsibility for the accuracy, completeness, or usefulness of any information, apparatus, product, or process disclosed, or represents that its use would not infringe privately owned rights. Reference herein to any specific commercial product, process, or service by trade name, trademark, manufacturer, or otherwise does not necessarily constitute or imply its endorsement, recommendation, or faworing by the United States Government or any agency thereof. The views and opinions of authors expressed herein do not necessarily state or reflect those of the United States Government or any agency thereof. 


\section{NOTICE}

This report was prepared as an account of work sponsored by an agency of the United States Government Netther the United States Government nor any agency thereof, or any of their employees. makes any warranty, expressed or implied, or assumes ny legal libility of responsibility for any third party's use, or the results of such use, of any information, apparatus. product or process disclosed in this report, or represents that its use by such third party would not infringe privately owned rights.

\section{NOTICE}

\section{Availability of Reference Materials Cited in NRC Publications}

Most documents cited in NRC publications will be available from one of the following sources:

1. The NRC Public Document Room, $1717 \mathrm{H}$ Street, N.W. Washington, DC 20555

2. The NRC/GPO Sales Program, U.S. Nuclear Regulatory Commission, Washington, DC 20555

3. The National Technical Information Service, Springfield, VA 22161

Although the listing that follows represents the majority of documents cited in NRC publications, it is not intended to be exhaustive.

Referenced documents available for inspection and copying for a fee from the NRC Public Document Room include NRC correspondence and internal NRC memoranda; NRC Office of Inspection and Enforcement bulletins, circulars, information notices, inspection and investigation notices; Licensee Event Reports; vendor reports and correspondence; Commission papers; and applicant and licensee documents and correspondence.

The following documents in the NUREG series are avallable for purchase from the NRC/GPO Sales Program: formal NRC staff and contractor reports, NRC-sponsored conference proceedings, and NRC booklets and brochures. Also available are Regulatory Guides, NRC regulations in the Code of Federal Regulations, and Nuclear Regulatory Commission issuances.

Documents available from the National Technical Information Service include NUREG series reports and technical reports prepared by other federal agencies and reports prepared by the Atomic Energy Commission, forerunner agency to the Nuclear Regulatory Commission.

Documents available from public and special technical libraries include all open literature items, such books. joumal and periodical articles, and transactions. Federal Register notices, federal and state legislation, and congressional reports can usually be obtained from these libraries.

Documents such as theses, dissertations, foreign reports and translations, and non-NRC conference proceedings are available for purchase from the organization sponsoring the publication cited.

Single copies of NRC draft reports are avalable free, to the extent of supply, upon written request to the Division of Technical Information and Document Control, U.S. Nuclear Regulatory Com. mission, Washington, DC 20555.

Copies of industry codes and standards used in substantive manner in the NRC regulatory proces are maintained at the NRC Library, 7920 Norfolk Avenue, Bethesda, Maryland, and are available there for reference use by the public. Codes and standards are usually copyrighted and may be purchased from the originating organization or, if they are American National Standards, from the American National Standards Institute, 1430 Broadwy. New York. NY 10018. 
,

, 


\section{ACKNOWLEDGMENTS}

The authors wish to acknowledge the sponsorship of the Fuel systems Research Branch of the U.S. Nuclear Regulatory Commission. Babcock and Wilcox Company supplied the irradiated cladding. The efforts of D. J. Deschane, H. N. Larson, and R. D. Bel1, Hanford Engineering Development Laboratory, for irradiated tube welding and ceramography are appreciated. We would also like to thank the following Pacific Northwest Laboratory staff: A. J. Anthony, experiment design; K. D. Hinkle, experiment assembly and test conducting; J. E. Coleman and H. E. Kjarmo, scanning electron microscopy; R. E. Williford, test planning, diametral measuring device design, and advice; and D. D. Lanning, program management. 
In a program sponsored by the Fuel Systems Research Branch of the U.S. Nuclear Regulatory Commission, a series of six electrically heated fuel rod simulation tests were conducted at Pacific Northwest Laboratory. The primary objective of these tests was to determine the susceptibility of irradiated pressurized-water reactor (PWR) Zircaloy-4 cladding to failures caused by pellet-cladding mechanical interaction (PCMI). A secondary objective was to acquire kinetic data (e.g., ridge growth or relaxation rates) that might be helpful in the interpretation of in-reactor performance results and/or the modeling of PCMI. No cladding failures attributable to PCMI occurred during the six tests. This report describes the testing methods, testing apparatus, fuel rod diametral strain-measuring device, and test matrix. Test results are presented and discussed. 


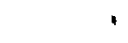

\section{,}


SUMMARY

Pacific Northwest Laboratory, under the sponsorship of the Fuel Systems Research Branch of the U.S. Nuclear Regulatory Commission, conducted six electrically heated fuel rod simulation tests using irradiated pressurized-water reactor (PWR) cold-worked Zircaloy-4 cladding. The primary objective of the tests was to determine the susceptibility of the cladding to failure due to irradiation embrittlement and/or stress-corrosion cracking (SCC). A secondary objective was to acquire kinetic data that might be helpful in the interpretation of in-reactor performance results and/or the modeling of pellet-cladding mechanical interaction (PCMI). The simulated fuel rods used a tungsten heater surrounded by annular urania fuel pellets, all within the irradiated cladding. A small fuel-cladding gap was used to promote PCMI by differential fuelcladding thermal expansion during power ascents. A diameter-measuring device was used during the tests to measure localized strain caused by PCMI. The tests were conducted in a water 10op at a temperature of $300^{\circ} \mathrm{C}$ and a pressure of $10.3 \mathrm{MPa}$. Five tests were conducted in the absence of iodine at various power/time conditions. One test was conducted by successively introducing increasing levels of iodine into the fuel rod interior. No cladding failures attributable to PCMI or SCC occurred during the six tests, probably because this type of cladding is simply not susceptible to these types of failure, although other possibilities exist (e.g., lack of sufficient irradiationinduced embrittlement or lack of adequate molecular iodine when at the stressed condition). Relatively large elastic pellet-to-pellet ridge strains were produced during the tests, with a small amount of plastic strain at the ridges after the first power cycle. The lack of ridge strain relaxation during these tests relative to that observed during in-reactor experiments indicates that a reactor environment has a significant effect on stress/strain relaxation. 
, 
CONTENTS

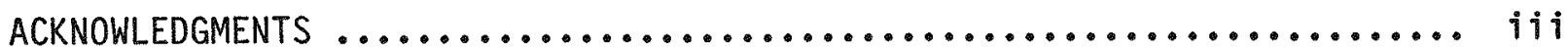

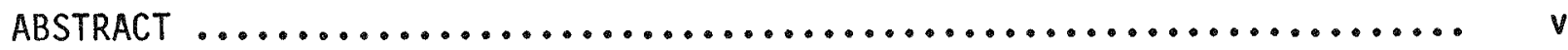

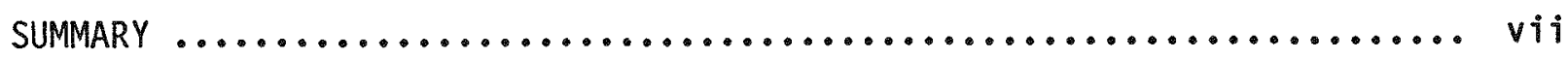

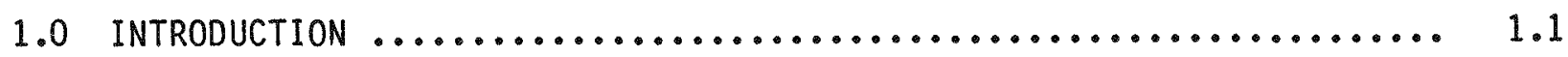

2.0 EXPERIMENT DESCRIPTION $\ldots \ldots \ldots \ldots \ldots \ldots \ldots \ldots \ldots \ldots \ldots \ldots \ldots \ldots \ldots \ldots \ldots \ldots \ldots \ldots \ldots$

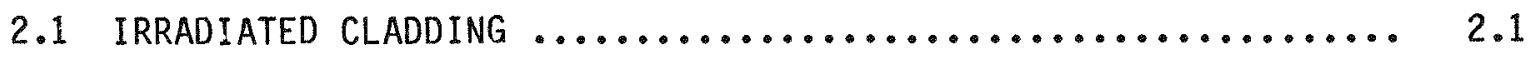

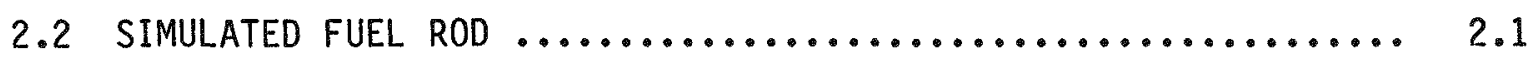

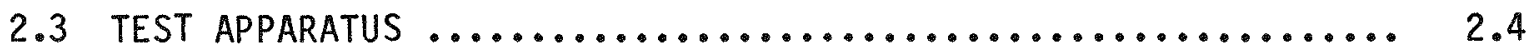

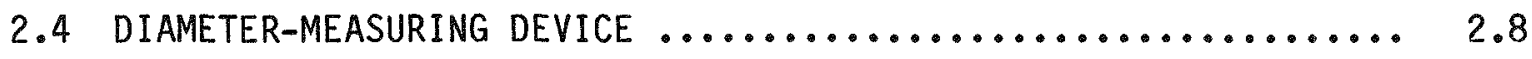

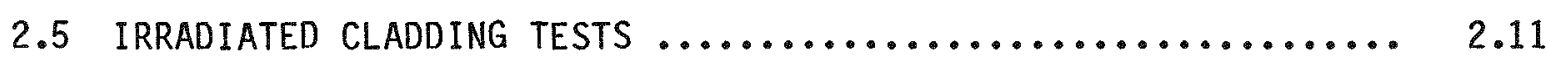

3.0 RESULTS AND DISCUSSION $\ldots \ldots \ldots \ldots \ldots \ldots \ldots \ldots \ldots \ldots \ldots \ldots \ldots \ldots \ldots \ldots \ldots \ldots \ldots \ldots \ldots$

3.1 PCMI DURING TRANSIENT OPERATION ..................... 3.1

3.2 PCMI DURING STEADY-STATE OPERATION $\ldots \ldots \ldots \ldots \ldots \ldots \ldots \ldots \ldots \ldots \ldots \ldots$

3.3 POST-TEST EXAMINATIONS $\ldots \ldots \ldots \ldots \ldots \ldots \ldots \ldots \ldots \ldots \ldots \ldots \ldots \ldots \ldots \ldots \ldots \ldots . \ldots \ldots$

3.4 COMPARISON OF TEST RESULTS $\ldots \ldots \ldots \ldots \ldots \ldots \ldots \ldots \ldots \ldots \ldots \ldots \ldots \ldots \ldots \ldots$

4.0 CONCLUSIONS ...................................... 4.1

5.0 REFERENCES .................................... 5.1

APPENDIX - BABCOCK AND WILCOX REPORT ON IRRADIATED CLADDING SELECTION AND GAMMA SCANNING .......................... A.1 


\section{FIGURES}

2.1 Schematic of Simulated Fuel Rod for PCI Testing .............. 2.3

2.2 Test Section Assembly ............................ 2.5

2.3 High-Pressure High-Temperature Water Loop ................ 2..7

2.4 Schematic of Diameter-Measuring Device $\ldots \ldots \ldots \ldots \ldots \ldots \ldots \ldots$

2.5 View of Interior of Diameter-Measuring Device .............. 2.10

2.6 View of Diameter-Measuring Device with Strain-Gage

Cantilever Uncovered ................................. 2.11

2.7 Power Histories for Tests PCII-1 Through PCII-5 ............. 2.13

2.8 Power Histories for Tests PCII-6a and PCII-6 .............. 2.15

2.9 Strain-Rate Sensitivity in Zircaloy Cladding ............... 2.16

3.1 Diameter Measurements During Power Ascent for PCII-4 .......... 3.3

3.2 Diametral Strain During Power Ascent for PCII-1 Test .......... 3.4

3.3 Diametral Strain During First Power Cycle for PCII-2 Test ....... 3.5

3.4 Diametral Strain During Second Power Cycle for PCII-2 Test ...... 3.6

3.5 Diametral Strain During Third Power Cycle for PCII-2 Test ........ 3.7

3.6 Summary of Diametral Strain During Power Ascents for PCII-2

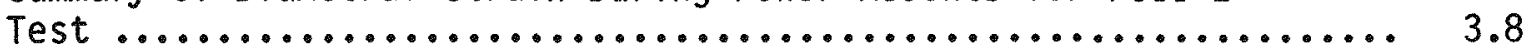

3.7 Summary of Diametral Strain During Power Descents for PCII-2

Test .......................................... 3.9

3.8 Diametral Strain During Power Ascent for PCII-3 Test ........... 3..10

3.9 Diametral Strain During First Power Cycle for PCII-4 Test ....... 3.11

3.10 Diametral Strain During Second Power Ascent for PCII-4 Test ..... 3.12

3.11 Diametral Strain During Third Power Ascent for PCII-4 Test ...... 3.13

3.12 Diametral Strain During Fourth Power Ascent for PCII-4 Test ...... 3.14

3.13 Diametral Strain During Fifth Power Ascent for PCII-4 Test ...... 3.15

3.14 Diametral Strain During the Power Cycle for PCII-5 Test ........ 3.16 
3.15 Diametral Strain During Power Cycles for PCII-6 Test........... 3.17

3.16 Diametral Strain During Power Holding Periods for PCII-1 Test .... 3.20

3.17 Diametral Strain During Power Holding Periods at $21.3 \mathrm{~kW} / \mathrm{m}$

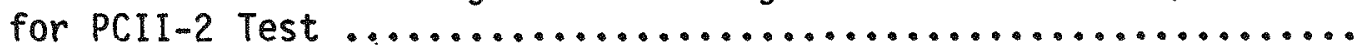

3.18 Diametral Strain During Power Holding Periods for PCII-3 Test .... 3.22

3.19 Diametral Strain During Power Holding Periods and After Second Through Fifth Power Cycles for PCII-4 Test ............. 3.23

3.20 Diametral Strain During Power Holding Periods for PCII-5 Test .... 3.24

3.21 Summary of Diametral Strain During Power Holding Periods for PCII-2 Through PCII-5 Tests .............................. 3.25

3.22 Diametral Strain During Power Holding Periods for PCII-6 ....... 3.26

$3.23 X$-Radiographs of Upper Portion of Fueled Length from

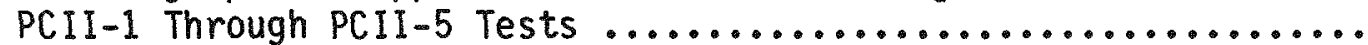

3.24 SEM View of Purposely Produced Scratch on Inner Cladding Surface for PCII-5 Test ................................ 3.30

3.25 SEM View of Ductile Failure After Bending of Cladding from

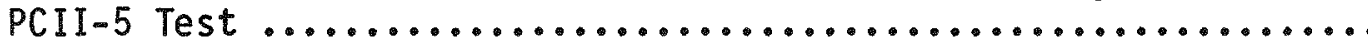

3.26 SEM View of Purposely Scratched Region on Flattened Cladding from PCII-5 Test ....................................

3.27 SEM View of Cracked Oxide on Inner Surface of Flattened Cladding from PCII-5 Test

3.28 Purposely Produced Scratch on Inner Surface of Cladding from PCII-5 Test

3.29 Oblique View of Cross Section from Near Electrically Produced

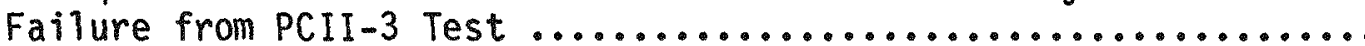

3.30 Oblique View of Typical Cross Section from PCII-5 Test ......... 3.33

3.31 Two Views of Fuel Heater-Rod Interface Near Failure Region from PCII-3 Test

3.32 Reaction Product Adhered to Tungsten Heater Rod from PCII-3 ..... 3.35

3.33 Oxide Layer on Inner Surface of Cladding from PCII-5 in Region Adjacent to Intentional Scratch 
3.34 Apparent Small Crack in Region of Intentional Scratch

in Cladding from PCII 5 ............................... 3.36 


\section{TABLES}

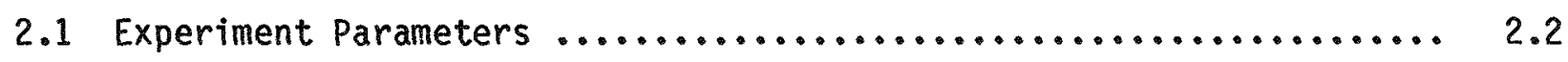

2.2 Summary of Tests and Ridge Measurements for Irradiated

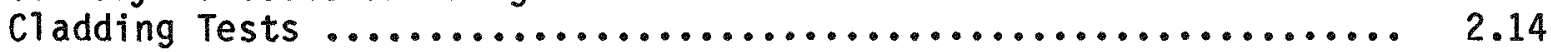

3.1 Summary of Interaction Parameters ........................ 3.19

3.2 Specimens from Simulated Fuel Rods ....................... 3.29 


\subsection{INTRODUCTION}

A small fraction of 1 ight-water reactor (LWR) fuel rods experience breach of the cladding due to pellet-cladding interaction (PCI). The PCI failure mechanism is attributed to stress-corrosion cracking (SCC); that is, chemically assisted fracture of the cladding under the mechanical load exerted by the thermally expanded fuel pellets. The chemical contribution is attributed to volatile fission products such as iodine or cadmium. Cladding failure usually occurs at or near pellet-to-pellet interfaces in regions of high cladding stress and concentrated volatile fission products. Many of the out-of-reactor experiments that have been performed to investigate the SCC phenomenon have used nonirradiated cladding and simulated fission products. It is possible, however, that an irradiation-induced mechanism in the cladding may be a primary cause of PCI failures (e.g., irradiation hardening) in combination with localized stress concentrations. A program, sponsored by the Fuel systems Research Branch of the U.S. Nuclear Regulatory Commission (NRC), was therefore initiated at Pacific Northwest Laboratory $(P N L)(a)$ to study the strain/failure behavior of the $\mathrm{UO}_{2}$-Zircaloy cladding system using electrically heated simulated fuel rods with irradiated cladding that had not been exposed to fission products.

PCI failures have occurred during transient operating conditions (i.e., when the rod power and cladding stresses were increasing), and after varying periods at elevated power when the cladding stresses were maintained at high 1evels. During ex-reactor transient simulations, nonirradiated cladding has been shown to be most sensitive to failure when the strain rate was approximately $2 \times 10^{-5} / \mathrm{min} .(1,2)$ Whether a failure occurs during a transient, after a period of high cladding stress, or not at all, has usually been attributed to a balance between the conditions necessary for crack initiation and/or growth and the presence of adequate concentrations of a corrodant. Most of the tests in this series on irradiated cladding were conducted in the strain rate range most sensitive to failure for nonirradiated cladding. If the cladding did not fail as the stress-strain was increased, the maximum test power was maintained for varying periods and, in some cases, the power was cycled in order to induce a PCI-type failure. Most tests were conducted in the absence of iodine and some tests contained intentional defects on the inner cladding surface to promote crack nucleation. A11 tests were conducted at temperature and differential pressure conditions that approximate those in a commercial pressurized-water reactor $(P W R)$.

(a) Operated for the U.S. Department of Energy by Battelle Memorial Institute. 


\subsection{EXPERIMENT DESCRIPTION}

The ex-reactor PCI simulation tests used irradiated cladding in electrically heated fuel rods that were tested in a pressurized high-temperature water loop. The diametral cladding strains were measured during the tests. The irradiated cladding is described in Section 2.1. The simulated fuel rod is described in Section 2.2; the test apparatus, in Section 2.3; and the diametermeasuring device, in Section 2.4. The individual PCI simulation tests are described in Section 2.5 .

\subsection{IRRADIATED CLADDING}

The irradiated Zircaloy-4 cladding pieces used in these experiments were obtained from Babcock and Wilcox Company (B\&W), and came from tubing that was irradiated in the nonfueled and nonpressurized conditions for one cycle in the AN0-1 PWR. During irradiation the tubes were exposed to cooling water on the inside as well as the outside. The criteria for selecting the pieces were homogeneity of the inner diameter (as determined by air-gaging) and homogeneity of neutron fluence (as determined by gamma scanning). The range of inner diameters for the tubing pieces used in the tests was from 9.581 to $9.586 \mathrm{~mm}$. The mean fluence value for 12 gamma scan measurements was determined to be $2.43 \times 10^{25} \mathrm{n} / \mathrm{m}^{2},(E>0.1 \mathrm{MeV})$, with standard deviation of $16 \%$.

The only unusual feature in the properties for the cladding was the yield strength, which was $547 \mathrm{MPa}$ at room temperature and $372 \mathrm{MPa}$ at $650 \mathrm{~F}$, these values are somewhat higher than usual for stress-relieved, cold worked cladding. Additional information concerning the cladding is presented in the B\&W report reproduced in Appendix A of this report.

\subsection{SIMULATED FUEL ROD}

The simulated fuel rod (Table 2.1 and Figure 2.1) consisted of two major components: the irradiated tube assembly, and the heater-pellet assembly, which was inserted into the irradiated tube assembly. The tube assembly consisted of a central piece of irradiated Zircaloy-4 approximately $470 \mathrm{~mm}$ (18-1/2 in.) long to which nonirradiated Zircaloy-4 extender tubes of a similar size were buttwelded. The lower extender tube was closed with a welded end plug to keep water from intruding into the simulated fuel rod. The upper extender tube had an adapter welded to the upper end for mating to the pressure housing assembiy. Overall length of the irradiated tube assembly was about $1067 \mathrm{~mm}$ (42 in.).

The heater-pellet assembly consisted of a central 457-mm (18-in.)-long tungsten heater rod with surrounding annular fuel pellets. Copper extension 
TABLE 2.1. Experiment Parameters

Item

Heater
Diameter, mm (in.)
Heated length, mm (in.)
End adapters

Fuel pellets

Diameter, mm (in.)

Length, mm (in.)

Type

Cladding

Outside dia. (OD), mm (in.)

Inside dia. (ID), mm (in.)

Equivalent burnup, MWd/kgM

End adapters

Fil1 gas

Pressure, $\mathrm{kPa}$ (psig)

Description

Tungsten

$3.81(0.150)$

457 (18)

$\mathrm{A}_{2} \mathrm{O}_{3}$-coated copper

Depleted $\mathrm{UO}_{2}$, nonirradiated

$9.50(0.374)$

$12.7(0.50)$

Dished, annular, $3.84 \mathrm{~mm}$ (0.15 in.) ID

Zircaloy -4 , irradiated one PWR cycle

$10.92(0.430)$

$9.58(0.377)$

7

Zircaloy-4, nonirradiated

Hel ium

$82.7(12)$

electrodes were soldered to the ends of the tungsten heater rod. With the heater-pellet assembly in place in the irradiated tube assembly, the heaterpellet column was centered within the length of the irradiated tube. The upper copper electrode extended beyond the end of the irradiated tube assembly by approximately $241 \mathrm{~mm}$ (9-1/2 in.), bringing the overall length of the simulated fuel pin to about $1308 \mathrm{~mm}(51-1 / 2 \mathrm{in.}$. The portion of the upper electrode that was within the irradiated tube assembly was electrically insulated from the tube assembly by a flame-sprayed alumina insulating layer. After the simulated fuel rod was installed in the pressure housing assembly (Section 2.3), electrical connections were made to the rod to supply electrical current. The voltage connections were made by bolting one voltage clamp onto the upper end of the upper electrode and another onto the lower tube extension, deforming the tube onto the lower copper electrode.

The 0.08-mm (0.003-in.) fuel-cladding diametral gap was selected to promote mechanical interaction during the tests. The internal volume of the simu1 ated fuel rod was degassed by evacuating the system with a mechanical floor pump for at least 12 hours at a temperature of $300^{\circ} \mathrm{C}$ before pumping and by 




FIGURE 2.1. Schematic of Simulated Fuel Rod for PCI Testing 
backfilling the system at least three times with helium. The final atmosphere in the fuel rod was helium at an absolute pressure of $184 \mathrm{kPa}$ (26.7 psia) for the tests without iodine and $115 \mathrm{kPa}(16.7 \mathrm{psia})$ for the tests with iodine.

\subsection{TEST APPARATUS}

Test Section Assembly

The test section assembiy consisted of the simulated fuel rod, a pressure housing assembly, and a diameter-measuring device. The simulated fuel rod was installed in the pressure housing assembly that also contained the diametermeasuring device and the electrical connections for powering the simulated fuel rod assembly, and that served as the flow duct for directing coolant past the simulated fuel rod (Figure 2.2) The pressure housing assembly was made up of a vertically mounted 74-mm (2.90-in.)-ID flanged pipe, upper and lower plenum pipes of $113 \mathrm{~mm}$ (4.44 in.) ID, and 3-in. 1500-1b-class closure flanges at each end; all of these components were Type 316 stainless steel. Flow from the test loop entered the pressure housing assembly through the lower closure flange, passed the simulated fuel rod, and exited through a side port in the upper flow plenum pipe.

The simulated fuel rod was mounted in the upper closure flange and extended through the upper plenum and the flanged pipe; its lower end terminated in the lower plenum. The adaptor on the upper end of the irradiated tube assembly portion of the simulated fuel rod was connected to the upper closure flange with a pressure-tight seal. The upper copper electrode of the heaterpellet assembly extended through a central hole in the upper closure flange and then passed through a gas plenum mounted to, but electrically insulated from, the outer face of the closure flange. An electrical clamp, bolted to the upper electrode, was connected to cables from the positive polarity bus of the power supply.

The interior of the gas plenum connected to the interior of the simulated fuel rod, providing a passage for controlling the atmosphere within the simulated fuel rod. Elastomer 0-ring seals sealed the upper electrode where it passed through the gas plenum. A manifold connected to a port on the gas plenum provided access to both a vacuum pump and a helium gas source. Before testing, the surfaces of the heater-pellet assembly and the interior of the irradiated tube assembly were out-gassed overnight at a temperature of $300^{\circ} \mathrm{C}$ under vacuum. The gas volume was then backfilled and evacuated several times. Before electrical power was applied to the heater, the gas volume was backfilled with helium.

In preparation for conducting PCII-6, the gas manifold was changed to allow the injection of iodine into the gas atmosphere. The new manifold included three tubes, each capped at one end and connected by a valve at the 

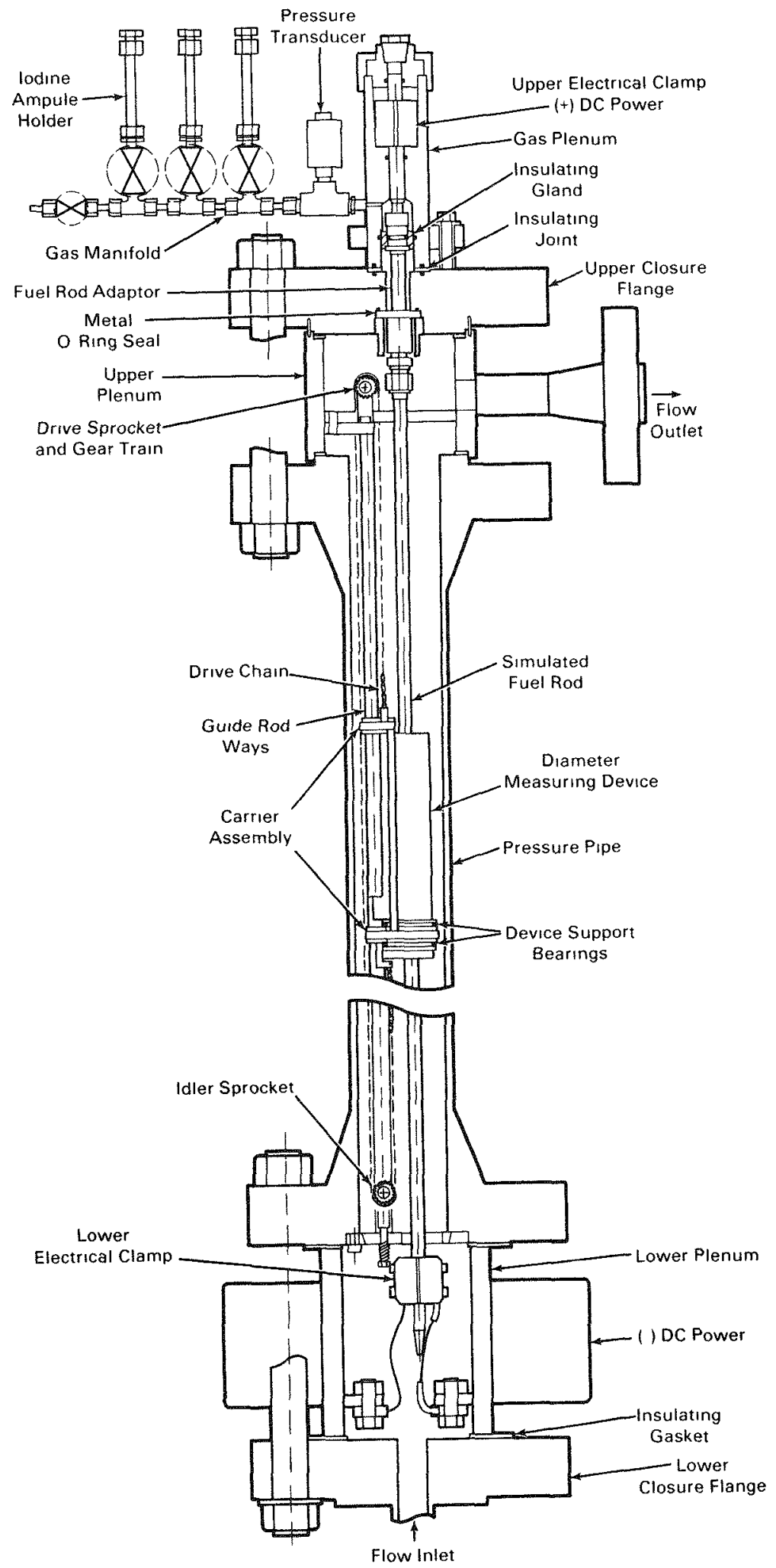

FIGURE 2.2. Test Section Assembly 
other end to a common header. Each of these capped tubes held an ampule containing a measured amount of iodine crystals. The entire manifold, the gas plenum, and a pressure transducer to measure the gas pressure were wrapped with trace heaters and insulation. Before testing, the gas volumes for the manifold were heated to $200^{\circ} \mathrm{C}$ to vaporize the iodine. Before the final helium backfill, the iodine was introduced into the evacuated gas manifold by valving open the tube containing the selected ampule, then flattening the tube to break the ampule.

The lower plenum pipe of the pressure housing assembly contained the electrical terminal lugs for connection to the lower end of the simulated fuel rod. An electrical clamp, bolted to the lower end of the simulated fuel rod, was connected to the lower plenum interior terminal lugs through flexible, multistrand lead wires. Cables from the negative polarity bus of the power supply were connected to the exterior lugs on the lower plenum.

The diameter-measuring device, which was mounted to and supported from the upper plenum pipe, is described in Section 2.4.

Flow Loop

The test section assembly was installed in the test section position of a high-pressure, high-temperature water loop located in the Thermal Hydraulics Laboratory at PNL. The 10op, made of 300 series stainless steel and shown in Figure 2.3, included a circulating pump, a pressurizer, water heaters, and a heat exchanger together with appropriate flow control values and instrumentation. The loop flow was circulated by a $1890-\mathrm{cm}^{3} / \mathrm{s}(30-\mathrm{gpm}), 122-\mathrm{m}(400-\mathrm{ft})$ sealless pump. A 10- $\mathrm{m}$ full-flow filter located downstream of the test section limited the circulation of any particles that might be released from the test specimens. Safety circuit instrumentation permitted the loop to operate unattended overnight, facilitating the bakeout of the simulated fuel rods. The operating conditions for the tests were:

$\begin{array}{ll}\text { Coolant } & \text { Deionized water } \\ \text { Pressure, MPa (psig) } & 10.3(1500) \\ \text { Temperature, }{ }^{\circ} \mathrm{C} & 300 \\ \text { Flow rate, } \mathrm{cm}^{3} / \mathrm{s}(\mathrm{gpm}) & 1890(30)\end{array}$

\section{Power Supply}

The electrically heated fuel pins were powered by a silicon-controlled rectifier power supply that had a filtered output and was rated at $30 \mathrm{~V}(\mathrm{dc})$, $1250 \mathrm{~A}$, and $37.5 \mathrm{~kW}$. The power supply included both voltage-limit and currentlimit controls that permitted the heater power to be closely controlled. This setup was very useful in applying power to the tungsten heater with its large change in resistance with temperature. A digital data logger and a strip chart 


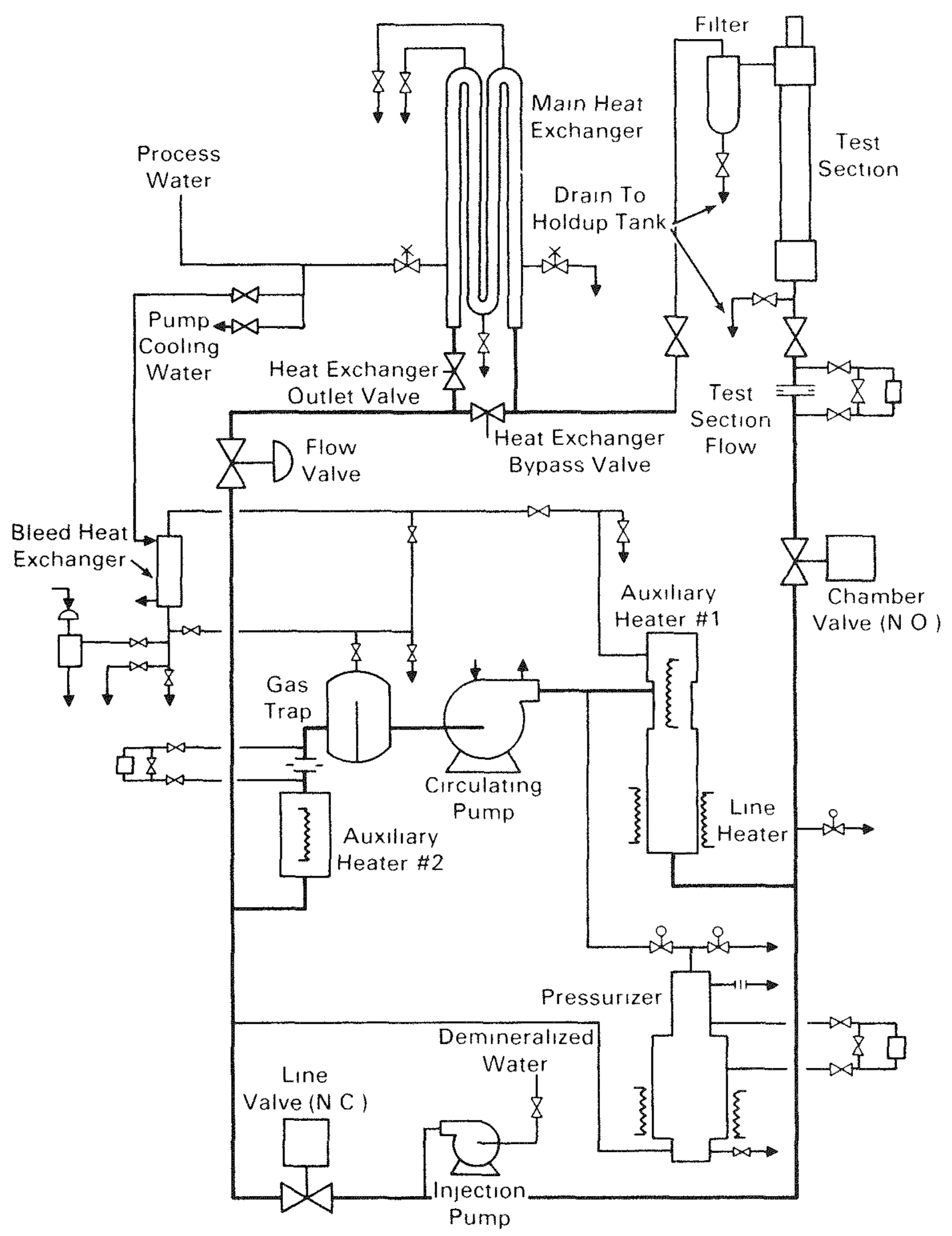

FIGURE 2.3. High-Pressure High-Temperature Water Loop

recorder were the principal devices used to record the test data. The data logger recorded the test section inlet and outlet temperature, pressure and flow rate, and the volts and amperes delivered to the simulated fuel rod. As described in Section 2.4, the strip chart recorder was used with the diametermeasuring device. 


\subsection{DIAMETER-MEASURING DEVICE}

An instrument was designed and constructed to measure the diameter of the simulated fuel rod at orthogonal positions along the length of the rod. The device, as illustrated in Figure 2.4, consisted of a body with an axial hole within which were mounted two fixed probes, $90^{\circ}$ apart in the same plane. Directly opposite each of the fixed probes was a movable probe, mounted to a lever arm which pivoted in the device body. The opposite end of the lever arm was in contact with a cantilever beam to which a strain gage was attached. When the simulated fuel rod was inserted into the device body, the probes contacted a rod diameter. A change in rod diameter moved the probe on the lever arm which in turn deflected the cantilever beam. The unequal-length arms of the lever arm amplified the movement of the probe by a ratio of $8: 1$, which resulted in a significant displacement of the cantilever beam and the corresponding change in output of the strain gage. A diameter change of $0.005 \mathrm{~mm}$ $(0.0002$ in.) was readily resolvable. Figure 2.5 shows an end view of the device with the silicon carbide tipped probes visible in the bore of the body of the device.

The device was calibrated in situ by traversing the probes over measured diameter steps machined into the tube extensions outside of the heated length of the rod. The change in the strain gage output associated with the diameter change at the steps served to calibrate the probe movement.

To make diameter measurements along the length of the simulated fuel pin, the measuring device was supported by an elevator-like carrier assembly. The measurement device was joined to the carrier with double-acting flat race thrust bearings, permitting $x-y$ motion of the measurement device while restricting relative motion in the vertical axis. This arrangement was needed to enable the device to track the axis of the simulated fuel pin while making a vertical traverse.

The carrier assembly rode on bushings guided by ways consisting of a pair of rods that extended the length of the pressure housing pipe. These rods were mounted to end plates; the upper plate was attached to the upper plenum pipe. The measurement device is seen in Figure 2.6, mounted on the carrier assembly which is riding on the way rods. The leads from the two strain gages are seen passing from the device body to the carrier assembly, then coiling as they travel up the way rods. These leads passed through a gland seal in the upper plenum. The visible portion of the cantilever was covered by a shroud before instaliing the assembly in the pressure housing.

The carrier assembly was raised and lowered by a chain-and-sprocket drive that was operated by a gear train in the upper plenum. The drive mechanism consisted of a reversible drive motor mounted outside the pressure housing, a drive shaft passing through a shaft seal in the upper plenum, and the gear 


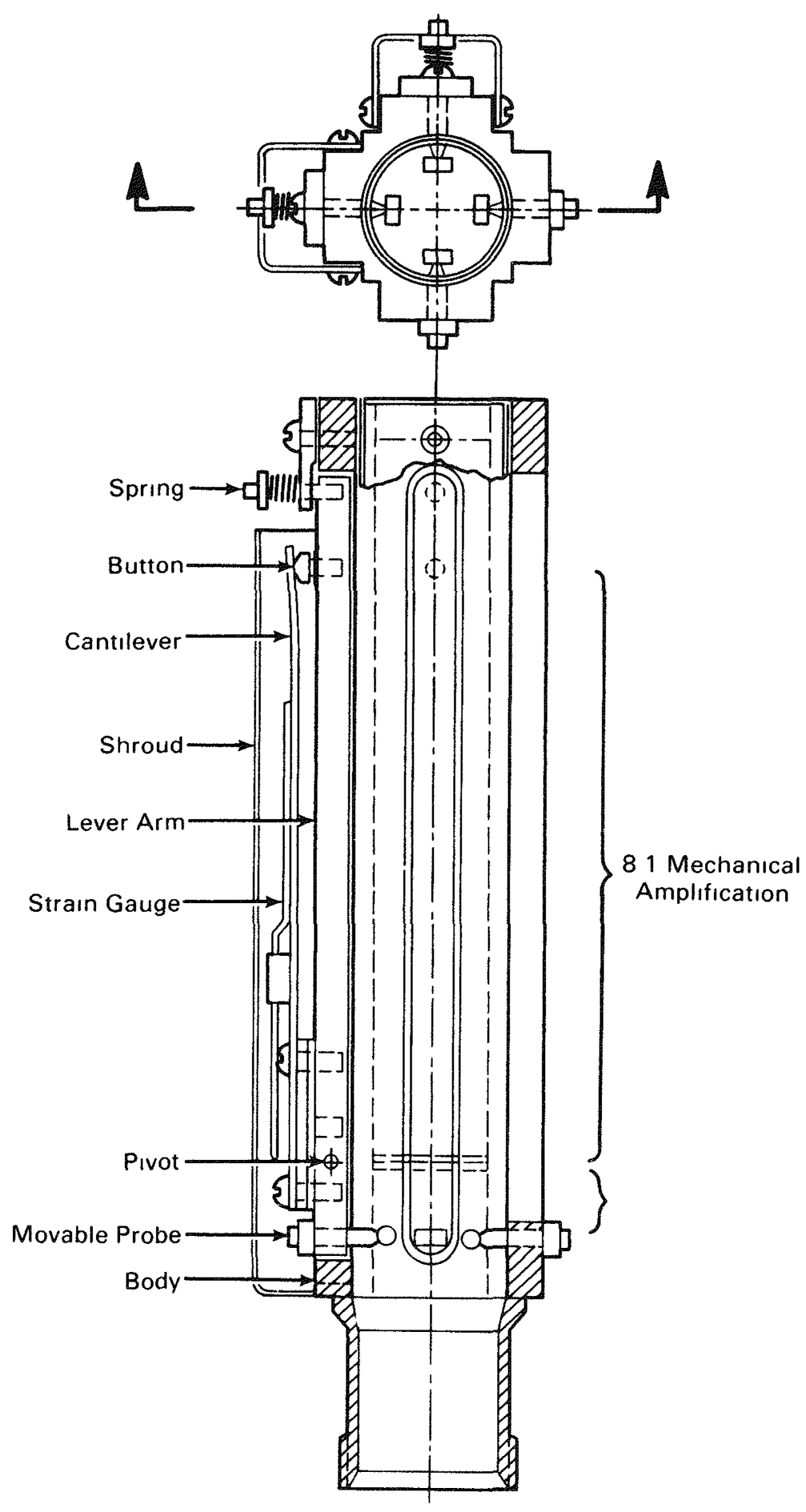

FIGURE 2.4. Schematic of Diameter-Measuring Device 


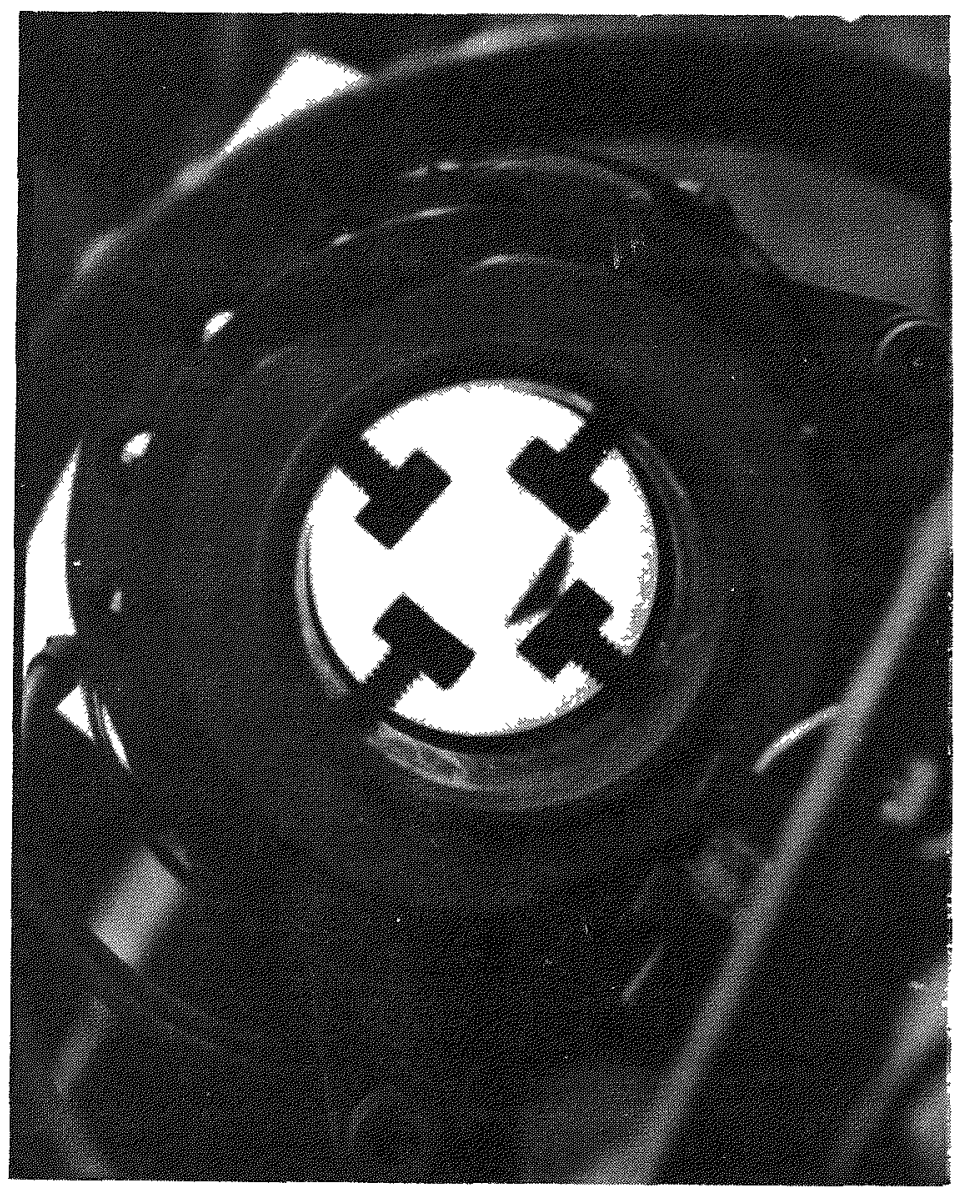

FIGURE 2.5. View of Interior of Diameter-Measuring Device

train and drive sprocket. The chain, with one end attached to the upper end of the carrier assembly, passed over the drive sprocket, then down and under an idler sprocket at the lower end plate of the way rods, then to the lower end of the carrier assembly, to which its other end was attached. Axial position and lower and upper travel 1 imits for the measurement device were determined by the output of a potentiometer operated by the drive shaft.

The strain gages used on the diameter measuring device were hermetically sealed, self-temperature-compensated, quarter-bridge units welded to the cantilevers. Duplicate strain gages mounted to cantilever-type material were installed in the upper plenum to serve as "dummy" elements. For each cantilever the active strain gage and the dummy strain gage were connected to form a half-bridge circuit in which the dummy el ement provided further temperature compensation. The half-bridge circuit was connected to two external inactive resistors to form a ful1-bridge that was connected to a signal conditioning 


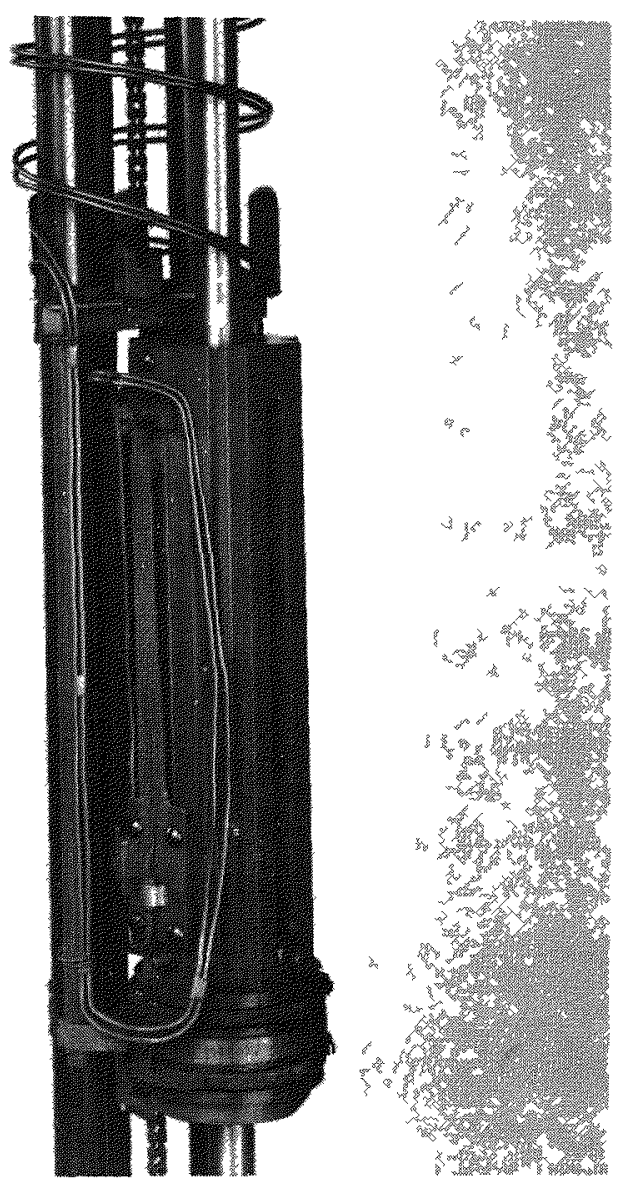

FIGURE 2.6. View of Diameter-Measuring Device with Strain-Gage Cantilever Uncovered

amplifier. The analog output of the signal conditioner was recorded on a multichannel strip chart recorder, which al so recorded axial position and time increments.

\subsection{IRRADIATED CLADDING TESTS}

A total of nine PCI simulation tests were conducted. Two tests were initially performed with nonirradiated cladding to check out the experimental system; however, the final design of the strain-measuring device was not complete at the time of these tests. The strain-measuring device used during these tests was not capable of axial translation, and ridge strains were not measured; therefore, these tests are not discussed in this report. The next five tests were conducted using irradiated cladding and the diametral strainmeasuring device, but no iodine was used in the tests. The power histories for 
PCII-1 through -5 are shown in Figure 2.7.(a) These tests are discussed in detail below. Finally, iodine was introduced during the eighth and ninth tests to promote SCC. The eighth test (PCII-6a) used nonirradiated cladding with three different depths of machined defects on the inner surface of the cladding, while the ninth test (PCII-6) used nondefected irradiated cladding. During the latter two tests the diametral strain device was also used. The results of the six irradiated-cladding tests are summarized in Table 2.2. The power histories for PCII-6a and 6 are shown in Figure 2.8. These two tests are also discussed in detail below.

The PCII-1 test was primarily conducted to obtain data that could be used to control the later tests; in other words, to determine 1) the linear heat generation rate (LHGR) levels at which PCMI first occurred, $\left.P_{j}, 2\right)$ the LHGR level at which significant $\mathrm{UO}_{2}$ creep or yielding permitted stress relaxation in the cladding, $P_{C}$, and 3 ) the adequacy of the translation and the measuring sensitivity of the diametral strain-measuring device. The power during subsequent tests was to be controlled at various rates between the $P_{j}$ and $P_{c}$ power levels. Because of previous difficulties, the translation of the diametermeasuring device was limited to approximately the lower half of fueled length of the simulated fuel rod for PCII-1.

For PCII-1 the LHGR was increased in approximately $3.3-\mathrm{kW} / \mathrm{m}(1-\mathrm{kW} / \mathrm{ft})$ steps (Figure 2.7) and was then held constant for varying periods up to $2 h$, during which the variation in cladding diameter along the length of the rod was measured several times. The heating rate, and resultant cladding strain rate, was not specified during the power steps for PCII-1, but was generally in the range from 1.6 to $3.3 \mathrm{~kW} / \mathrm{m}$-min $(0.5$ to $1 \mathrm{~kW} / \mathrm{ft}$-min). After $30 \mathrm{~min}$ at the peak LHGR of $26.3 \mathrm{~kW} / \mathrm{m}(8 \mathrm{~kW} / \mathrm{ft})$, the simulated fuel rod cladding failed by electrical short-circuiting through the fuel to the cladding at a point approximately $5 \mathrm{~cm}$ (2 in.) from the top of the fuel stack. Based on the initial measurement of 10 randomly selected ridges in the cladding at pellet-pellet interfaces, $P_{i}$ was determined to be approximately $6.6 \mathrm{~kW} / \mathrm{m}(2 \mathrm{~kW} / \mathrm{ft})$, while $P_{c}$ was between 19.7 and $23.0 \mathrm{~kW} / \mathrm{m}(6$ and $7 \mathrm{~kW} / \mathrm{ft})$. Subsequent analyses of al the observed ridges indicated that the $P_{C}$ was probably actually between 16.4 and $19.7 \mathrm{~kW} / \mathrm{m}$ ( 5 and $6 \mathrm{~kW} / \mathrm{ft}$ ), which is consistent with later tests.

Based on the results from the first test, the second test, PCII-2, was conducted between 6.6 and $21.3 \mathrm{~kW} / \mathrm{m}(2$ and $6.5 \mathrm{~kW} / \mathrm{ft})$ (Figure 2.7). Based on reported values of the strain rate sensitivity for failures of Zircaloy- 4

(a) Note that the calculated equivalent power ratio (i.e., the power in a centrally heated rod compared to the power in a fission-heated rod), based on differential fuel-cladding expansion, is 1.28. For example, a centrally heated rod operating at $6.0 \mathrm{KW} / \mathrm{ft}$ is equivalent to a fission-heated rod operating at $7.8 \mathrm{~kW} / \mathrm{ft}$. 


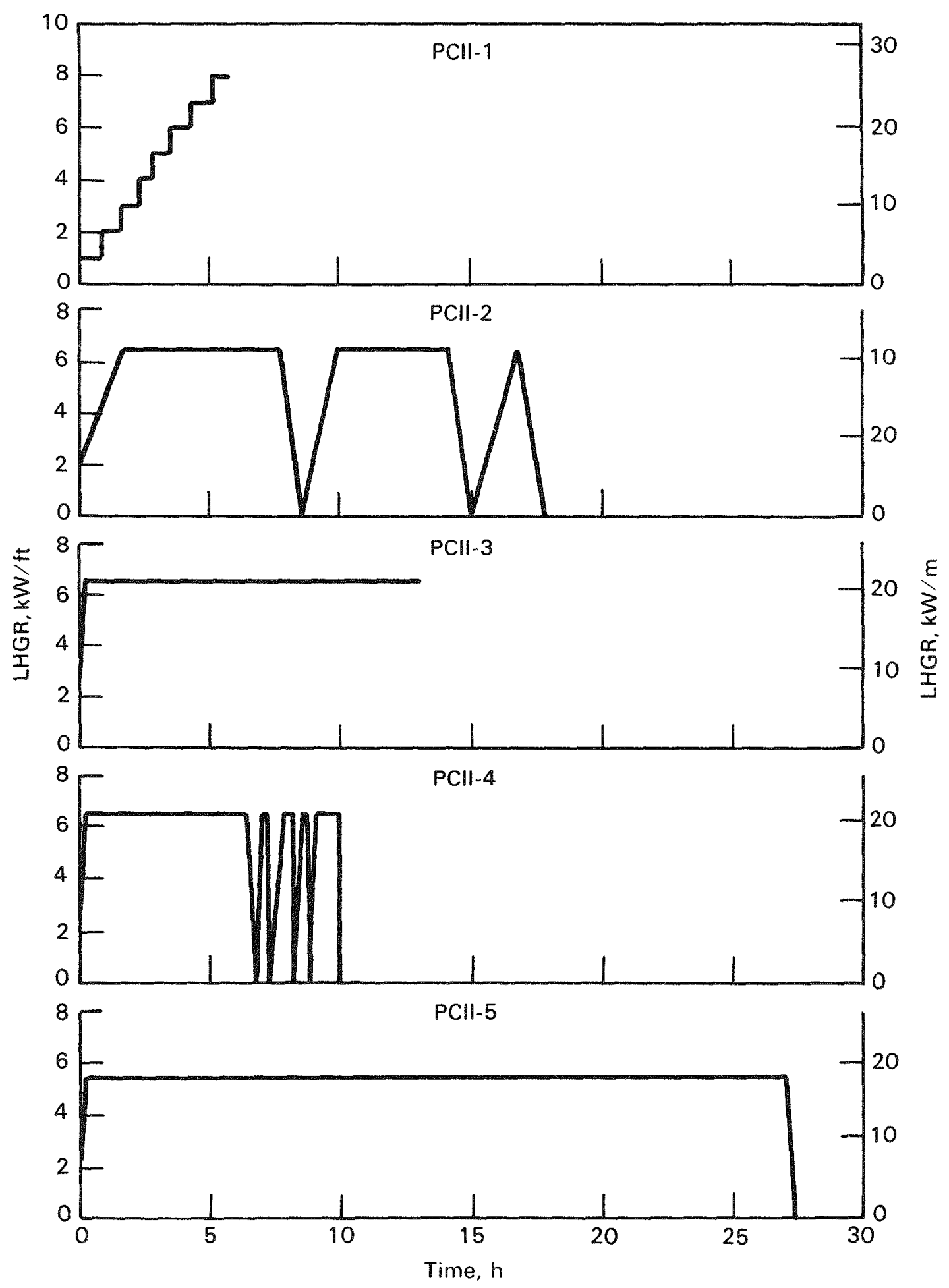

FIGURE 2.7. Power Histories for Tests PCII-1 Through PCII-5 
TABLE 2.2. Summary of Tests and Ridge Measurements (a)

for Irradiated Cladding Tests

\begin{tabular}{|c|c|c|c|c|c|c|c|}
\hline \multirow[b]{2}{*}{$\begin{array}{l}\text { Test } \\
\text { No. }\end{array}$} & \multirow[b]{2}{*}{$\begin{array}{l}\text { Power } \\
\text { Cycles } \\
\end{array}$} & \multirow{2}{*}{$\begin{array}{l}\text { Peak } \\
\text { LHGR, } \\
\mathrm{kW} / \mathrm{ft} \\
\end{array}$} & \multirow[b]{2}{*}{$\begin{array}{l}\text { Integrated Period } \\
\text { at Peak Power, } h \\
\end{array}$} & \multicolumn{2}{|c|}{$\begin{array}{l}\text { No. Ridges } \\
\text { Measured }\end{array}$} & \multicolumn{2}{|c|}{$\begin{array}{l}\text { No. Mid-Pellet } \\
\text { Ridges Measured }\end{array}$} \\
\hline & & & & Transient & $\begin{array}{l}\text { Steady- } \\
\text { State } \\
\end{array}$ & Transient & $\begin{array}{l}\text { Steady- } \\
\text { State }\end{array}$ \\
\hline 1 & 1 & 8.0 & $\sim 0.5$ & -- & 38 & -- & 38 \\
\hline $\begin{array}{l}2 \\
3 \\
4\end{array}$ & $\begin{array}{l}3 \\
1 \\
5\end{array}$ & $\begin{array}{l}6.5 \\
6.5 \\
6.5\end{array}$ & $\begin{array}{r}7.25 \\
\sim 13.0 \\
8.25\end{array}$ & $\begin{array}{l}-- \\
14 \\
12\end{array}$ & $\begin{array}{l}30 \\
20 \\
52\end{array}$ & $\begin{array}{l}-- \\
14 \\
12\end{array}$ & $\begin{array}{l}30 \\
10^{(c)} \\
52\end{array}$ \\
\hline 5 & 1 & 5.5 & 27.0 & 13 & 66 & 13 & 66 \\
\hline 6 & 3 & 10.7 & -- & 6 & 20 & -- & 20 \\
\hline
\end{tabular}

(a) Cladding strain rates were $2 \times 10^{-5} / \mathrm{min}$ for PCII-2 and $12 \times 10^{-5} / \mathrm{min}$ for PCII-3, -4 , and -5 . The strain rates were based on the sum of the general cladding strain and the pellet-pellet ridge strain produced during the PCII-1 test. Because there is a large uncertainty $(-50 \%)$ in the general cladding strain measurement, the listed strain rate should be considered to have an uncertainty of \pm 25 to $30 \%$.

(b) Ridge heights were measured during steady-state power holds during the ascent to power for PCII-1 and -2 . Ridge heights during transient conditions for PCII-3, $-4,-5$, and -6 were measured over approximately 6 pelletpellet interfaces near the center of the fueled length during the power ascent.

(c) The midpellet ridges for PCII-3 were deliberately selected to represent the largest ridges observed in the data set in order to observe any changes over time at stress. Therefore, the averages listed in Section 3.0 are much larger than for a random data set.

in the presence of iodine of about $1 \times 10^{-5} / \mathrm{min}^{(1)}$ (Figure 2.9) and $3 \times$ $10^{-5} / \mathrm{min}^{(2)}$, a strain rate of $2 \times 10^{-5} / \mathrm{min}$ was selected to promote cladding failure during the power ascent phase of the PCII-2 test. The average of the estimated total diametral strain (including ridges) and the diametral ridge height strains from PCII-1 was used to estimate the strain rate. Subsequent estimates of the total strain in later tests indicated that the average total strain was not very reproducible from measurement to measurement, varying up to $50 \%$, while the average ridge strain was much less variable. This resulted from the difficulty in assigning a reference diameter from measurement to measuremert for the total strain, while only peak heights on a single chart paper were measured for the ridges. As a result, the estimated strain rates during the power ascents for 211 the tests in this series should be considered to have an uncertainty ranging from $25 \%$ to $30 \%$ of the 1 isted value. 


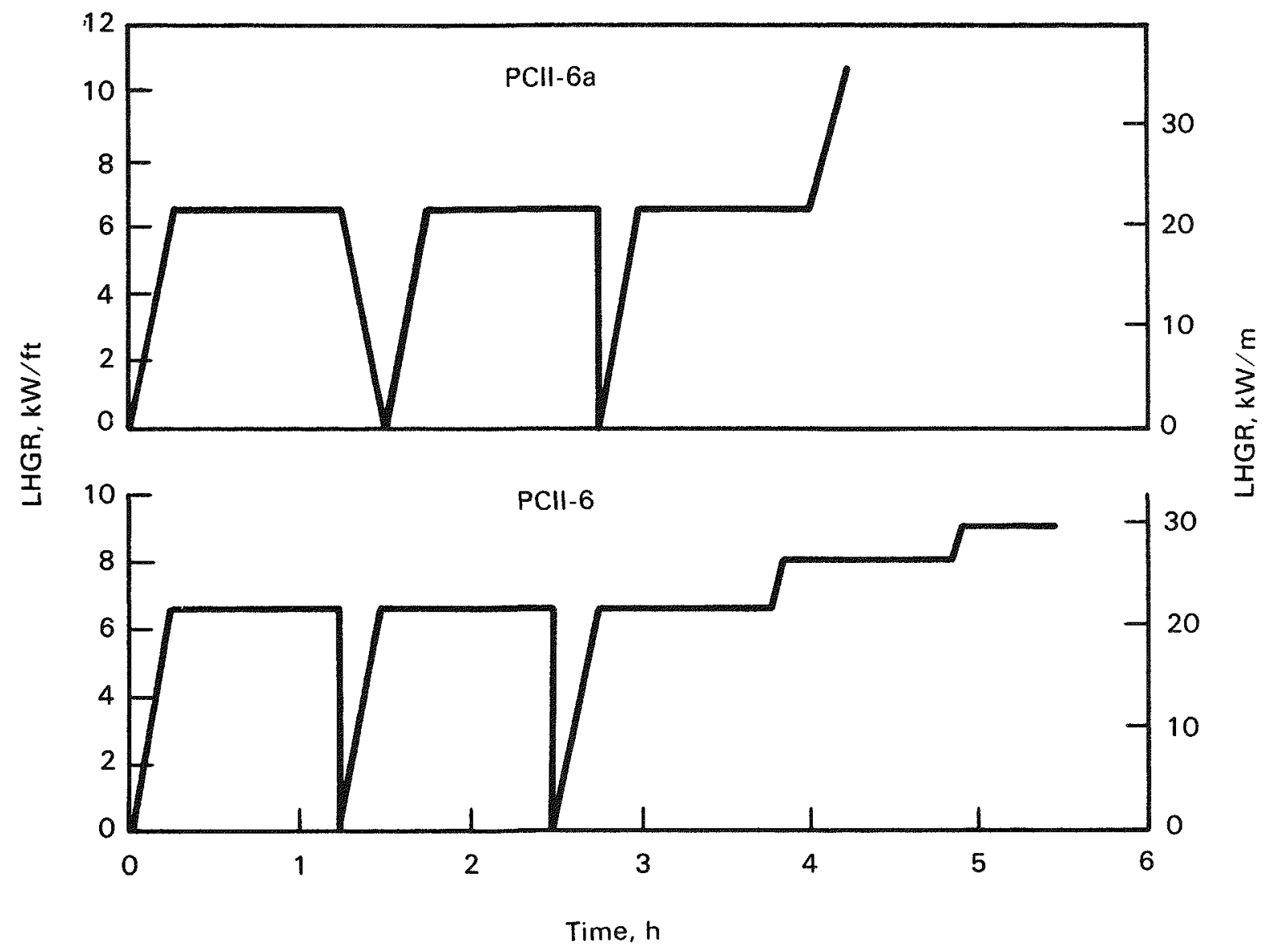

FIGURE 2.8. Power Histories for Tests PCII-6a and PCII-6

The simulated fuel rod for the PCII-2 test survived the initial power ascent to $21.3 \mathrm{~kW} / \mathrm{m}(6.5 \mathrm{~kW} / \mathrm{ft})$ and a subsequent power hold of $6 \mathrm{~h}$. To promote relocation and misalignment of fuel fragments and thereby induce additional localized fuel-cladding mechanical interaction, the fuel rod was subjected to two additional power cycles to $21.3 \mathrm{~kW} / \mathrm{m}(6.5 \mathrm{~kW} / \mathrm{ft})$ using the $2 \times 10^{-5} / \mathrm{min}$ cladding strain rate. After an integrated period of $7.25 \mathrm{~h}$ at the peak power and the three power cycles, the cladding in the PCII-2 test had not failed.

Based on the results from the first two tests, the conditions for the third test (PCII-3) were selected to provide a more rapid strain rate in the cladding and to maintain the power and resultant cladding strain for the significant period of $48 \mathrm{~h}$ (Figure 2.7 ). The more rapid strain rate of $12 \times$ $10^{-5} / \mathrm{min}$ was selected to simulate more closely the maximum power ascent rate of a commercial reactor. This resulted in a power ascent from 6.6 to $21.3 \mathrm{~kW} / \mathrm{m}$ (2 to $6.5 \mathrm{~kW} / \mathrm{ft}$ ) in $15 \mathrm{~min}$. After $13 \mathrm{~h}$ at the peak LHGR, the simulated fuel 


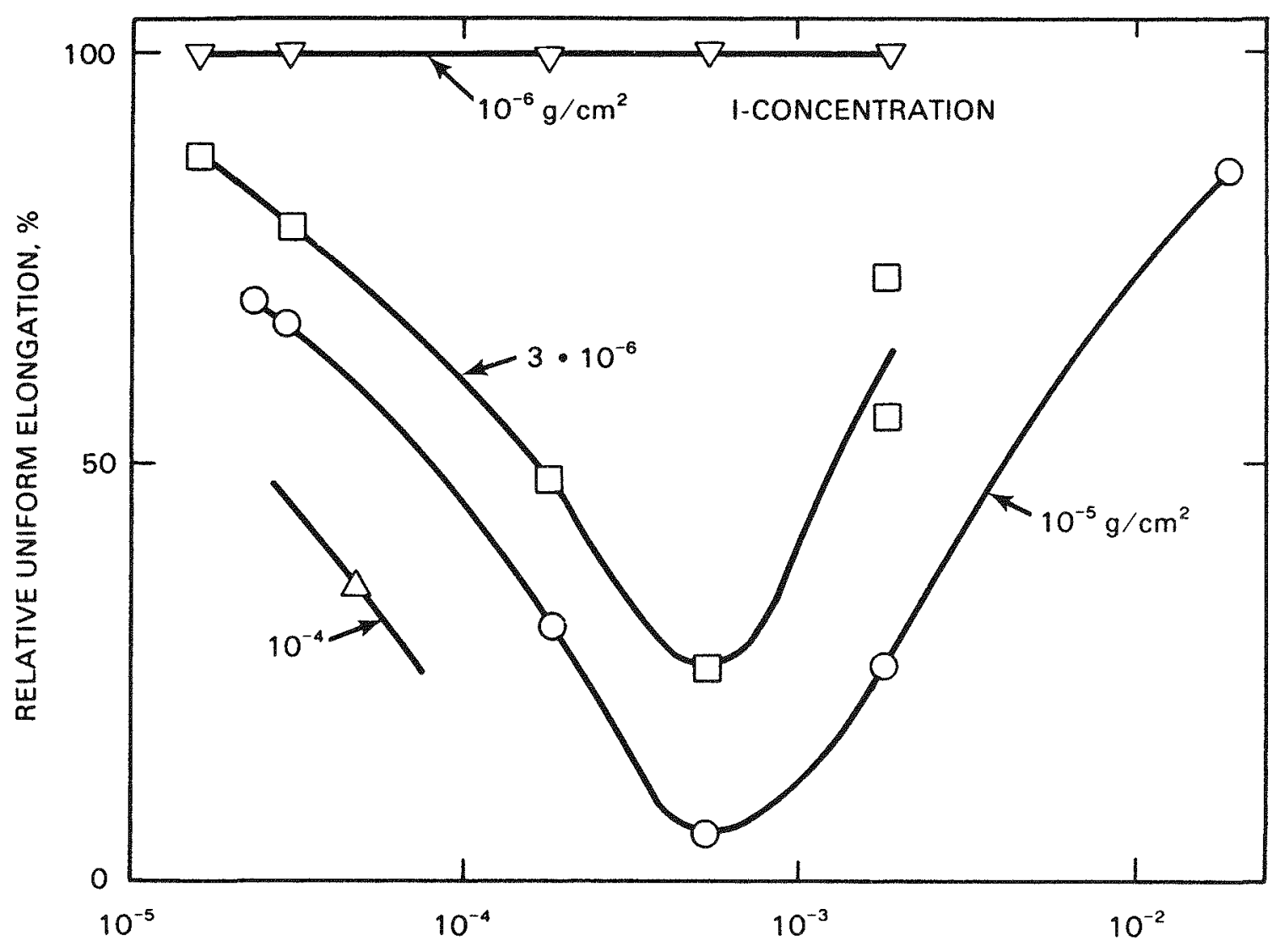

DEFORMATION RATE, $1 / \mathrm{h}$

FIGURE 2.9. Strain-Rate Sensitivity in Zircaloy Cladding (Ref. 1)

rod failed, apparently by electrical short-circuiting through the fuel to the cladding. The failure location was in a region similar to that in PCII-1, near the top of the fuel stack.

The first three PCI simulations with irradiated cladding indicated that strain rates in the sensitive range for failures of nonirradiated cladding and hold times up to $13 \mathrm{~h}$ at the peak LHGR of $21.3 \mathrm{~kW} / \mathrm{m}(6.5 \mathrm{~kW} / \mathrm{ft})$-electrical were not sufficient to induce PCI-type failures in this irradiated cladding. Therefore, the fourth and fifth tests, PCII-4 and PCII-5, were conducted with cladding that had scratches on the inner surfaces. The scratches were produced by pulling a sharp-pointed tool-steel scriber through the irradiated cladding tube. In nonirradiated cladding, the scriber had produced sharp-rooted scratches varying in depth from $5 \%$ to $10 \%$ of the wa 11 thickness. Examination of the irradiated cladding after simulated PCI testing showed that the actual scratch produced in the irradiated cladding for the PCII-5 test was much less deep than the developmental scratches on nonirradiated cladding and had a 
rounded root (Section 3.3). The reason for the difference in scratch geometry between the nonirradiated and irradiated cladding is not known; perhaps it was due to the zirconium oxide film on the inner surface of the irradiated cladding, which may have affected the translation of the scriber.

The PCII-4 test was conducted using a power ascent strain rate of $12 \times$ $10^{-5}$ /min (Figure 2.7). The cladding did not fail during the initial power ascent or the subsequent $6-\mathrm{h}$ hold period at $21.3 \mathrm{~kW} / \mathrm{m}(6.5 \mathrm{~kW} / \mathrm{ft})$. After a controlled power descent for the first power cycle, the PCII-4 test was power cycled four additional times to $21.3 \mathrm{~kW} / \mathrm{m}$, al so with no cladding failure. The last four power cycles were conducted at a strain rate of $12 \times 10^{-5} /$ min during the power ascent and a very rapid (in a few seconds to simulate a reactor scram) power descent rate. The scram simulation was added to the test parameters to promote thermal shock and possible fuel fragment generation, relocation, and misalignment.

Analysis of the results from the first four tests suggested that perhaps the peak LHGR of $21.3 \mathrm{~kW} / \mathrm{m}$ was permitting significant stress relaxation in the fuel (i.e., that the selected $P_{C}$ was too high), and that a peak power reduction might promote adequate cladding stresses for a longer period. A peak power reduction would al so be expected to promote longer simulated fuel rod 1 ife from the standpoint of electrical short-circuiting. Therefore, the PCII-5 test was conducted using a power ascent strain rate of $12 \times 10^{-5} / \mathrm{min}$ to a peak LHGR of $18.0 \mathrm{~kW} / \mathrm{m}(5.5 \mathrm{~kW} / \mathrm{ft})$. The peak LHGR was held for $27 \mathrm{~h}$ with no cladding failure (Figure 2.7).

Because no PCI-type failures had occurred during any of the five tests using irradiated cladding, including two with intentional inner-surface cladding defects, it was decided to attempt to induce SCC by the introduction of iodine into the interior of the fuel rod. The test apparatus was modified to permit the introduction of iodine at three pressure levels: approximately $69 \mathrm{~Pa}$ (equivalent to a calculated monolayer of $\mathrm{ZrI}_{4}$ on the inner surface of the claddingl, $690 \mathrm{~Pa}$, and $70,000 \mathrm{~Pa}$. All surfaces of the interior volume of the fuel rod pressurization system were maintained at a temperature of $200^{\circ} \mathrm{C}$ or greater (i.e., above the boiling point of iodine), so as to prevent plateout of liquid iodine in regions away from the test section. A pressure switch was al so added to the system to disconnect the fuel rod heater power in the event of a cladding failure, in an attempt to preserve any failure features in the event of a PCI-type failure.

A system checkout test, PCII-6a (Figure 2.8), was conducted using nonirradiated $c l$ adding with internal machined $c l$ adding defects to test the iodine delivery system, the SCC susceptibility of the cladding, and the power shutoff function of the pressure switch. The internal cladding defects were machined using an electrical-discharge machine (EDM), which produced a relatively rounded root. The three defects were each $38 \mathrm{~mm}(1.5 \mathrm{in.}) 1 \mathrm{ong}$ and $0.25 \mathrm{~mm}$ 
( 0.1 in.) wide, and penetrated the cladding approximately $19 \%, 42 \%$, and $60 \%$ of the wall thickness, respectively. The length of the defects was selected to ensure that there were at least two pellet-pellet interfaces within the defect length. The plan was to introduce sequentially the three iodine levels, as required, and then to raise the power of the heater rod; however, a power supply malfunction at the lowest iodine level permitted testing only with the two higher iodine levels for the PCII-6a test. For the $690-\mathrm{Pa}$ iodine level, the fuel rod power was raised at a cladding strain-rate equivalent of $12 \times$ $10^{-5} / \mathrm{min}$ to $21 \mathrm{~kW} / \mathrm{m}$ and held for $1 \mathrm{~h}$. When no failure occurred, the power was decreased to zero, the $70,000-\mathrm{Pa}$ iodine level was introduced, and the power was increased at the same rate back to $21 \mathrm{~kW} / \mathrm{m}$. The integral fuel rod pressure decreased drastically immediately after the iodine injection. When no failure occurred after one hour at $21 \mathrm{~kW} / \mathrm{m}$, the power was increased at $1.5 \mathrm{~kW} / \mathrm{m}$-min to promote an SCC failure or to at least be able to test the pressure switch function in the event of a short-circuit failure. A terminal LHGR of $35 \mathrm{~kW} / \mathrm{m}$ $(10.7 \mathrm{~kW} / \mathrm{ft})$ was reached before a short-circuit failure of the heater occurred. However, the cladding was not breached and the pressure switch function was not able to be tested. Cladding ridge heights during the PCII-6a test were comparable to those in previous tests, indicating that cladding stresses were at or near the cladding yield strength during the test.

The final test with irradiated cladding, PCII-6 (Figure 2.8), was conducted using iodine to promote SCC. Three power cycles using the strain rate of $12 \times 10^{-5} / \mathrm{min}$ and $1-\mathrm{h}$ power holding levels of $21 \mathrm{~kW} / \mathrm{m}$ were imposed on the cladding at the three sequential iodine levels of 69,690 , and $70,000 \mathrm{~Pa}$. Ridge heights were comparable to previous tests and an average elastic strain of $1.4 \times 10^{-4}$ was observed after the first cycle. When no cladding failure occurred after $1 \mathrm{~h}$ with the highest iodine level, the LHGR was raised to $26 \mathrm{~kW} / \mathrm{m}(8 \mathrm{~kW} / \mathrm{ft})$ for an additional $1 \mathrm{~h}$ period. When no failure occurred, the LHGR was raised to $29 \mathrm{~kW} / \mathrm{m}(9 \mathrm{~kW} / \mathrm{ft})$ and held for $27 \mathrm{~min}$, at which time the heater failed by short-circuiting through the fuel to the cladding, and the cladding did not breach during the heater failure. Again the internal fuel rod pressure decreased significantly immediately after the injection of iodine at $70,000 \mathrm{~Pa}$. The pressure decrease was manually recorded as a function of time during this period. The results indicated that the pressure decreased approximately exponentially, reaching a constant level about 3 or 4 minutes after injection. Apparentiy the molecular iodine reacted totally with the metal surfaces in the system during this period. 


\subsection{RESULTS AND DISCUSSION}

As described in Section 2.5, the electrically heated PCI simulation tests were conducted under a variety of conditions to attempt to induce cladding failure in irradiated cladding. Tests were conducted with a small fuelcladding gap to maximize the fuel-cladding differential thermal expansion and resultant cladding stresses. Power ascents were conducted with cladding strain rates in the range where nonirradiated cladding is most sensitive to iodineinduced SCC. The peak power, and resultant high cladding stress level, was maintained at significant levels and for significant time periods to permit crack growth in the cladding. The power was cycled in some tests to induce fuel fragment relocation and misalignment and, therefore, possibly higher localized cladding stresses during subsequent power ascents. Intentional defects (scratches) were produced on the inner surface of some of the claddings to provide points for crack nucleation. None of these test conditions resulted in a cladding breach that could be attributed to a PCMI failure mode. Finally, iodine was introduced in an attempt to cause failure by SCC. An SCC failure could not be induced in either nonirradiated-defected or irradiated cladding even though cladding stresses were sufficient to produce small permanent ridges. Therefore, the test results are described in terms of the mechanical interaction in the rods. The PCMI during transient and steady-state operation are described in Sections 3.1 and 3.2, respectively. The results of post-test examinations conducted to document the condition of the fuel and cladding are described in Section 3.3. An intercomparison of all the test results is described in section 3.4 .

\subsection{PCMI DURING TRANSIENT OPERATION}

The induced diametral strain in the cladding of a simulated fuel rod during a power ascent can be divided into two components, a general strain and a localized strain. The general strain was caused by the general differential fuel-cladding thermal expansion as the power and temperature increased. Typical values for the general strain were $1.4 \times 10^{-4}$ per $\mathrm{kW} / \mathrm{m}\left(4.6 \times 10^{-4} \mathrm{per}\right.$ $\mathrm{kW} / \mathrm{ft}$ ) after fuel-cladding interaction commenced for PCII-1. However, this value varied $\pm 25 \%$ because of difficulties in assigning an absolute reference diameter at a known point on the fuel rod on the recording charts. The behavior of the measured general strain as functions of the other test variables therefore could not be reliably determined, and the general strain will not be further discussed in this report. The localized strains at pelletpellet interfaces (ridges) and at midpellet locations (midpellet ridges) were produced by localized fuel fragment distortions caused by fuel thermal expansion (e.g., hourglassing). These localized strains were much easier to measure than the general strain because they were a differential (peak-to-valley) measurement on a single chart, rather than a differential value from chart to 
chart as was the case for the general strain. An example of the pellet-pellet. ridges and midpellet ridges is shown in Figure 3.1. Comparisons of PCMI in the remainder of this report are discussed in terms of the localized strains.

The localized diametral strains as a function of LHGR, herein defined as transient operation, were measured in two ways. For the PCII-1 and -2 tests, the LHGR was increased in discrete steps and the diameter-measuring device was used to measure the cladding diameter along the length of the rod during the power hold. For the PCII-3, $-4,-5$, and -6 tests, the LHGR was increased relatively linearly with a predetermined amount of power to be provided during successive 1-min periods. Normally it took from 25 to $50 \mathrm{~s}$ to achieve the assigned power increase for a particular minute. During each 1-min period the diameter-measuring device traversed upwards or downwards near the center of the fuel stack, covering a length of approximately eight fuel pellets. After each minute, the direction was reversed, and the average LHGR during that minute was assigned for the entire period. The pellet-pellet ridge heights were determined by drawing a line between appropriate minimum diameters (valleys) and measuring the height between the midpoint of this line and the maximum diameter (peak). For comparison, the averages of several ridges were determined for the appropriate test condition.

Because the midpellet ridge height was more variable and much smaller than the pellet-pellet ridge height, and because only a few were measured during the power ascents, a comparison between tests for midpellet ridge height during transients is not made in this report. Steady-state midpellet ridge heights are discussed in Section 3.2.

The ridge heights for each transient condition are shown in the figures as follows:

$\begin{array}{cccc}\text { Test } & & \text { Condition } & \text { Figure No. } \\ \text { PCII-1 } & & \text { Power ascent } & 3.2 \\ \text { PCII-2 } & \text { Cycle 1 } & & 3.3 \\ & \text { Cycle 2 } & & 3.4 \\ & \text { Cycle } 3 & 3.5 \\ & \text { Power ascents } & 3.6 \\ & \text { Power descents } & 3.7 \\ \text { PCII-3 } & \text { Power ascent } & 3.8 \\ \text { PCII-4 } & \text { Cycle 1 } & 3.9 \\ & \text { Power ascent 2 } & 3.10 \\ & \text { Power ascent 3 } & 3.11 \\ & \text { Power ascent 4 } & 3.12 \\ \text { PCII-5 } & \text { Power ascent 5 } & 3.13 \\ \text { PCII-6 } & \text { Power ascents } 1 & 3.14\end{array}$




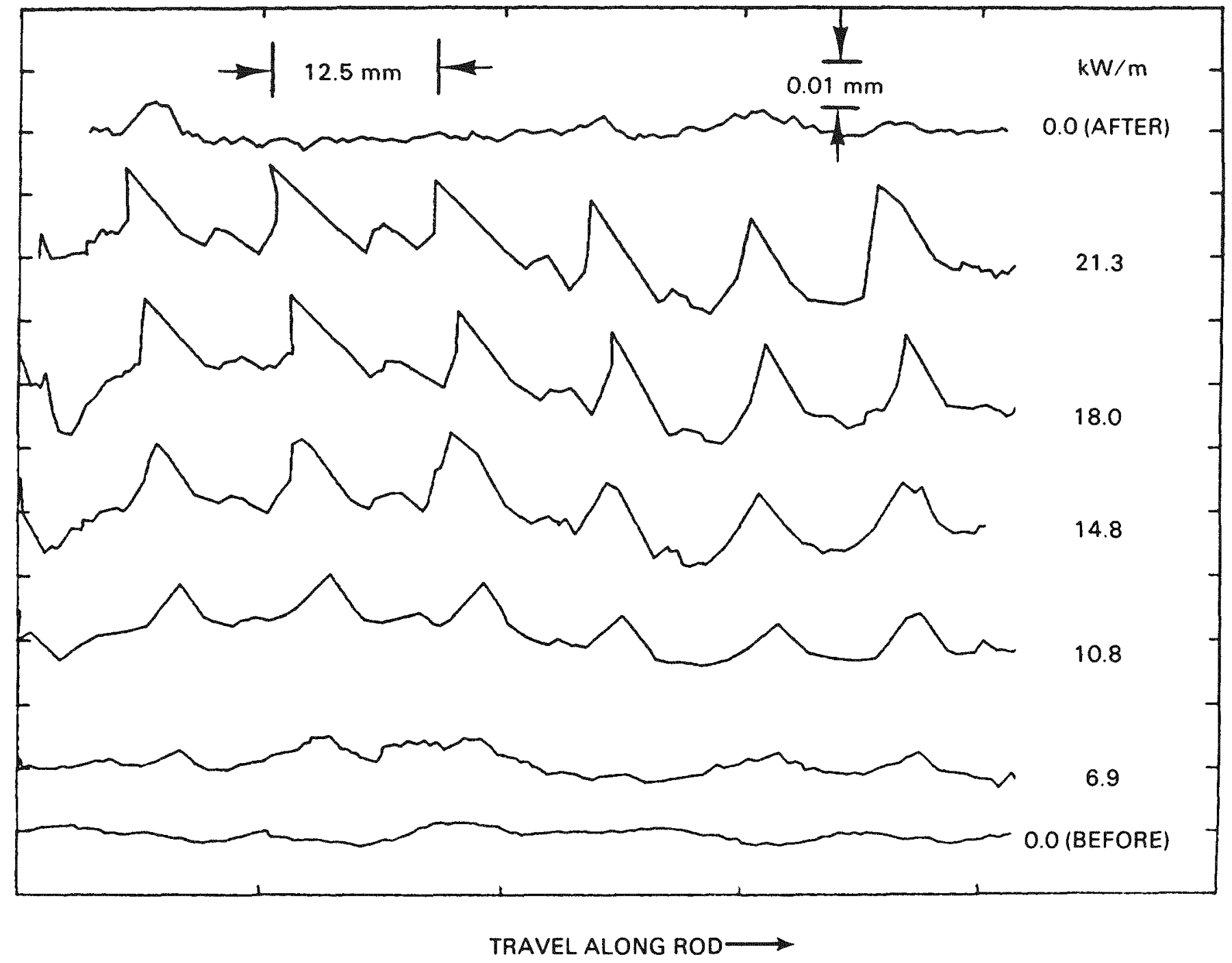

FIGURE 3.1. Diameter Measurements During Power Ascent for PCII-4 


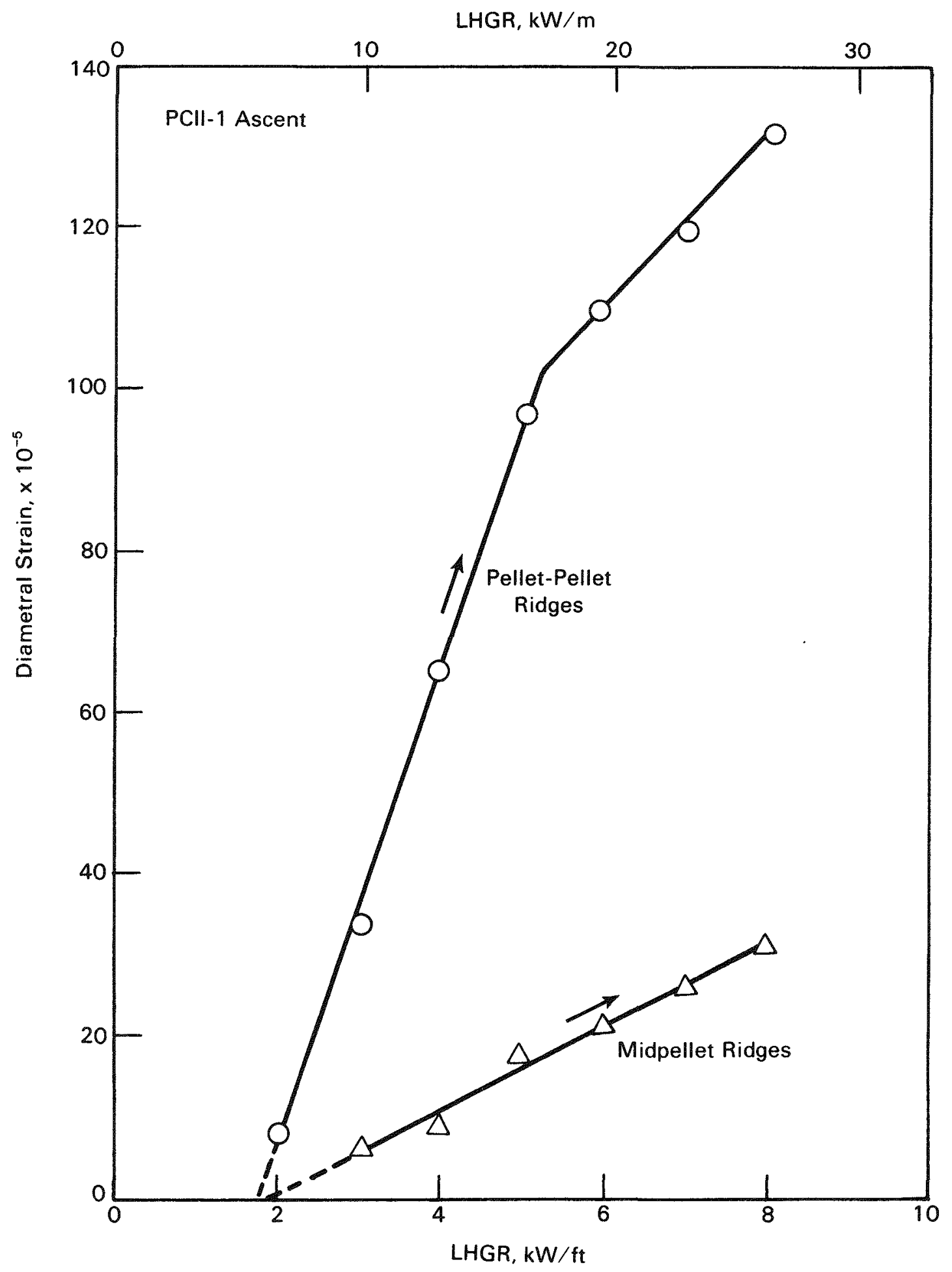

FIGURE 3.2. Diametral Strain During Power Ascent for PCII-1 Test 


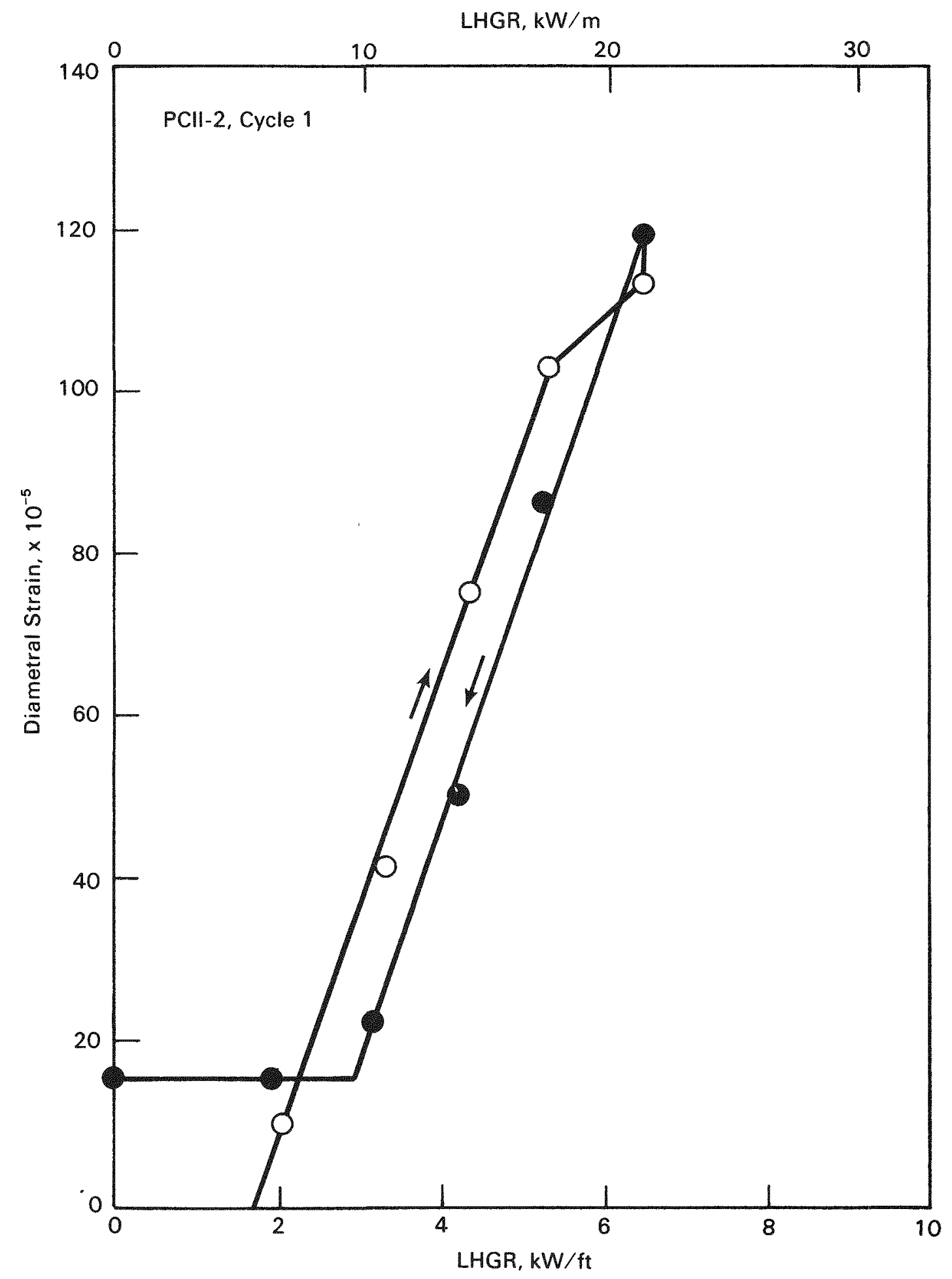

FIGURE 3.3. Diametral Strain During First Power Cycle for PCII-2 Test 


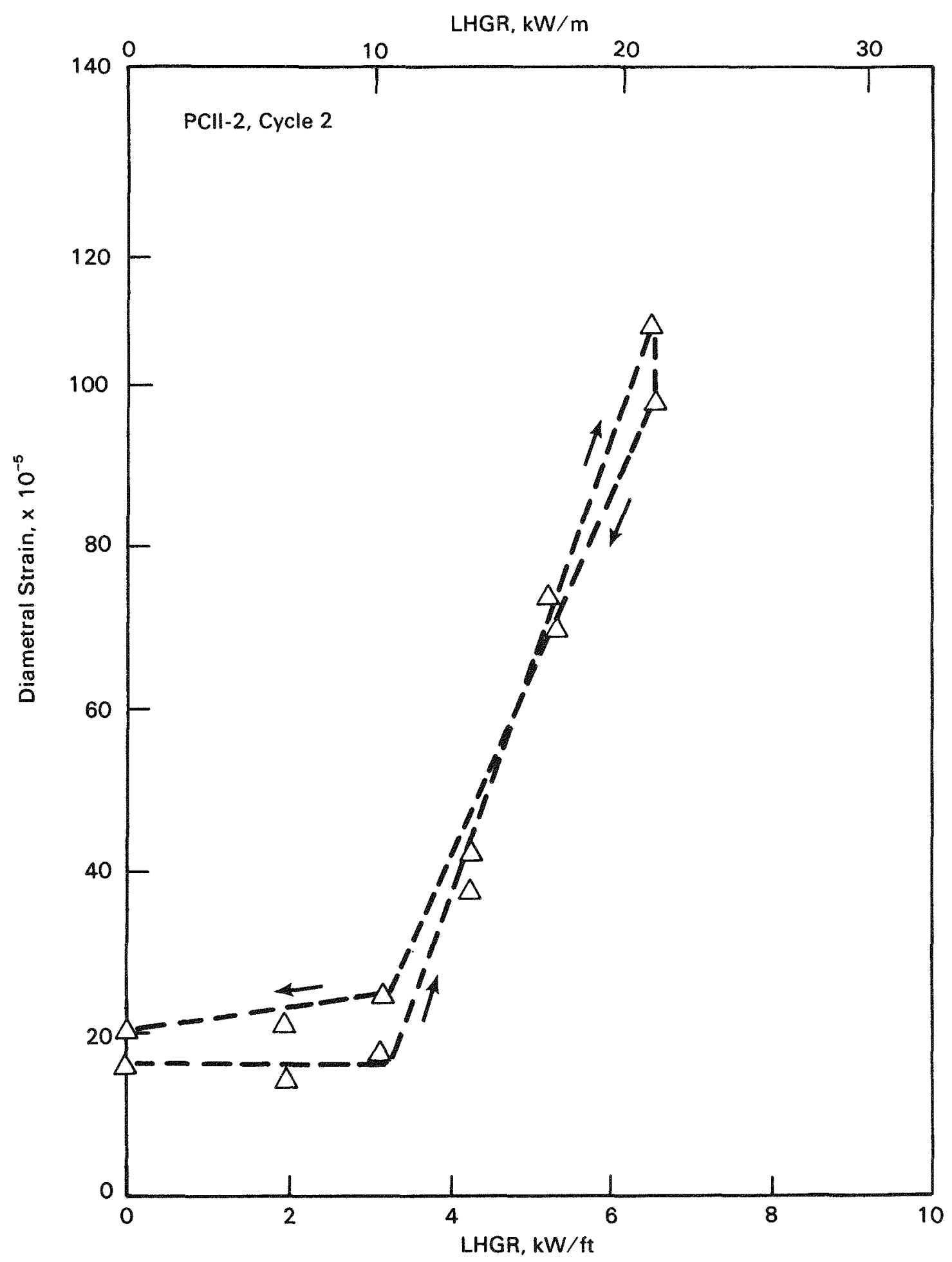

FIGURE 3.4. Diametral Strain During Second Power Cycle for PCII-2 Test 


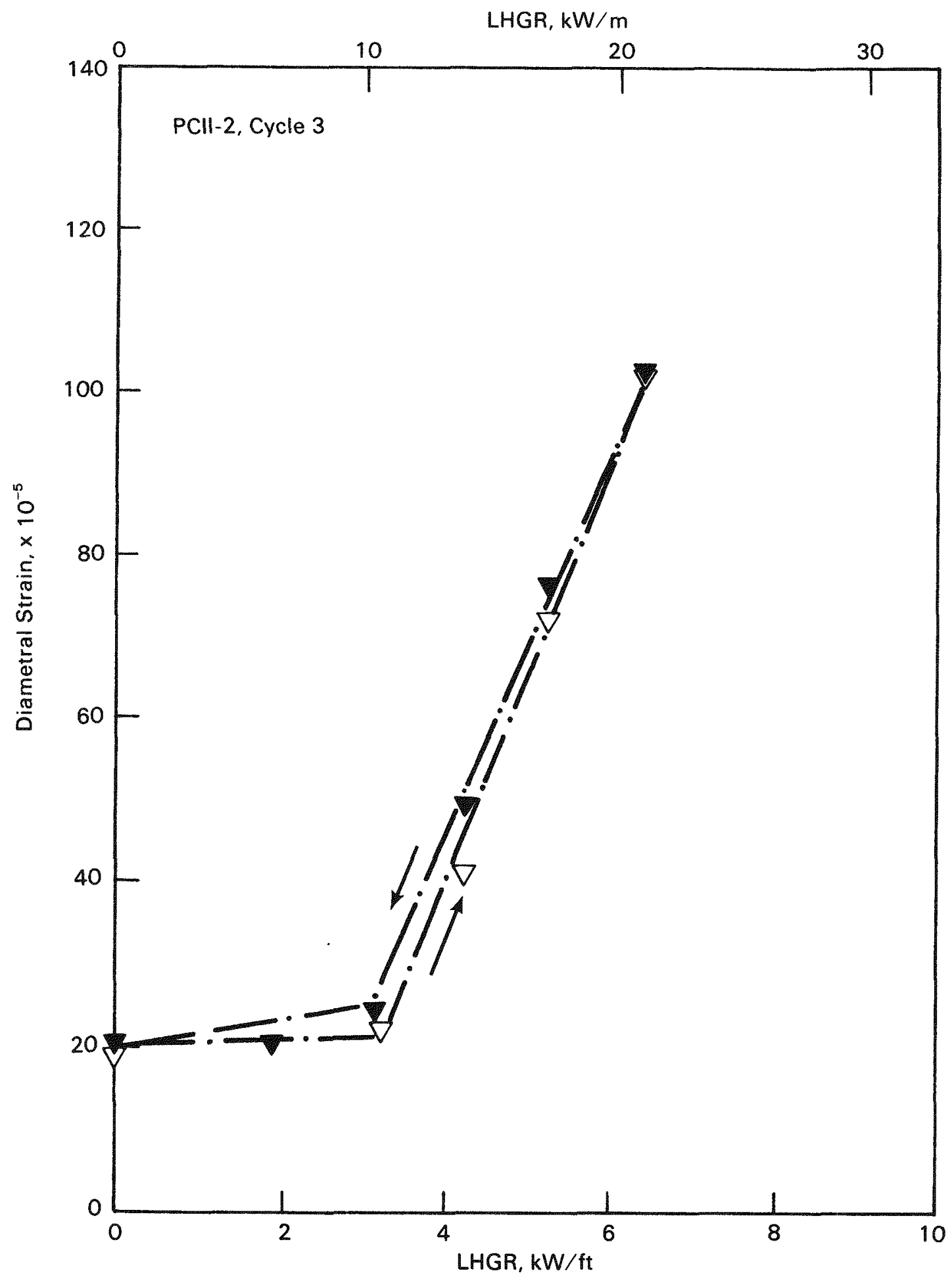

FIGURE 3.5. Diametral Strain During Third Power Cycle for PCII-2 Test 


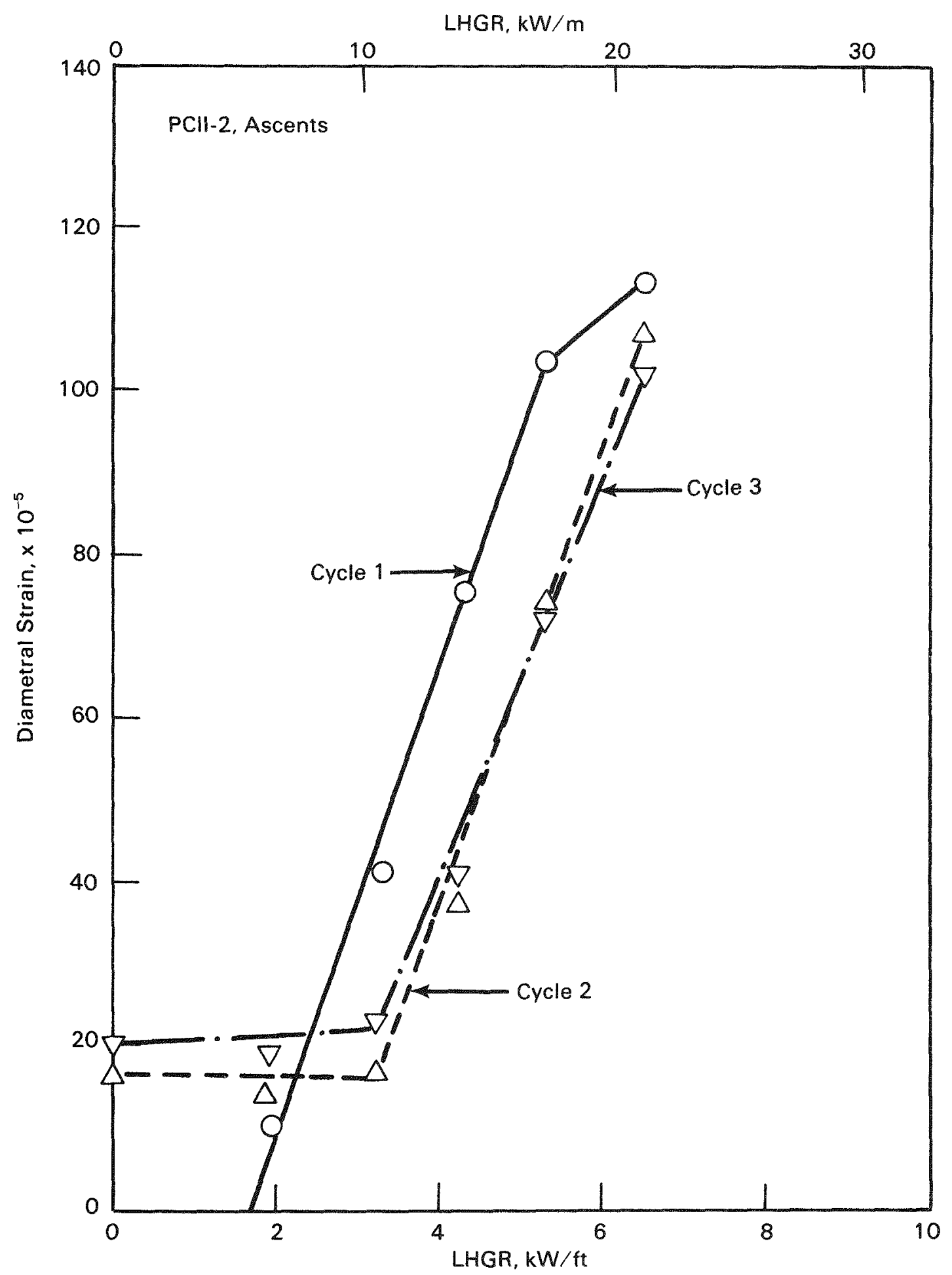

FIGURE 3.6. Summary of Diametral Strain During Power Ascents for PCII-2 Test 


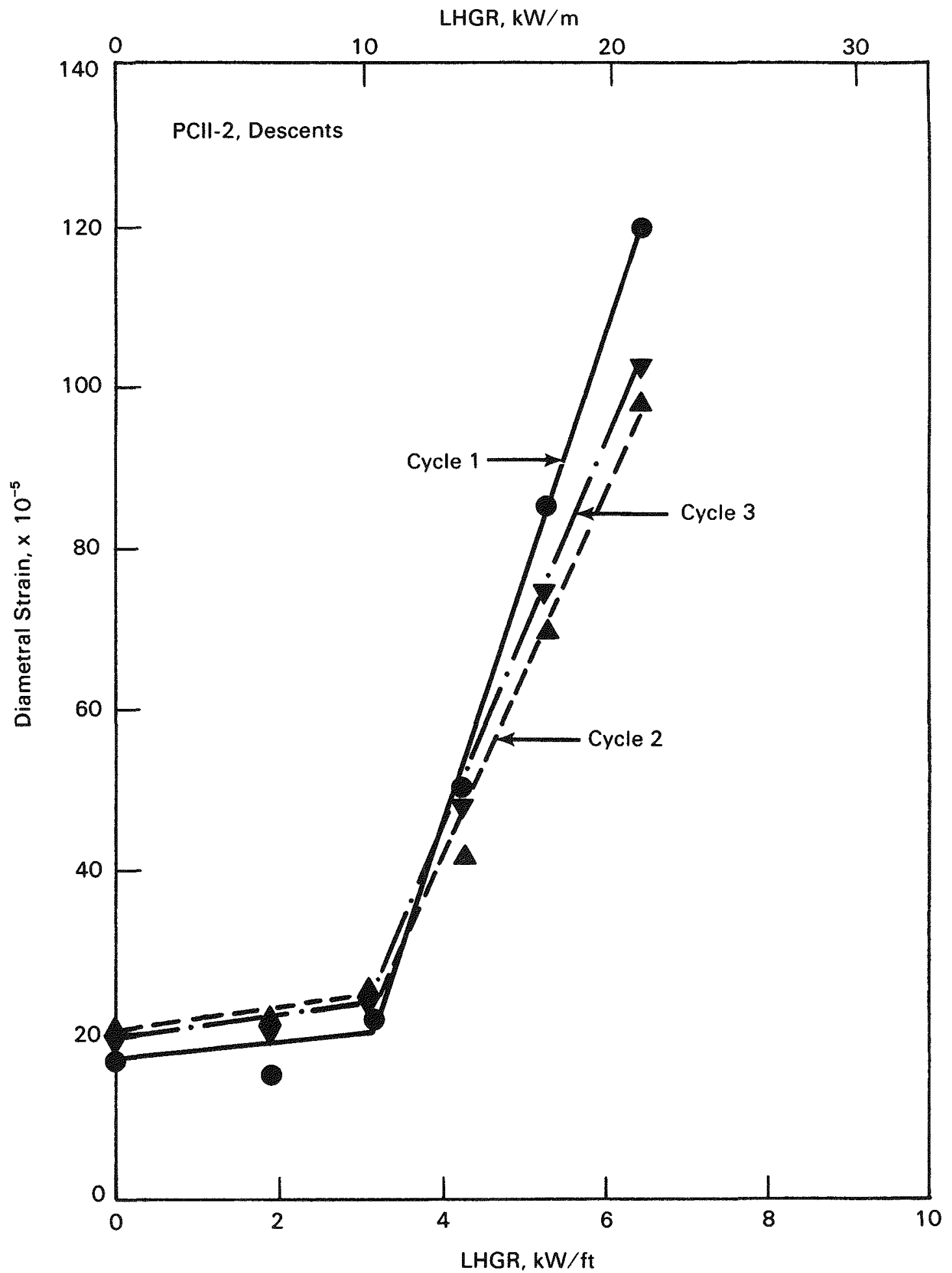

FIGURE 3.7. Summary of Diametral Strain During Power Descents for PCII-2 Test 


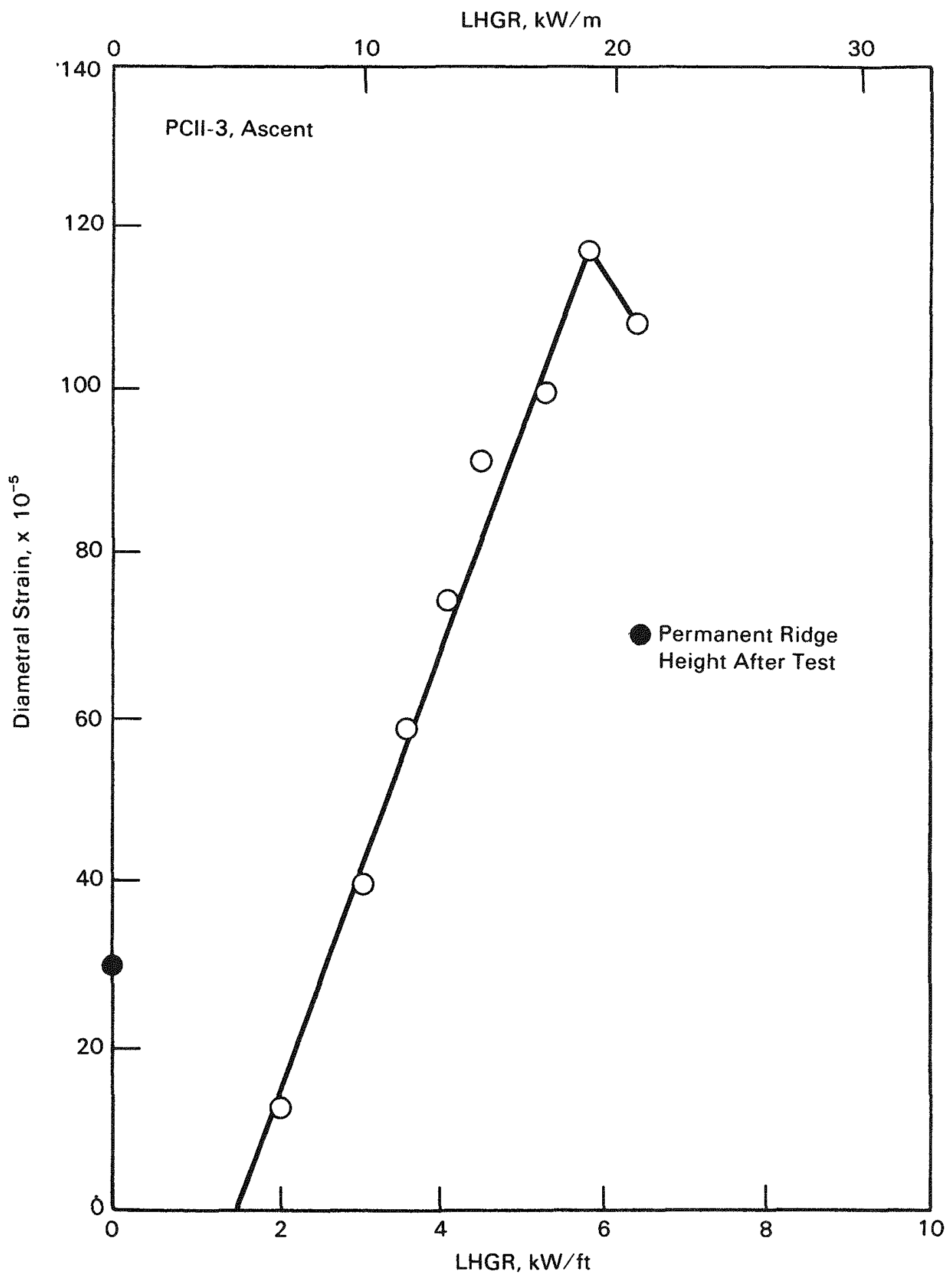

FIGURE 3.8. Diametral Strain During Power Ascent for PCII-3 Test 


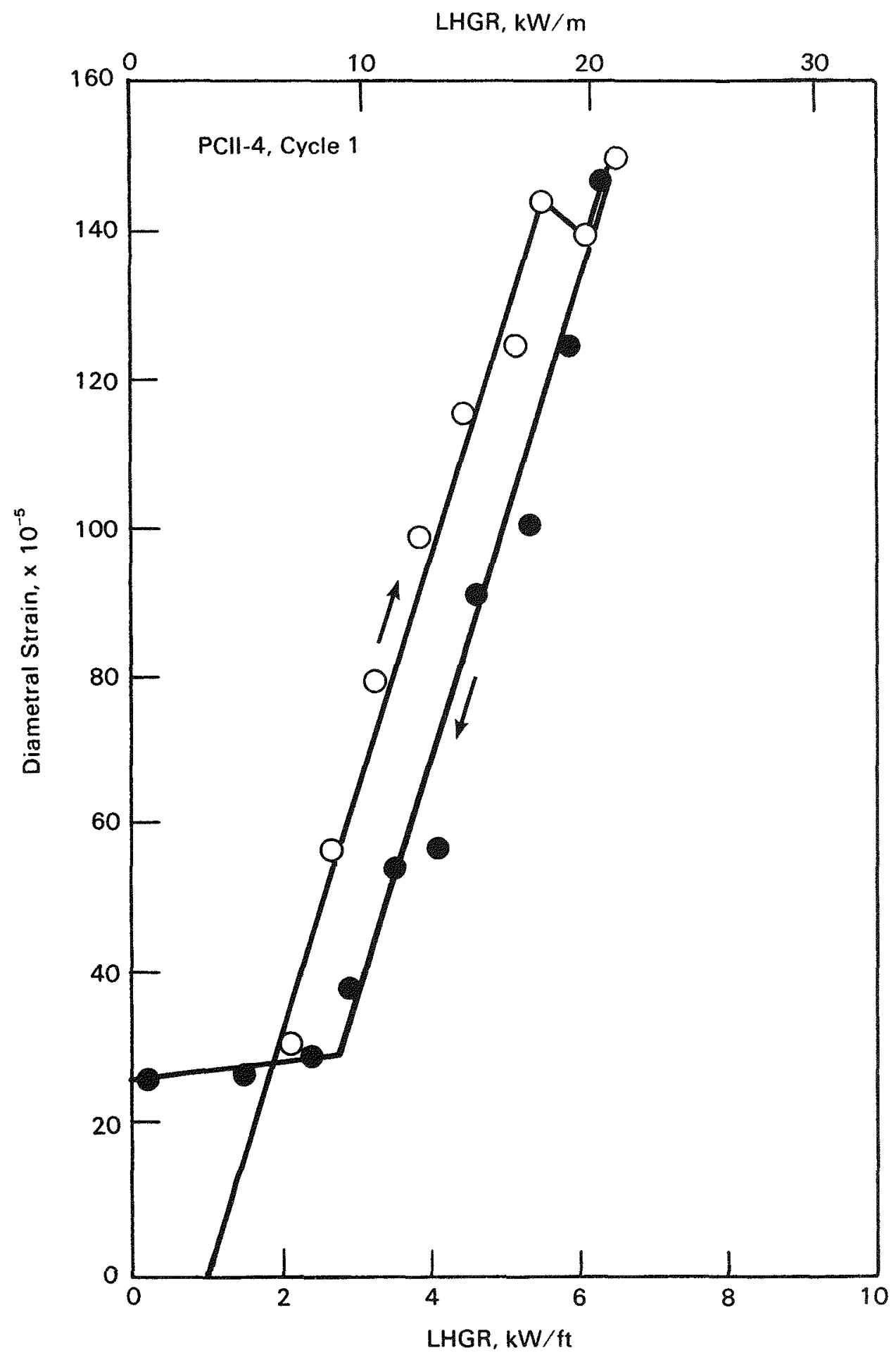

FIGURE 3.9. Diametral Strain During First Power Cycle for PCII-4 Test 


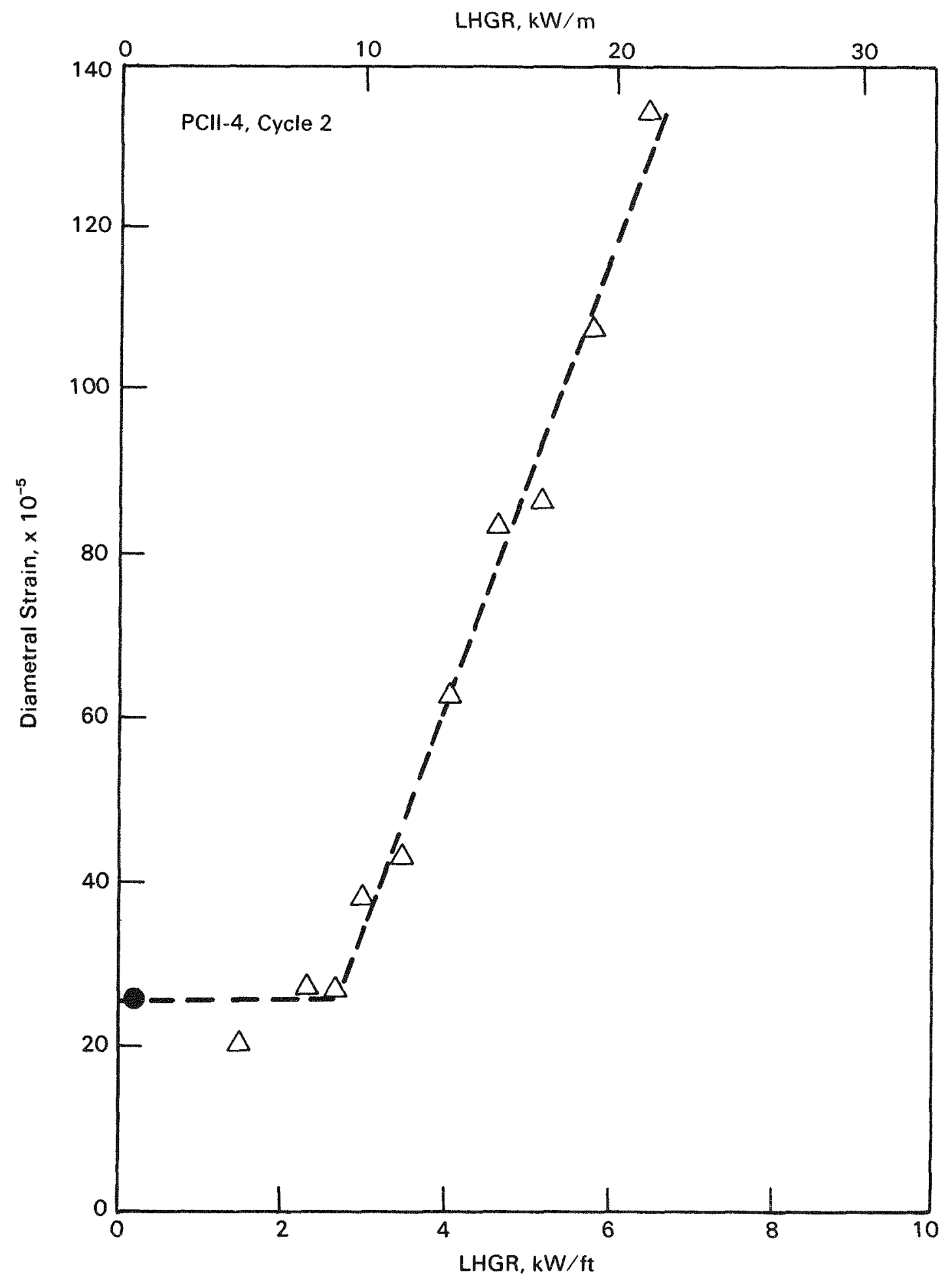

FIGURE 3.10. Diametral Strain During Second Power Ascent for PCII-4 Test 


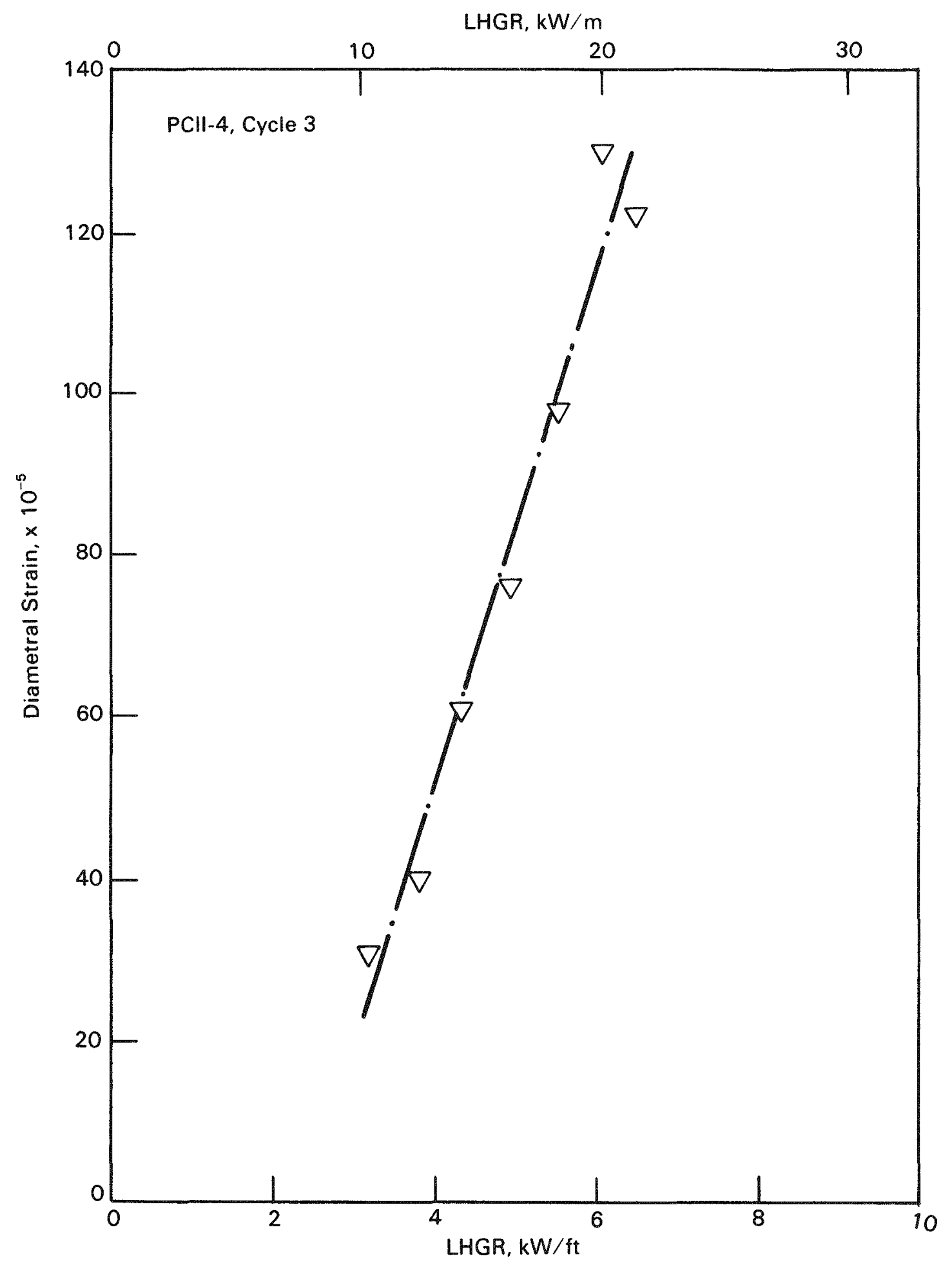

FIGURE 3.11. Diametral Strain During Third Power Ascent for PCII-4 Test 
For various reasons, such as rod failure or operation to simulate a scram, the ridge heights were not measured during some power descents.

The interaction data is summarized in Table 3.1. For each test the initial strain behavior, between 6.6 and $\sim 19.7 \mathrm{~kW} / \mathrm{m}(2$ and $\sim 6 \mathrm{~kW} / \mathrm{ft}$ ), was linear with LHGR (Figures 3.2,3.3,3.8, 3.9, 3.14, and 3.15). A linear extrapolation of this data to zero LHGR indicates that the power required for initial mechanical interaction, $P_{i}$, varied between 3.2 and $6.6 \mathrm{~kW} / \mathrm{m}(1$ and $2 \mathrm{~kW} / \mathrm{ft})$ and that the slopes during the initial power ascents were very similar between tests, ranging from $89.9 \times 10^{-5}$ to $105.3 \times 10^{-5}$ per $\mathrm{kW} / \mathrm{m}\left(27.4 \times 10^{-5}\right.$ to $32.1 \times$ $10^{-5}$ per $\mathrm{kW} / \mathrm{ft}$ ). For the four tests that were primarily conducted at a peak LHGR of $21.3 \mathrm{~kW} / \mathrm{m}$, a decrease in slope occurred at the higher LHGRs in the range from 16.4 to $19.7 \mathrm{~kW} / \mathrm{m}(5$ to $6 \mathrm{~kW} / \mathrm{ft})$, indicating that the fuel strength was probably reduced to a level that permitted yielding or rapid creep to reduce the system forces. In those tests for which it was possible to measure the ridges during power descents (PCII-2, the first power descent for PCII-4, and PCII-5), the slopes of the strain versus LHGR were slightly lower than but similar to the slopes during the initial power ascent.

Permanent ridge strain occurred during the first power cycle for each test. The amount of permanent ridge strain did not correlate with the differential LHGR after which mechanical interaction occurred, as might be expected. For those tests that were exposed to several power cycles to the same peak LHGR, no apparent increase in permanent ridge strain occurred after the first power cycle. The presence of iodine in the PCII-6 test did not cause any strain-type behavior different from the tests without iodine.

\subsection{PCMI DURING STEADY-STATE OPERATION}

During each PCI simulation, the test rod was subjected to various periods at steady-state power at various power levels. The pellet-pellet ridges and midpellet ridges were measured several times during these periods and the results are shown in the figures as follows:

\begin{tabular}{|c|c|c|}
\hline Test & LHGR & Figure No. \\
\hline PCII-1 & Variable & 3.16 \\
\hline PCII-2 & $21.3 \mathrm{~kW} / \mathrm{m}(6.5 \mathrm{~kW} / \mathrm{ft})$ & 3.17 \\
\hline PCII-3 & $21.3 \mathrm{~kW} / \mathrm{m}(6.5 \mathrm{~kW} / \mathrm{ft})$ & 3.18 \\
\hline PCII-4 & $21.3 \mathrm{~kW} / \mathrm{m}(6.5 \mathrm{~kW} / \mathrm{ft})$ & 3.19 \\
\hline PCII-5 & $18.0 \mathrm{~kW} / \mathrm{m}(5.5 \mathrm{~kW} / \mathrm{ft})$ & 3.20 \\
\hline $\begin{array}{l}\text { PCII }-2,-3,-4 \text {, } \\
\text { and }-5 \text { Summary }\end{array}$ & -- & 3.21 \\
\hline PCII-6 & Variable & 3.22 \\
\hline
\end{tabular}


TABLE 3.1. Summary of Interaction Parameters

\begin{tabular}{|c|c|c|c|c|c|c|}
\hline Test & $\begin{array}{c}\text { Power } \\
\text { Ascent/Descent }\end{array}$ & $\begin{array}{r}\text { Intel } \\
\text { LHGR, } \mathrm{kl} \\
\end{array}$ & $\begin{array}{l}\text { action } \\
/ \mathrm{m}(\mathrm{kW} / \mathrm{ft})\end{array}$ & $\begin{array}{c}\text { Interaction } \\
\text { Slope } \\
\text { Strain, } \times 10^{-5}\end{array}$ & Permanent Ridge & $\begin{array}{c}\text { Coefficient of } \\
\text { (e) }\end{array}$ \\
\hline No. & No. & Initial (a) & Subsequent $(b)$ & $\mathrm{kW} / \mathrm{m}(\mathrm{kW} / \mathrm{ft})^{(\mathrm{c})}$ & Strain, $\times 10^{-5(\mathrm{~d})}$ & Determination $^{(\mathrm{e})}$ \\
\hline 1 & $1 A^{(f)}$ & $\overline{5.84(1.78)}$ & $\overline{--}$ & $97.4(29.7)$ & -- & 1.00 \\
\hline 2 & $\begin{array}{l}1 A \\
1 D \\
2 A \\
2 D \\
3 A \\
3 D\end{array}$ & $\begin{array}{l}5.64(1.72) \\
-- \\
-- \\
-- \\
-- \\
--\end{array}$ & $\begin{array}{l}-- \\
9.55(2.91) \\
10.63(3.24) \\
10.67(3.25) \\
10.63(3.24) \\
10.20(3.11)\end{array}$ & $\begin{array}{ll}94.2 & (2.87) \\
96.8 & (2.95) \\
92.2 & (28.1) \\
79.1 & (24.1) \\
81.0 & (24.7) \\
77.8 & (23.7)\end{array}$ & $\begin{array}{l}\overline{16} \\
\overline{20} \\
\overline{19}\end{array}$ & $\begin{array}{l}1.00 \\
1.00 \\
0.99 \\
1.00 \\
0.99 \\
1.00\end{array}$ \\
\hline 3 & $1 A^{(f)}$ & $4.92(1.50)$ & - & $89.9(27.4)$ & 30 & 1.00 \\
\hline : & $\begin{array}{l}1 A \\
10 \\
2 A(g) \\
3 A(g) \\
4 A(g) \\
5 A(g)\end{array}$ & $\begin{array}{l}3.28(1.00) \\
-- \\
-- \\
-- \\
-- \\
--\end{array}$ & $\begin{array}{l}-- \\
9.28(2.83) \\
8.69(2.65) \\
--(h) \\
9.94(3.03) \\
12.04(3.67)\end{array}$ & $\begin{array}{l}105.3(32.1) \\
104.7(31.9) \\
88.9(27.1) \\
104.3(31.8) \\
90.9(27.7) \\
101.4(30.1)\end{array}$ & $\begin{array}{l}-- \\
25 \\
-- \\
-- \\
18 \\
20\end{array}$ & $\begin{array}{l}1.00 \\
0.98 \\
0.98 \\
0.96 \\
0.97 \\
0.99\end{array}$ \\
\hline 5 & $\begin{array}{l}1 \mathrm{~A} \\
1 \mathrm{D}\end{array}$ & $\begin{array}{ll}3.87 & (1.18) \\
-- & \end{array}$ & $\overline{8.67}(2.67)$ & $\begin{array}{l}92.2(28.1) \\
86.3(26.3)\end{array}$ & $\overline{22}$ & $\begin{array}{l}1.00 \\
0.98\end{array}$ \\
\hline 6 & $\begin{array}{l}1 A \\
2 A \\
3 A\end{array}$ & $\begin{array}{ll}5.41 & (1.65) \\
-- & \\
-- & \end{array}$ & $\begin{array}{l}-- \\
5.73(2.05) \\
73.37(2.25)\end{array}$ & $\begin{array}{ll}90.8 & (27.67) \\
89.1 & (27.17) \\
98.8 & (30.11)\end{array}$ & $\begin{array}{l}14 \\
11 \\
17\end{array}$ & $\begin{array}{l}0.99 \\
0.98 \\
0.99\end{array}$ \\
\hline
\end{tabular}

(a) Initial interaction LHGR for first ascent was determined by extrapolation of higher-power data to zero power.

(b) Subsequent interaction LHGRs were determined by intercept of linear extrapolations of high- and lower-power data.

(c) Slope during interaction, i.e., higher-power data.

(d) Permanent diametral strain at zero power measured after power cycle.

(e) Coefficient of determination for linear regression curve fit to data between 6.6 and $21.3 \mathrm{~kW} / \mathrm{m}$ during interaction.

(f) PCII-1 and -3 failed by electrical shorting before controlled power descent; permanent strains could not be measured.

(g) Second through fifth power cycles for PCII-4 were simulations of reactor scrams in an attempt to promote thermal shock and fuel fragment rearrangement.

(h) Low-power data lost because of recorder malfunction. 


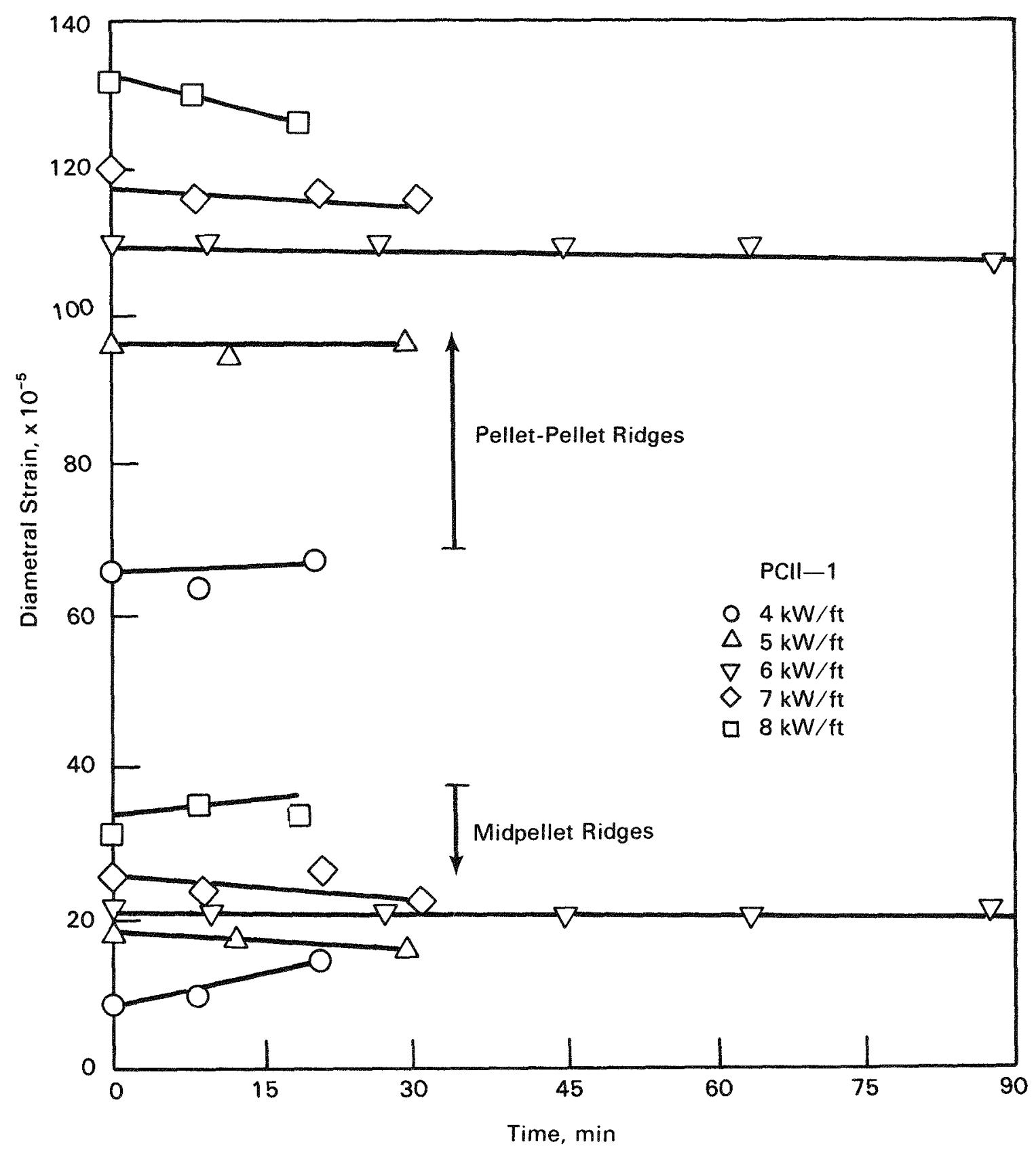

FIGURE 3.16. Diametral Strain During Power Holding Periods for PCII-1 Test 


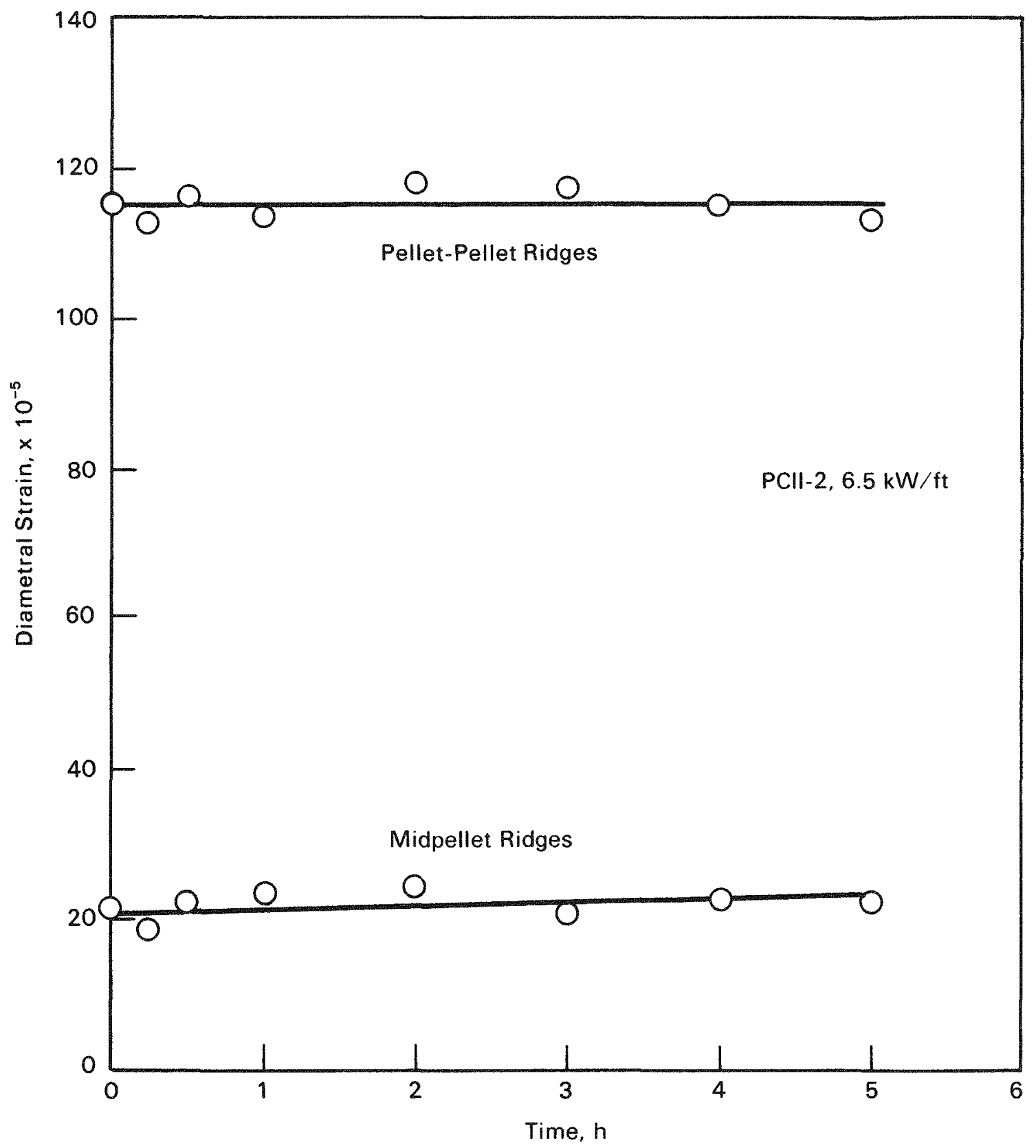

FIGURE 3.17. Diametral Strain During Power Holding Periods at $21.3 \mathrm{~kW} / \mathrm{m}$ for PCII-2 Test 


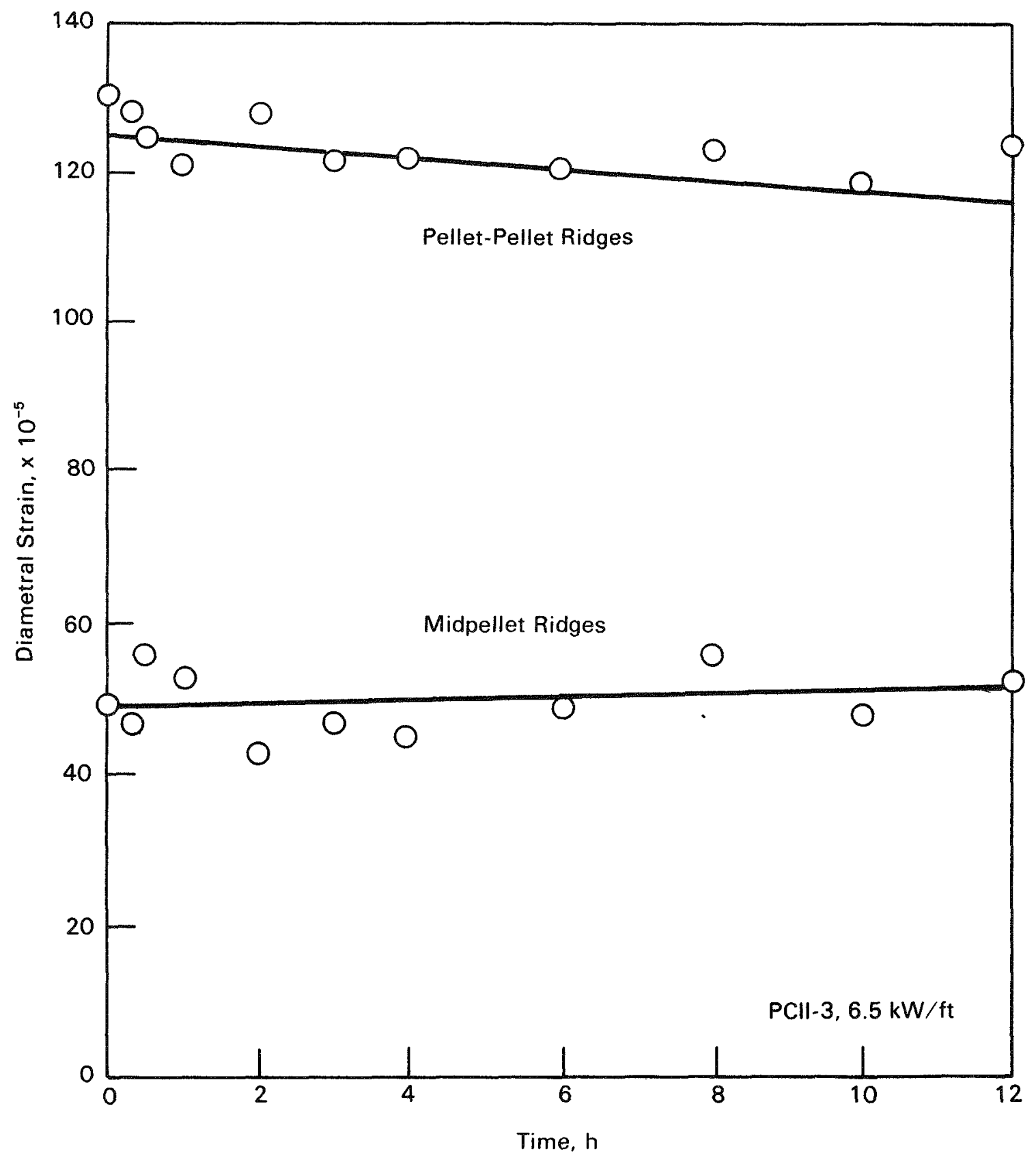

FIGURE 3.18. Diametral Strain During Power Holding Periods for PCII-3 Test 


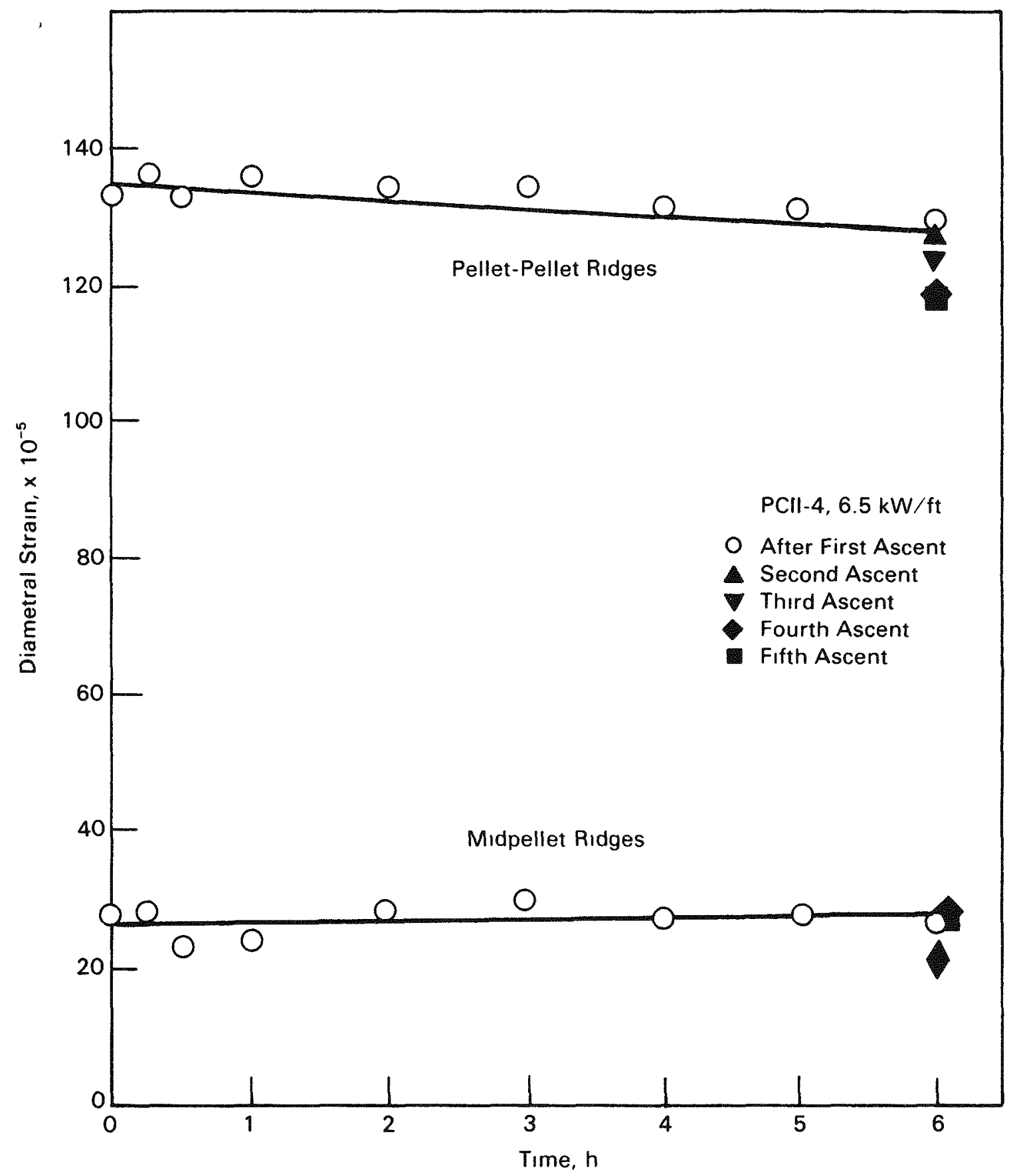

FIGURE 3.19. Diametral Strain During Power Holding Periods and After Second Through Fifth Power Cycles for PCII-4 Test 


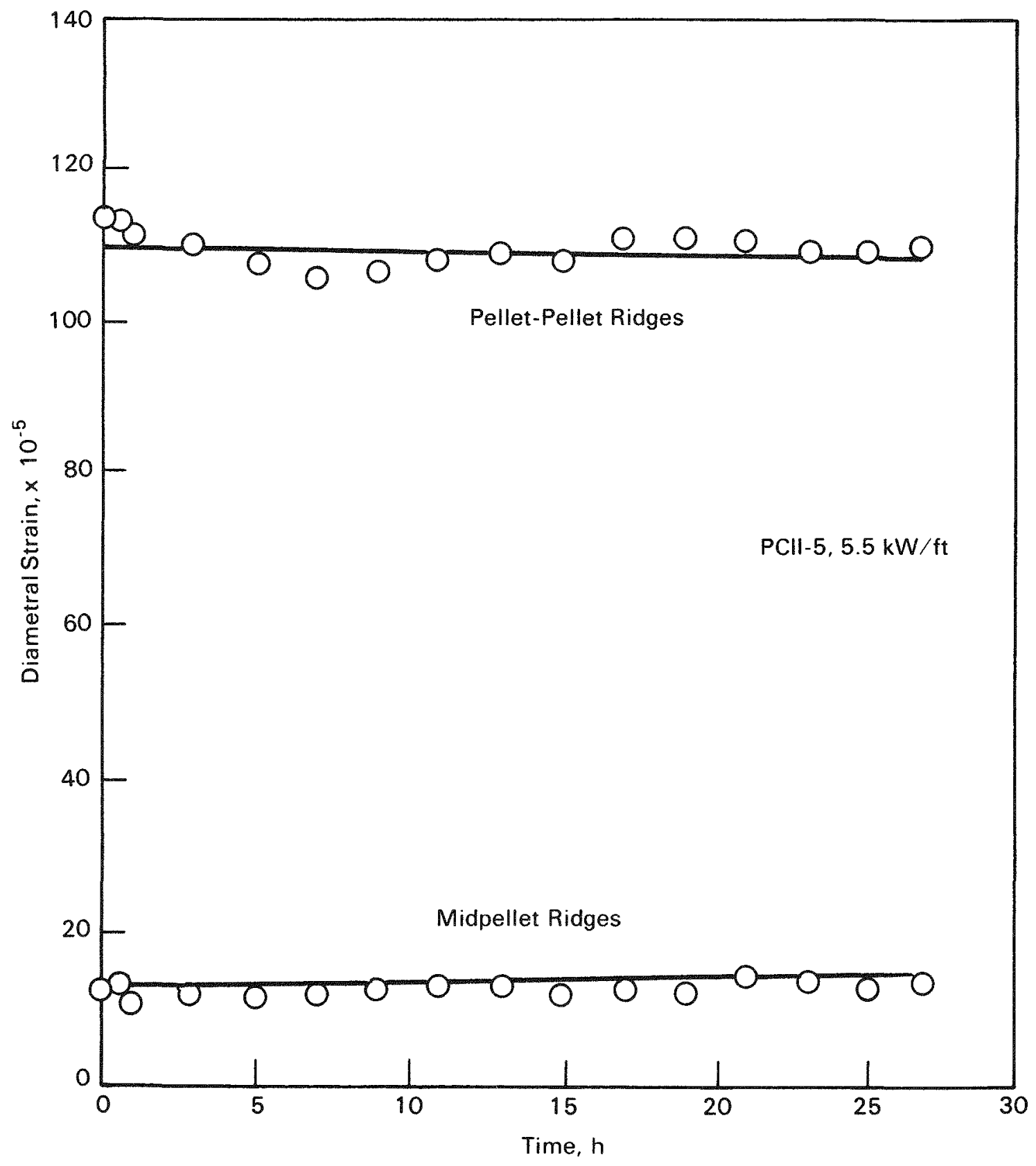

FIGURE 3.20. Diametral Strain During Power Holding Periods for PCII-5 Test 


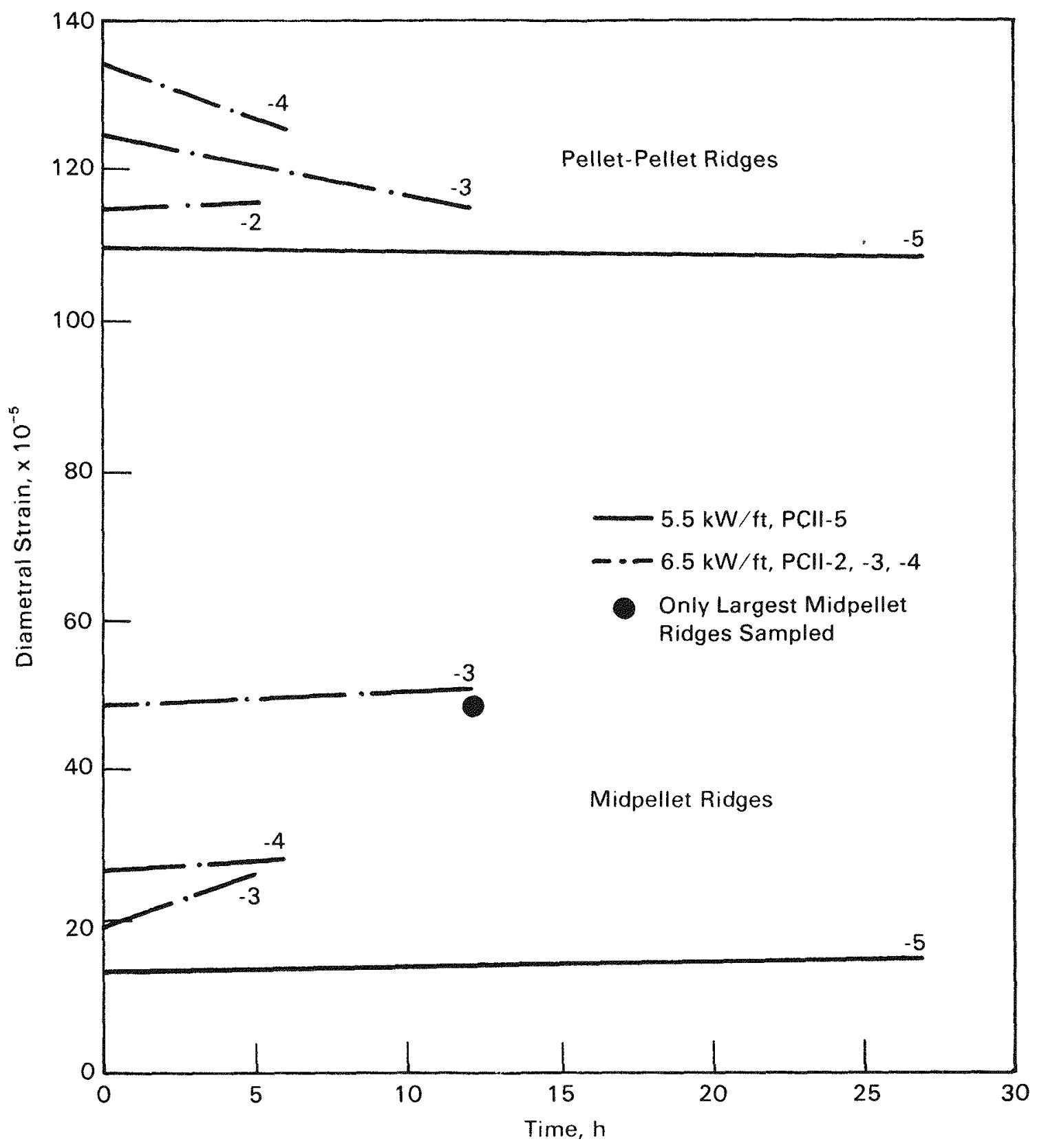

FIGURE 3.21. Summary of Diametral Strain During Power Holding Periods for PCII-2 Through PCII-5 Tests 


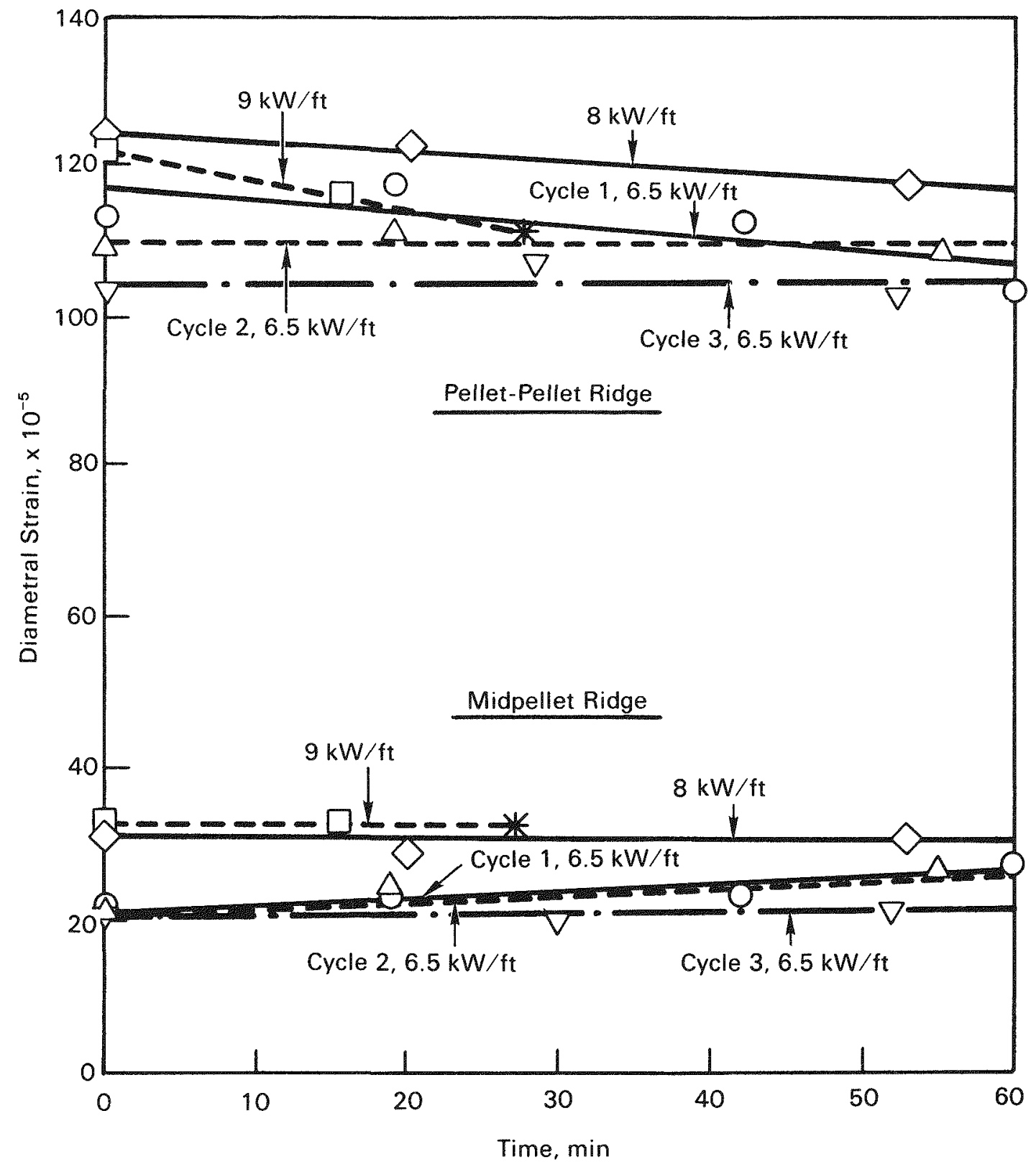

FIGURE 3.22. Diametral Strain During Power Holding Periods for PCII-6 
It should be noted that for PCII-3 only the ten largest midpellet ridges were measured in an attempt to maximize any observable behavior as a function of time at power. Therefore, the average midpellet ridge heights shown for this test are larger than those shown for the other tests.

In all the tests there was a reduction of the height of the pellet-pellet ridges as a function of the power holding period at LHGRs at or above $18 \mathrm{~kW} / \mathrm{m}$ $(5.5 \mathrm{~kW} / \mathrm{ft})$, especially at $21.3 \mathrm{~kW} / \mathrm{m}(6.5 \mathrm{~kW} / \mathrm{ft})$ or higher. However, the standard deviation for a typical averaged ridge strain was 1 arge, about $25 \%$ of the strain value. In PCII-5, the strain at zero time was compared to the strain at $7 \mathrm{~h}$ (Figure 3.20). The standard deviate for the mean between the two strains was 1.76 standard deviations, corresponding to a probability of only about 0.70 that the two values are different. At the $95 \%$ confidence level, it can be concluded that the values are not different. Similar comparisons can be made for other extreme values for each of the data sets, with the same conclusion. Therefore, the reductions in height of the pellet-pellet ridges over time are not statistically significant and should only be considered a trend.

There was apparently an increase in midpellet ridge height as a function of time at power in most tests. However, because of the large standard deviations (approximately one-half the ridge strain values), the probability of significant differences between extreme values is less than 0.15 . Therefore, at best, the ridge height increases over time can only be considered a trend. The presence of iodine in the PCII-6 test did not cause any significant difference in strain behavior with respect to the tests without iodine.

\subsection{POST-TEST EXAMINATIONS}

Scanning electron microscopy (SEM) and ceramography examinations were conducted on selected regions from two simulated fuel rods, primarily to examine the inner surface of the cladding for evidence of incipient cladding cracks. The ceramographic examinations also provided data concerning fragmentation of the fuel and the presence of abnormal phases in the fuel in the failure region for those rods that failed due to electrical short-circuiting. X-radiographs were used to determine where the sectioning cuts should be made for the sampling, for the SEM samples in particular because it was desired to have the location of a pellet-pellet interface near the midlength of the specimen. An example of the $X$-radiographs is shown in Figure 3.23 . The specimen locations are listed in Table 3.2 .

Each 19-mm (3/4-in.)-long SEM specimen was axially slit to provide two half-shells. One of the halves from each specimen was examined as cut, while the second half was flattened between two aluminum plates before examination. Examination of the six as-cut specimens revealed nothing unusual, no cladding cracks or even cracks in the zirconium oxide surface. One of these specimens 


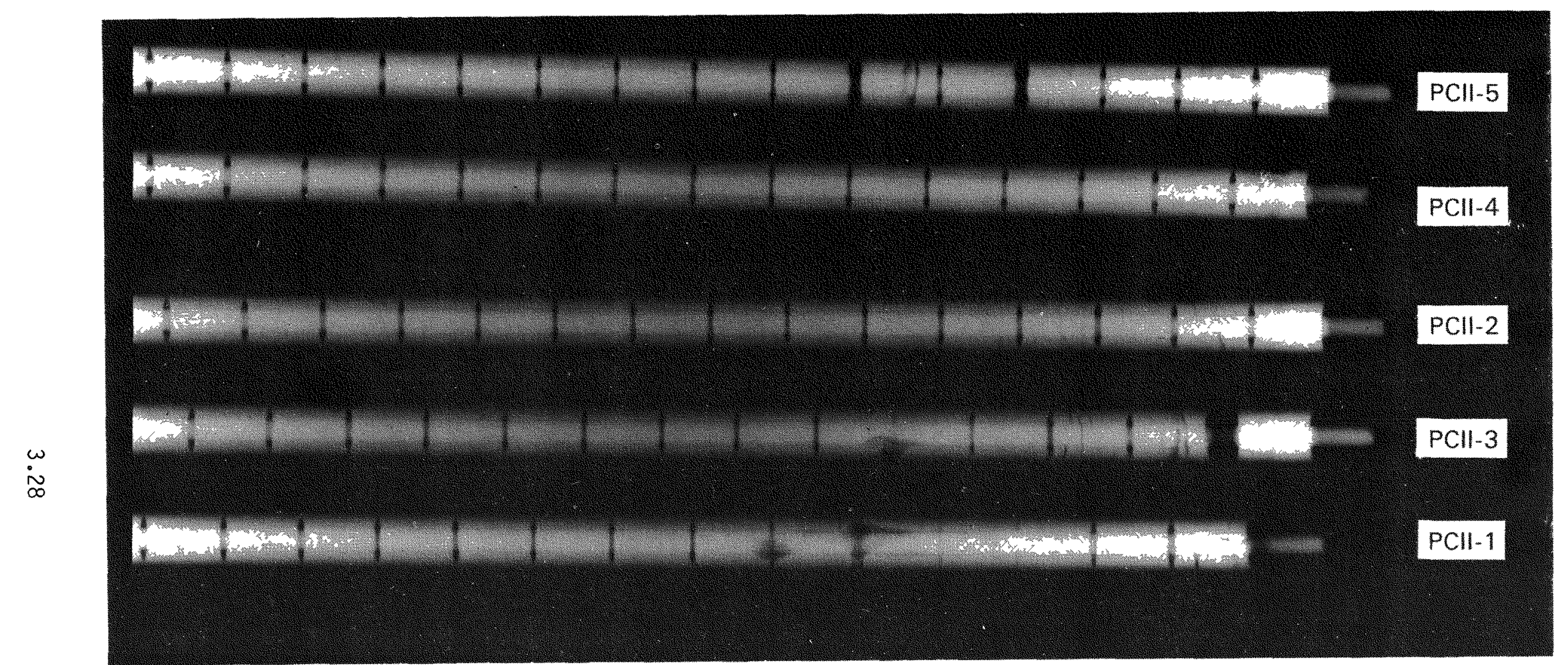

FIGURE 3.23: X-Radiographs of Upper Portion of Fueled Length from PCII-1 Through PCII-5 Tests 
TABLE 3.2. Specimens from Simulated Fuel Rods

\begin{tabular}{|c|c|c|c|}
\hline $\begin{array}{l}\text { Test } \\
\text { No. } \\
\end{array}$ & $\begin{array}{c}\text { Specimen } \\
\text { Identification } \\
\end{array}$ & $\begin{array}{l}\text { Section Locations } \\
\text { in. From Upper Weld }(a) \\
\end{array}$ & Specimen Type \\
\hline PCII-1 & D & $8-5 / 8$ to $9-3 / 8$ & SEM \\
\hline PCII-3 & $\begin{array}{l}G \\
E \\
C\end{array}$ & $\begin{array}{l}11-3 / 4 \text { to } 12-1 / 2 \\
9-5 / 8 \text { to } 10-3 / 8 \\
2-7 / 8 \text { to } 3-3 / 8 \\
\text { in failure region }\end{array}$ & $\begin{array}{l}\text { SEM } \\
\text { SEM } \\
\text { Transverse ceramography }\end{array}$ \\
\hline PCII-5 & $\begin{array}{l}\text { J } \\
H \\
\text { F } \\
D\end{array}$ & $\begin{array}{l}14-5 / 8 \text { to } 15-3 / 8 \\
10-1 / 8 \text { to } 10-7 / 8 \\
8-1 / 8 \text { to } 8-7 / 8 \\
5-3 / 8 \text { to } 5-7 / 8\end{array}$ & $\begin{array}{l}\text { SEM } \\
\text { SEM } \\
\text { SEM } \\
\text { Transverse ceramography }\end{array}$ \\
\hline
\end{tabular}

(a) Reference is upper irradiated to nonirradiated butt weld.

(No. PCII-5-H2) contained a region with the purposely made scratch (Figure 3.24). A area that was burnished by the tool holder was observed running parallel to the scratch. This half-shell was subjected to severe bending and it fractured in the region of the initial scratch. The failure was ductile (Figure 3.25). A similar specimen (Figure 3.26) was flattened without failure. All of the flattened specimens exhibited cracks in the zirconium oxide surface layer (Figure 3.27) but no evidence of brittle cladding fracture or incipient cracks in the underlying metal.

The inner surface of the cladding in the two transverse ceramography specimens was examined optically at high magnification. Initially, no evidence of any cladding cracks was observed. The purposely made scratch was not sharp rooted or as deep (Figure 3.28) as had been expected based on developmental scratches made on nonirradiated cladding. The major cracks in the fuel pellets were primarily radialiy oriented (Figures 3.29 and 3.30 ). However, a fine matrix of fuel cracks superimposed on the major crack pattern was observed in the region of the electrical short-circuit failure. This fine matrix of cracks is not typical of thermal-stress-induced cracking. The tungsten heater rod had apparently reacted with the fuel in the region of the failure as evidenced by a reaction zone (Figure 3.31a) and a light-colored phase deposited within the fuel adjacent to the heater rod (Figure 3.31b). The reaction product apparently filled an adjacent fuel pellet dish and was adhered to the heater ro' (Figure 3.32).

In an effort to determine whether excessive " tinn of the " of the cladding would affect the test results, the " 


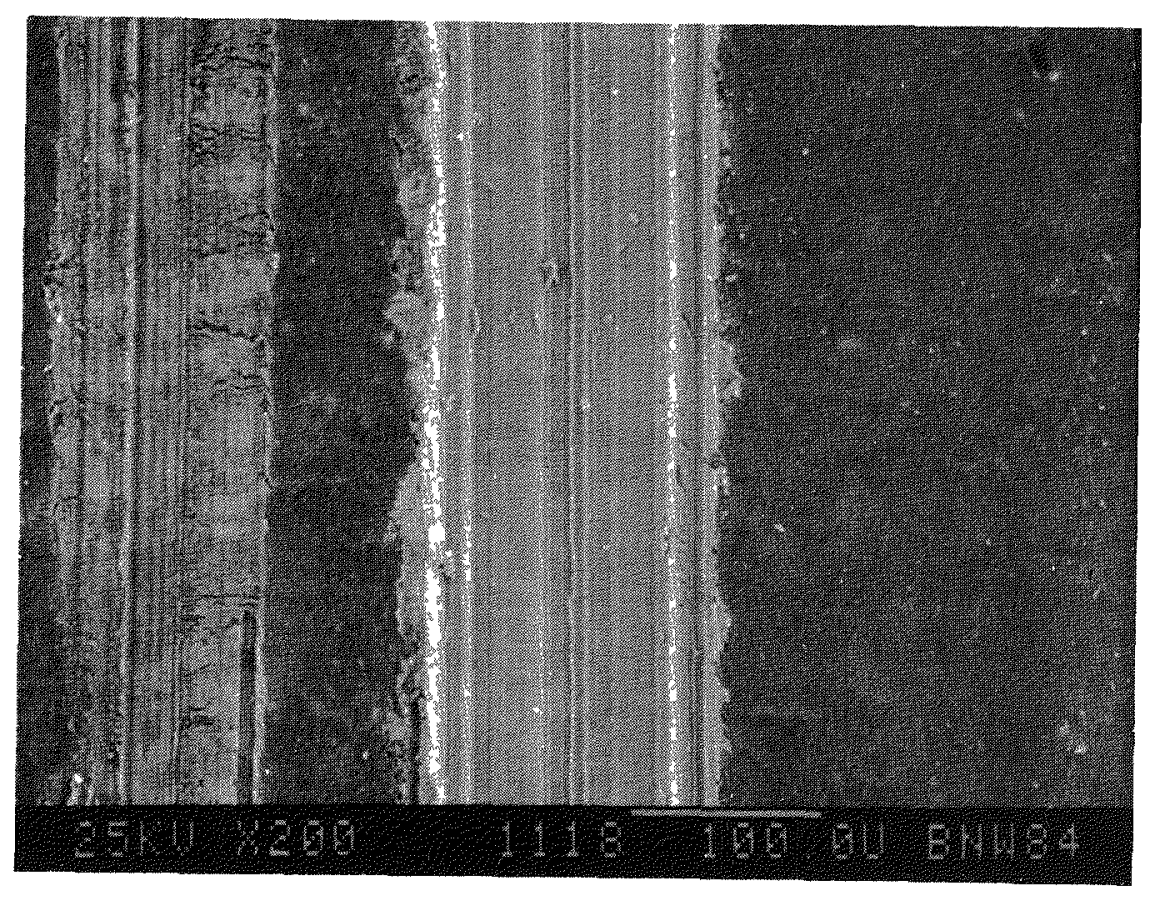
FIGURE 3.24. SEM View of Purposely Produced Scratch on Inner Cladding
Surface for PCII-5 Test (200X)

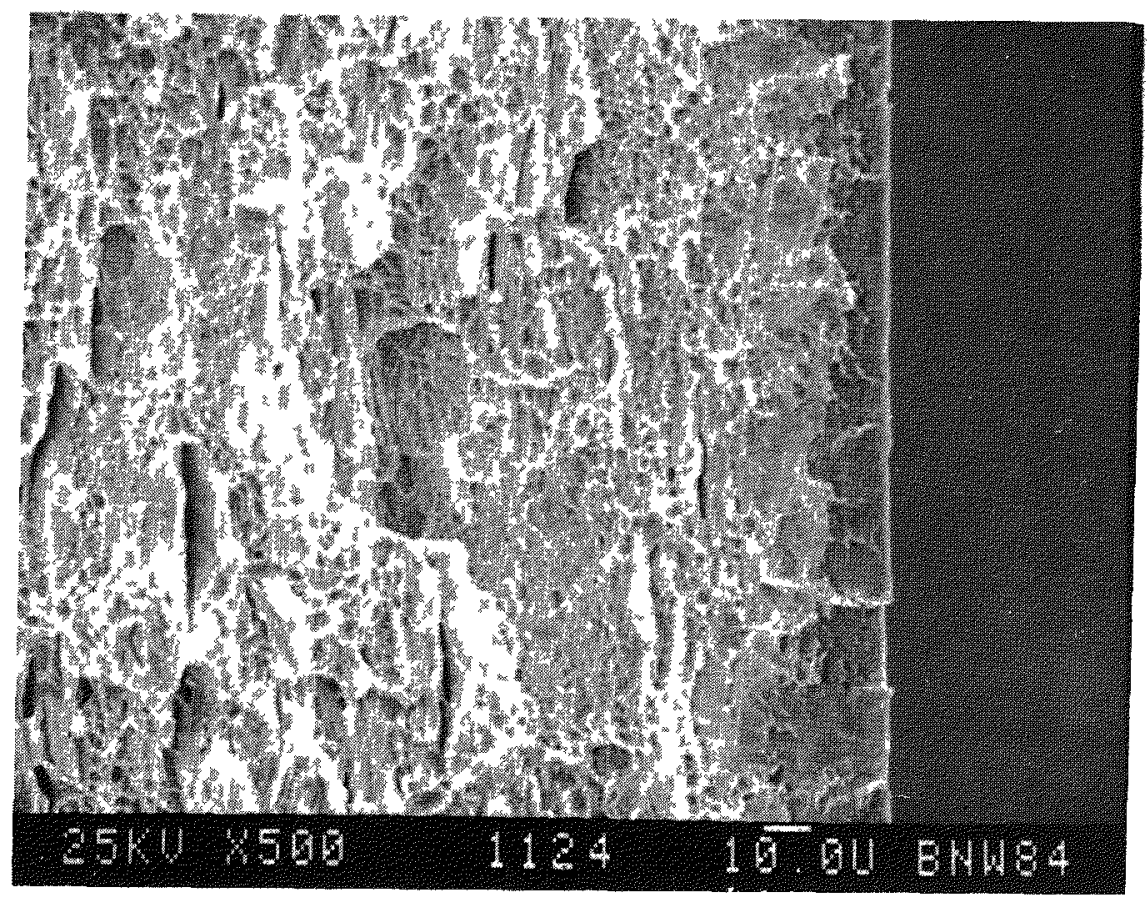

FIGURE 3.25. SEM View of Ductile Failure After Bending of Cladding from PCII-5 Test (500X) 


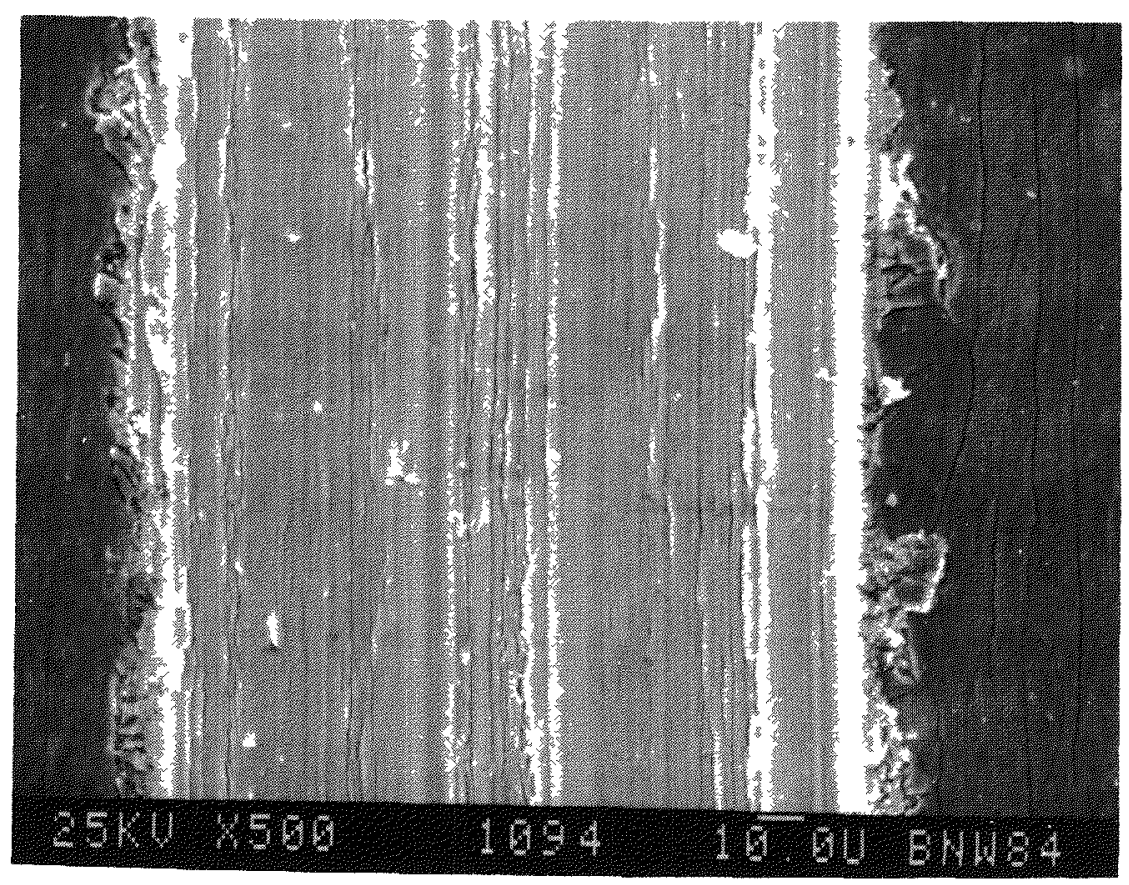

FIGURE 3.26. SEM View of Purposely Scratched Region on Flattened $\mathrm{Cl}$ adding from PCII-5 Test (500X)

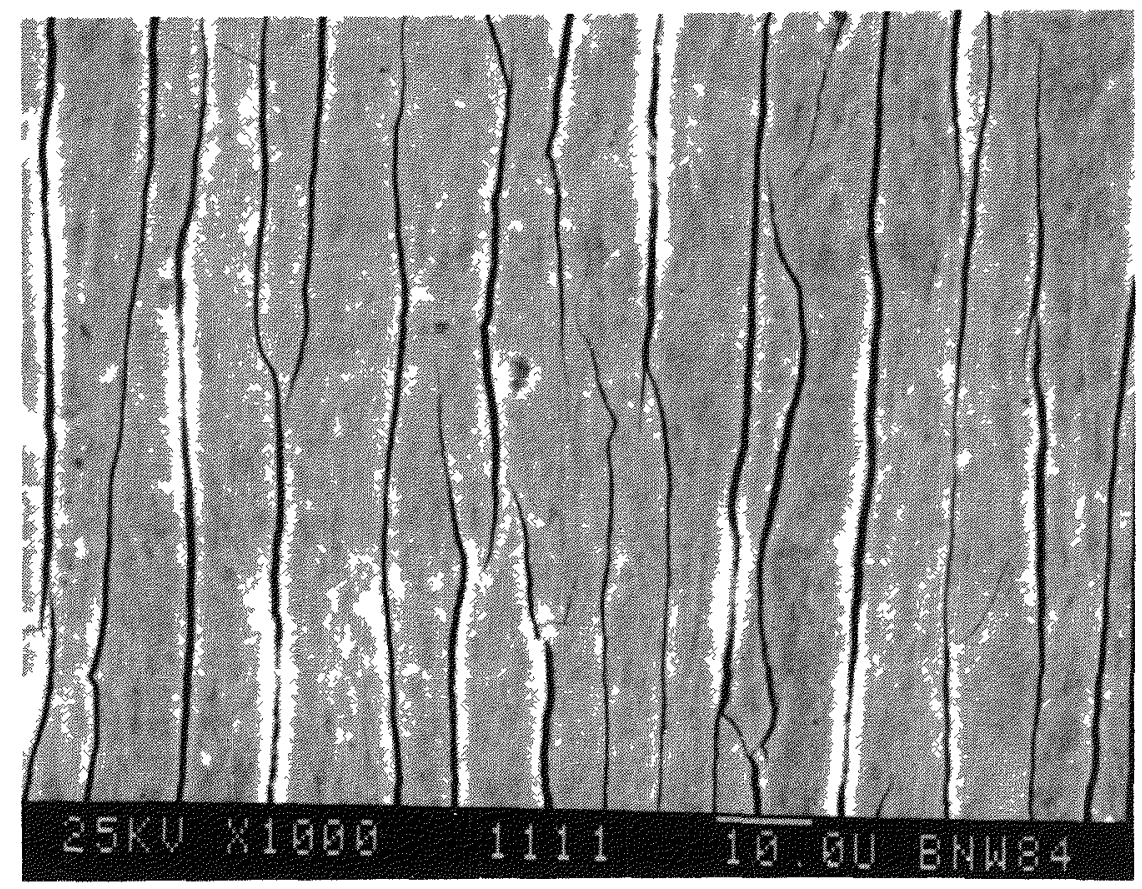

FIGURE 3.27. SEM View of Cracked Oxide on Inner Surface of Flattened Cladding from PCII-5 Test (1000X) 


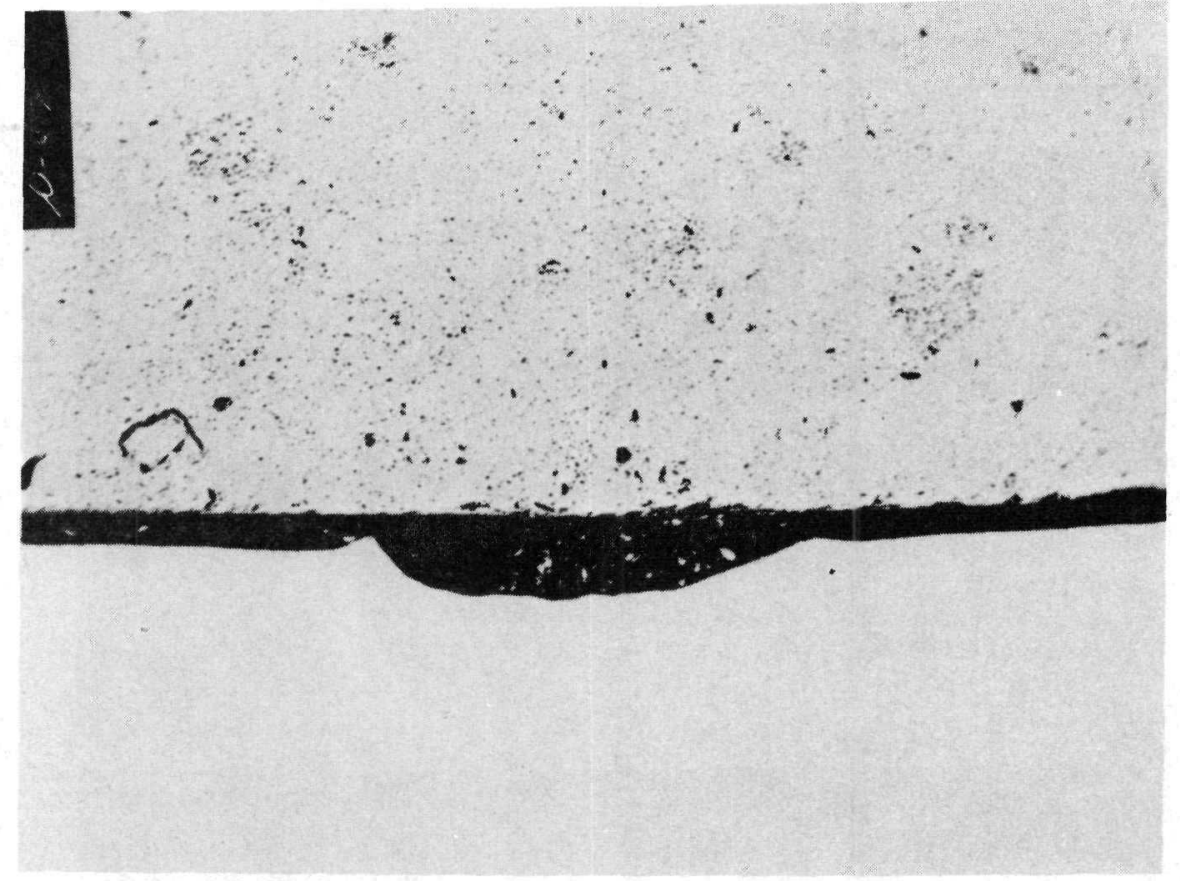

FIGURE 3.28. Purposely Produced Scratch on Inner Surface of Cladding from PCII-5 Test (250X)

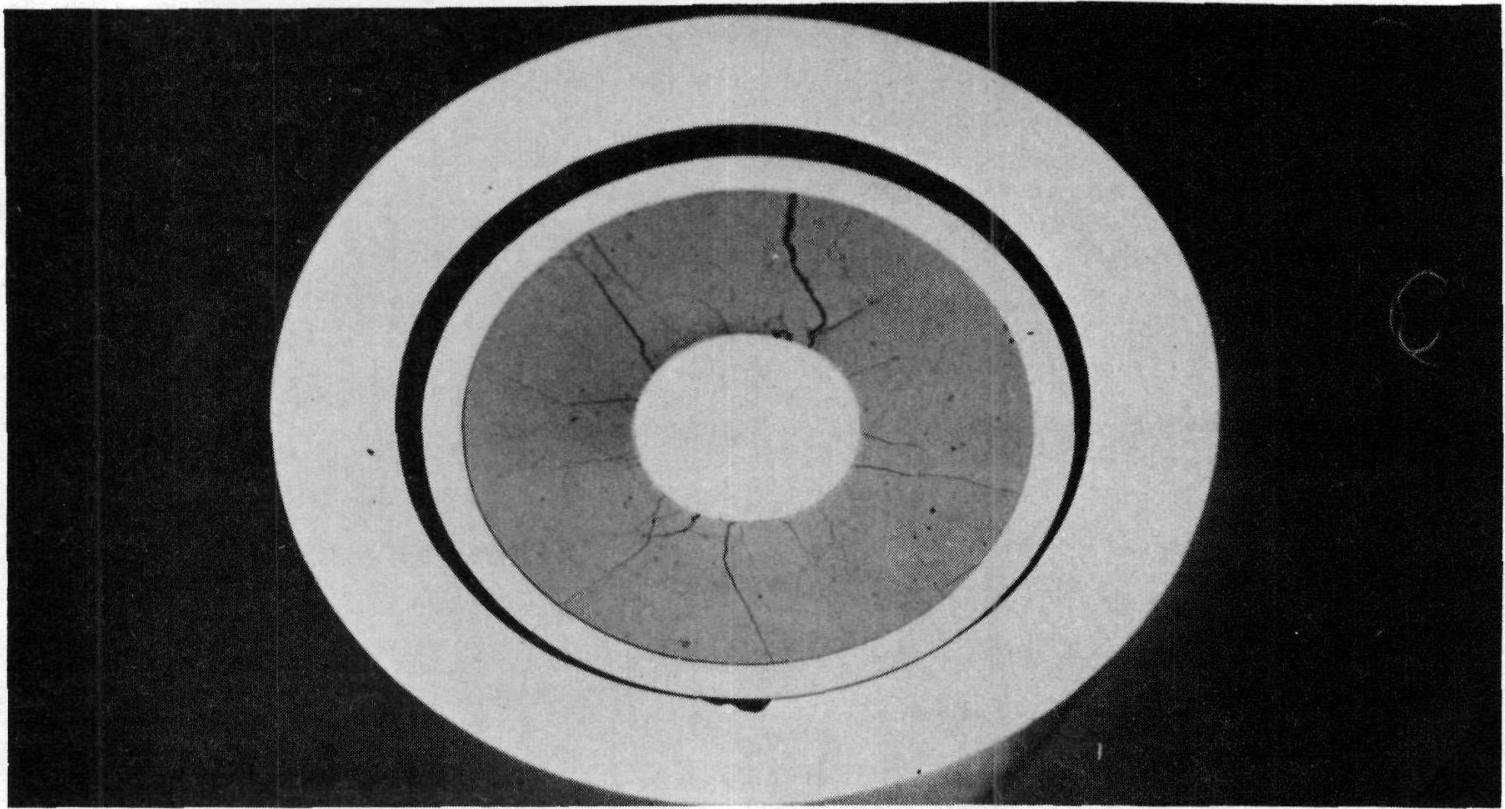

FIGURE 3.29. Oblique View of Cross Section from Near Electrically Produced Failure from PCII-3 Test (6X) 


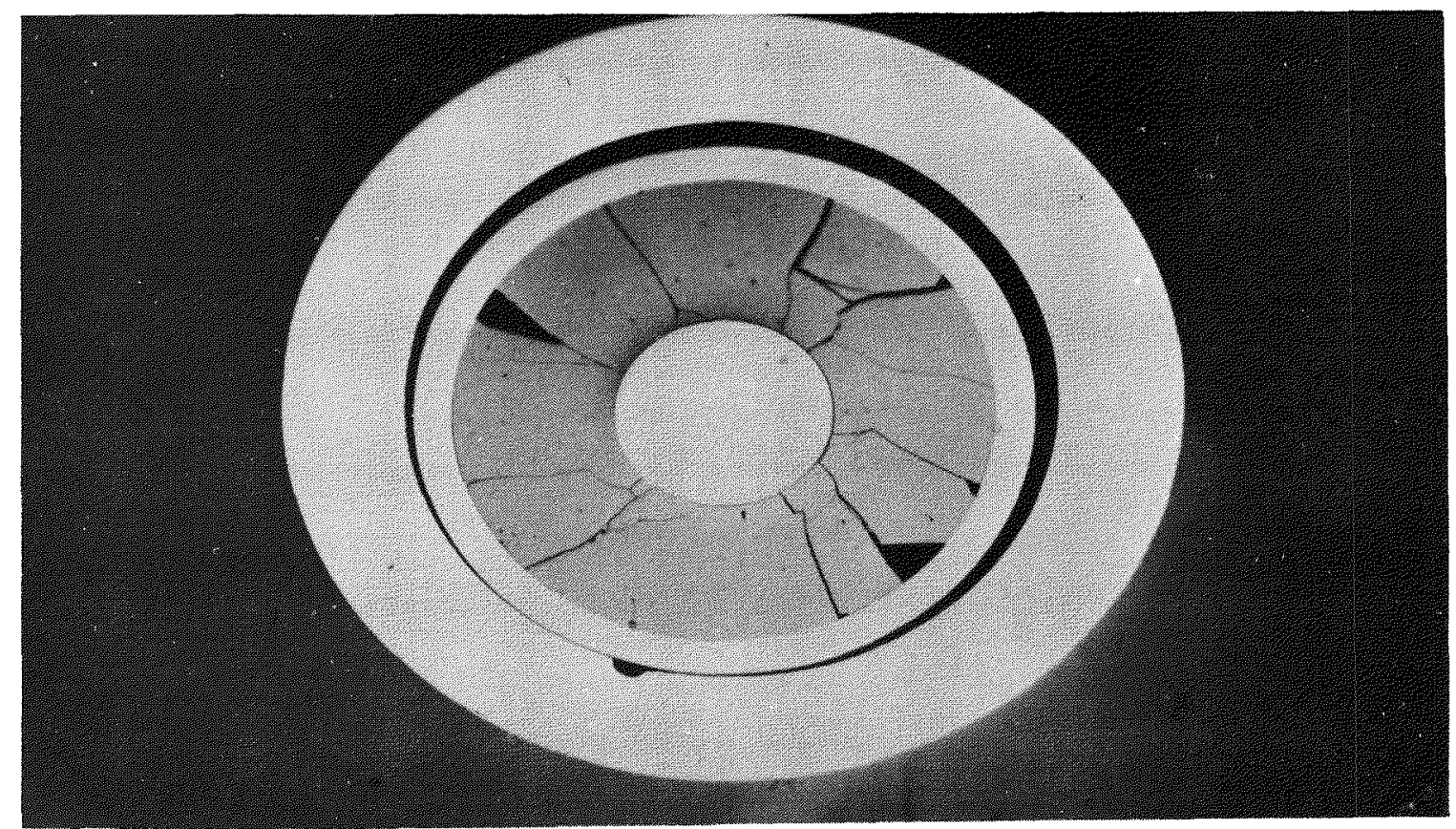

FIGURE 3.30. Oblique View of Typical Cross Section from PCII-5 Test (6X)

sample from PCII-5 was repolished so that the inner oxide surface layer could be investigated. The oxide layer in the regions away from the intentional scratch was uniformly $\sim 1 \mathrm{\mu m}$ thick (Figure 3.33 ). No oxide layer was observed in the region of the intentional scratch; however, an apparent small crack, about $10 \mu \mathrm{m}$ deep, was observed in the scratched region (Figure 3.34). During subsequent final polishing in preparation for planned etching to determine crack/grain boundary orientations, the apparent crack became shorter until it was no longer observable.

The three sections containing machined defects from the nonirradiated cladding tube from the PCII-6a test were given a cursory examination for any evidence of embrittlement from the iodine. Each piece, approximately $40 \mathrm{~mm}$ long, was axially cut into two halves. The half containing the machined defect was placed in a vise and flattened until it fractured. All three pieces failed in a brittle manner with a relatively small amount of strain. Visual examination of the fracture surface at magnifications in the $25 X$ to $40 X$ range indicated that the fractures had occurred along grain boundaries. A nondefected half-shell was also tested in a vise. This specimen was completely flattened, producing a ductile-appearing tear at the point of maximum strain. Clearly the two halves behaved in different ways. The brittleness of the defected pieces may be due to an artifact of the EDM machining process, perhaps in combination with an effect from the iodine. Consideration was given to attempting to define the iodine species on the surface of these samples; however, because these samples were sectioned from the tubing in a moist air atmosphere and because iodine compounds react easily with moisture and oxygen, further investigation was not pursued. 

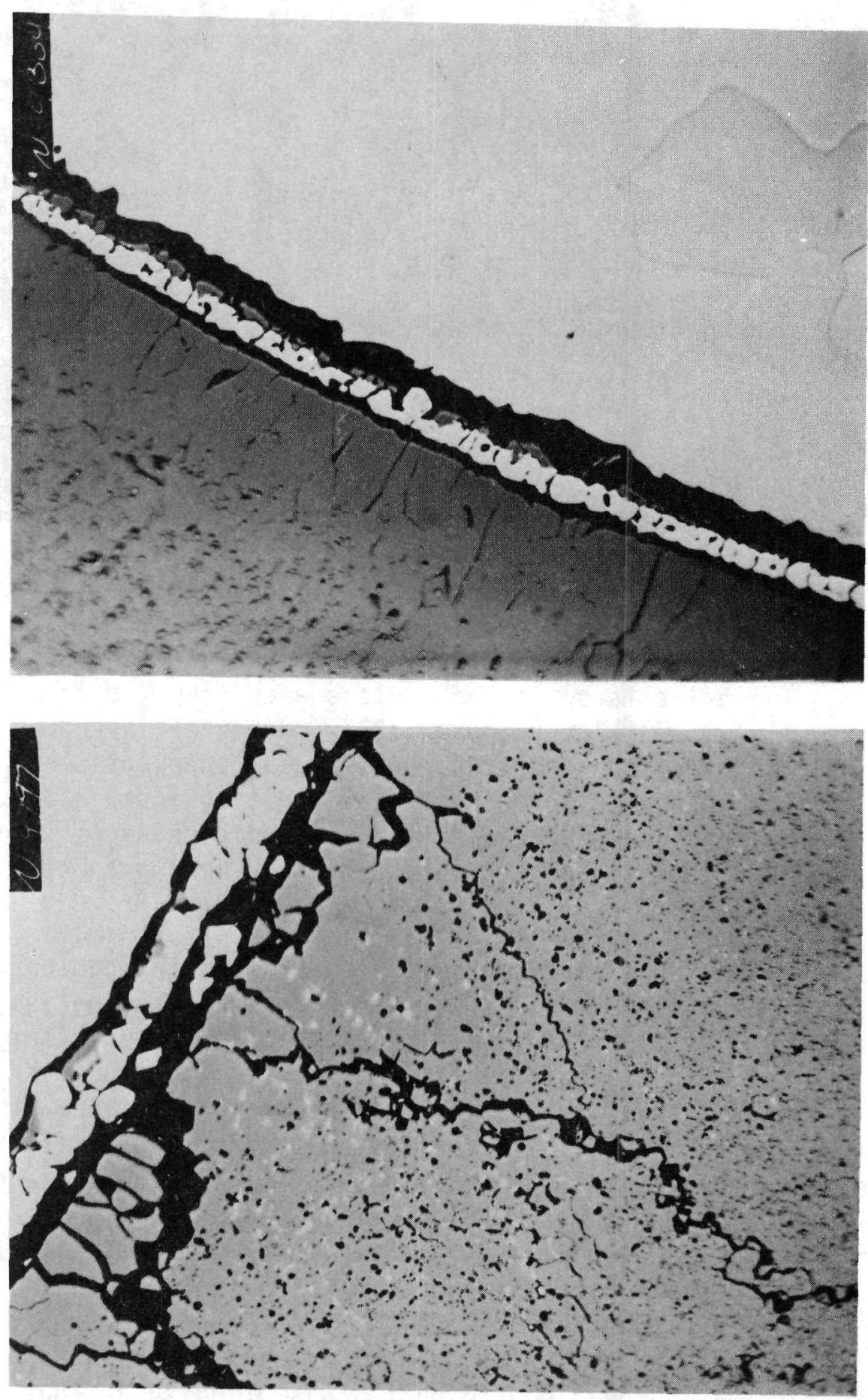

FIGURE 3.31. Two Views of Fuel Heater-Rod Interface Near Failure Region from PCII-3 Test (250X) 


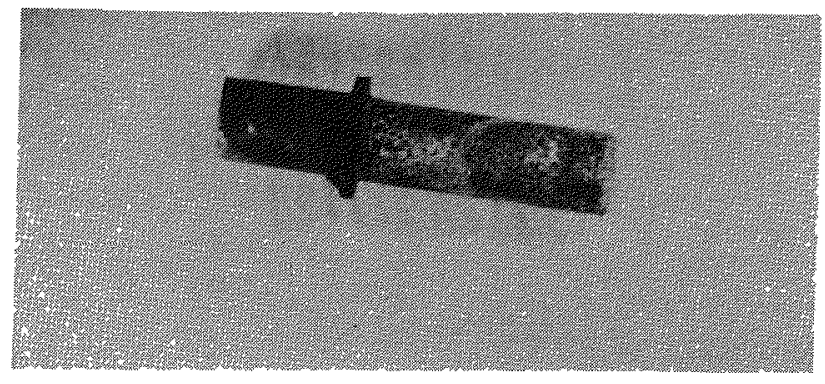

FIGURE 3.32. Reaction Product Adhered to Tungsten

Heater Rod from PCII-3

\subsection{COMPARISON OF TEST RESULTS}

Even though the simulated PCI-type tests were conducted at a variety of conditions, similar mechanical results were obtained in each test. The LHGR required to induce mechanical interaction was similar for each test. Pelletpellet and midpellet ridges were induced in the cladding during power ascents due to differential fuel-cladding thermal expansion. The magnitude of the ridges increased relatively linearly with increasing LHGR until the fuel apparently become hot and weak enough that it could not support an increasing load. Small plastic pellet-pellet ridge strains and, in some cases, midpellet ridge strains were observed in the cladding after peak power holding periods of relatively short duration; this indicates that at least the localized ridge stresses in the cladding were in excess of the Zircaloy yield strength at or near the peak power conditions during the tests. In some tests, interior surface defects in the cladding, although not with a perfect crack-inducing geometry, were included with no apparent effect on the cladding failure susceptibility. Likewise, the introduction of large quantities of iodine had no apparent effect on the failure susceptibility of the cladding. During power ascents, most of the tests were conducted at strain rates at which experience had shown Zircaloy to be susceptible to SCC. From an experimental standpoint, the conditions that should promote cladding failure (i.e., irradiation embrittlement, strain rate, high localized stresses, and, finally, iodine) were present in the test series. Logically, some failures that are attributable to PCI-SCC would be expected to occur, yet they did not. The only evidence of any deleterious effect of the PCI simulation was one small apparent crack in the region of an intentional scratch in the cladding of PCII-5. Examination of the test results suggests the following possibilities for the lack of cladding failures:

- The irradiation-induced embrittlement after one cycle of operation in a PWR is not sufficient to promote PCI-induced SCC in these samples. 
FIGURE 3.33. 0xide Layer on Inner Surface of Cladding from PCII-5 in Region Adjacent to Intentional Scratch

FIGURE 3.34. Apparent Small Crack in Region of Intentional Scratch in Cladding from PCII-5 
- The availability of molecular iodine when the stress is induced in the cladding is not sufficient to promote SCC. The test procedural limitations suggest that the molecular iodine that was introduced into the interior of the fuel rod reacted with the metal surfaces within the fuel rod pressurization system, resulting in only an equilibrium partial pressure of molecular iodine over the reaction products when the cladding was stressed; this level of iodine may not be sufficient to induce SCC.

- This PWR-type cladding is not susceptible to failure induced by PCMI either in the presence or absence of iodine. Possible explanations include a lack of surface inclusions that promote SCC, as suggested by Cubiccotti, $(4)$ or a texture where basal planes, which might be crack nucleation points, are oriented predominantly tangentially and do not intersect the inner cladding surface.

Although it is not possible to differentiate definitely between these possibilities or to ascertain any synergistic effects, it likely that the cladding is simply not susceptible to SCC.

The apparent ridge strain relaxation $(6 \%$ to $8 \%$ ) that occurred during the long peak power holding periods in PCII-3 and PCII-5 was considerably less than that which occurred in in-reactor tests on rods that produced ridges of a simi1 ar magnitude; rods containing dished pellets from IFA-508 irradiated in the Halden Boiling Water Reactor experienced ridge strain relaxation of about $30 \%$ in $10 \mathrm{~h} .(3)$ This observation indicates the potential importance of irradiationinduced relaxation mechanisms, such as densification or irradiation creep, in the fuel and cladding of actual operating fuel rods. 


\subsection{CONCLUSIONS}

This study produced the following conclusions:

- Al though cladding strain rates used in the tests were in the range that had previously been shown to produce SCC-type failures, and al though the tests produced localized stress levels sufficient to produce plastic deformation, PCI-type failures could not be induced, either in the presence or absence of iodine, in PWR Zircaloy-4 cladding that had previously been irradiated in the absence of fuel and fission products for one commercial reactor cycle.

- Although other possibilities exist for the lack of SCC-type failure of the irradiated cladding (e.g., the irradiation dose may not be sufficient to embrittle the cladding or an adequate partial pressure of moleculer iodine was not present when the cladding stress was present), the most likely explanation is that this cladding is simply not susceptible to this type of failure.

- Pellet-pellet ridges and midpellet ridges were produced in the cladding, and caused high localized stress levels and small amounts of localized yielding.

- The apparent ridge strain relaxation that occurred during power hold periods was considerably less than that which occurs in-reactor. This observation indicates the potential importance of irradiation-induced relaxation mechanisms. 
,

. 


\subsection{REFERENCES}

1. M. Peehs, H. Stehle, and E. Steinberg. 1979. "Out-of-Pile Testing of Iodine Stress Corrosion Cracking in Zircaloy Tubing in Relation to the Pellet $\mathrm{Cl}$ adding Interaction Phenomenon." In Proceedings of the Fourth Annual Conference on Zirconium in the Nuclear Industry Sponsored by the American Society for Testing and Materials, Stratford-upon-Avon, England, June $26-29,1978$, p. 250 .

2. K. Une. 1980. "Threshold Values Characterizing Iodine-Induced SCC of Zircaloys." In Proceedings of IAEA Specialists Meeting on PelletCladding Interaction in Water Reactors, Riso, Denmark, September 22-26, 1980 .

3. M. Uchida, and M. Ichikawa. 1980. "In-Pile Diameter Measurement of Light-Water Reactor Test Fuel Rods for Assessment of Pellet-Cladding Mechanical Interaction." Nucl. Tec., 51, pp. 33-44.

4. D. Cubiccotti, R. L. Jones, and B. C. Syrett. 1980. Stress-Corrosion Cracking of Zircaloys. NP-1329, Electric Power Research Institute, Palo ATto, California. 


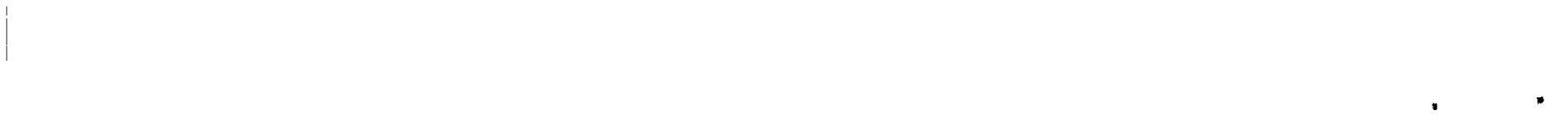

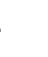


APPENDIX

BABCOCK AND WILCOX REPORT ON IRRADIATED CLADDING SELECTION AND GAMMA SCANNING 



\section{Babcock \& Wilcox}

SELECTION, GAMMA SCANNING,

AND NEUTRON FLUENCE MEASUREMENTS

OF IRRADIATED ZIRCALOY CLADDING

Submitted by

CONTRACT RESEARCH DIVISION

P. 0. BOX 1260

Lynchburg, Virginia 24505

Prepared for

Battelle Pacific Northwest Laboratories

Battelle Subcontract No. B-D2599-A-X

B\&W Contract No. CRD 1095

A. 1 


$$
\text { "MnTIC:" }
$$

"This report was prepared as an account of work sponsored by the United States Government. "either the United States nor the Department of Energy nor any of their employees, nor any of their contractors, subcontractors, or the ir employees, makes any warranty, express or implied, or assumes any legal liability or responsibility for the accuracy, completeness or usefuiness of any information, apparatus, product or process disclosed, or represent. that its use wcul ret infringe privately ouned righes. 


\section{TABLE OF CONTENTS}

Section

Page

1.0

INTRODUCTION

$1-1$

$2.0 \quad$ EXPERIMENTAL METHODS............................ 2-1

2.1 Measurements of $\mathrm{Cladding}$ Inside Diameters........... 2-2

2.2 Gross Gamma Scans........................... 2-2

2.3 Isotopic Gamma Measurements.................... 2-2

2.4 Methodology of Neutron Fluence Determination......... 2-3

2.4.1 Determination of Normalization Constant....... 2-4

2.5 Radiation Levels and Radioisotope Content of

Gamma Scanned Zircaloy Cladding................ 2-5

RESULTS AND DISCUSSION......................... 3-1

3.1 Inside Diameters of Selected Cladding Segments........ 3-1

3.2 Gross Gamma Scans.......................... 3-4

3.3 Isotopic Gamma Scan Measurements.................. 3-4

3.4 Evaluation of Normal ization Constant.............. 3-5

3.4.1 Neutron Fluences from Isotopic Gamma Scans..... 3-5

3.5 Radiation Levels and Radioisotope Content

of Irradiated Zircaloy $\mathrm{Cl}$ adding................. 3-7

4.0

REFERENCES................................ 4-1 


\section{ACKNOWLEDGEMENTS}

It is a pleasure to acknowledge the assistance and cooperation of

Bernard Parham, Dave Kimme1, and Richard Beauregard during the experimental phases of the work. Measurements of inside diameters for the selection of cladding segments were performed under the direction of Bill Machin. 


\section{SUMMARY}

Twenty tube segments of approximately 30 inches in length were selected for their acceptable physical dimensions of inside diameter and ovality. These segments were obtained from prototypical full-length, empty Zircaloy fuel cladding irradiated as part of two poison rod clusters in ANO-1 reactor during cycle 2.

Four specimens from the selected lot of twenty irradiated Zircaloy fuel cladding were examined by gamma scan method. A high purity intrinsic Ge gamma detector, modular electronics, and Nuclear Data ND-6620 system were employed.

Axial gross gamma scan traces of activity due to gamma rays of up to $2 \mathrm{MeV}$ in energy and a single channel selected ${ }^{54} \mathrm{Mn}$ photopeak region indicated the absence of regions of high activity.

Isotopic gamma scan spectral data taken at 8,15 and 22 inches from the top of each tube segment were utilized to determine the activity of ${ }^{54} \mathrm{Mn}$ formed by the reaction ${ }^{54} \mathrm{Fe}(n, p)^{54} \mathrm{Mn}$.

The absolute activity of ${ }^{54} \mathrm{Mn}$ in a 0.10 -inch transverse section of a tube was determined by gamma spectroscopy using a precalibrated Ge gamma detector. The tube was also examined at the same axial position by isotopic gamma scan. These measurements were used to calculate a normalization constant to convert isotopic gamma scan data of ${ }^{54} \mathrm{Mn}$ activity to absolute specific activity (activity/g) of ${ }^{54} \mathrm{Mn}$.

Neutron fluences (neutrons $/ \mathrm{cm}^{2}$ ) of neutrons with energies $>0.1 \mathrm{MeV}$ experienced by Zircaloy at the 12 axial positions of isotopic gamma scans were calculated. The average neutron fluence was $2.43 \times 10^{21}$ neutrons $/ \mathrm{cm}^{2}$ with an 
associated 1-sigma value of $16 \%$, corresponding to a fuel burnup of 7.01 GWD/MTU.

Two representative samples of irradiated Zircaloy cladding of approximately 2.5 inches in length were examined by high resolution gamma spectroscopy. The radioisotope activities and radiation levels were determined. At the time of measurement on Apri1 13, 1982, the nuclides ${ }^{51} \mathrm{Cr}$, ${ }^{54} \mathrm{Mn},{ }^{60} \mathrm{Co},{ }^{125} \mathrm{Sb}$ and ${ }^{137} \mathrm{Cs}$ were detected. The activity of ${ }^{125} \mathrm{Sb}$ and ${ }^{60} \mathrm{Co}$ was about $95 \%$ of the total specific activity of $1670 \mathrm{uCi} / \mathrm{inch}$. The small contribution (approximately $0.1 \%$ ) of ${ }^{137} \mathrm{Cs}$ activity is attributable to its origin, namely, the reactor coolant. The radiation levels corresponding to the observed activity were estimated as $1.8 \mathrm{mR} / \mathrm{hr} / \mathrm{inch}$ at one meter. 


\subsection{INTRODUCTION}

The characterization of irradiated Zircaloy fuel cladding segments was performed by physical and radiochemical measurements. The pre-irradiation specifications of the cladding are given in Appendix $A$. The requisites of this subcontract No. B-D2599-A-X are identified in the Statement of Work given in Appendix B.

The required 20 segments, each approximately 30 inches in length, were obtained from full-length, empty cladding tubes irradiated as part of two poison rod clusters (0353 and 0355) for one cycle (cycle 2) at ANO-1 reactor. The duration of the cycle was 306 days (2 Apri1 1977 to 2 February 1978) with 272 effective power days (EFPD). The selected tube segments met the specifications of physical dimensions of inside diameter and ovality.

Measurements of inside diameters and radiochemical measurements consisting of gross gamma scans of and isotopic determinations in four of the segments selected at random are presented in this report. This investigation was aimed at ascertaining the uniformity and magnitude of neutron fluence along the tube axis experienced by the cladding during irradiation. The results were made available to interested parties and this report constitutes a documentation of the procedures, methodology and results. 


\subsection{EXPERIMENTAL METHODS}

The inside diameters of Zircaloy fuel cladding tubes were ascertained by using 36-inch-long, high-precision centerless grind drill rods with diameters ranging from 0.3750 inches to 0.3790 inches in 0.5 -mil increments. The rods were supplied by Battelle-Pacific Northwest Laboratories.

The radiochemical measurements performed with four irradiated cladding segments each approximately 30 inches in length comprised of axial gross gamma scans and isotopic determinations at three axial positions. Additional sections of a segment were examined by high resolution gamma spectroscopy in order to determine a normalization constant to convert the measured isotopic ${ }^{54} \mathrm{Mn}$ concentrations into neutron fluence and for obtaining the true composition of radioactive nuclides in the cladding. The latter was needed to evaluate the expected radiation levels. The experimental details of the investigations are presented below.

The axial gamma scans and isotopic measurements were performed on rods consisting of an irradiated zircaloy cladding segment extended by solid al umi num rods on both ends. This was accomplished by threading together two pieces of solid aluminum rods with tapered ends. The tapered end of the bottom rod was extended by a thin rod of al uminum that passed through the zircaloy tube and was threaded into the tapered end of the upper rod. When assembled, the Zircaloy tube was seated properly on the tapered ends, and the rod appeared to be an intact rod with a dark middle zone of Zircaloy.

A constituted composite rod was suspended vertically inside a Hot Cell in front of a collimator. An axial segment of the rod was seen by a high purity intrinsic Ge detector located outside the Hot Cell through the 42-inch collimator system located in the wall of the Hot Cell. The collimator system consisted of two sets of parallel plates. The front plates, 12 inches in length, were separated by 0.437 inch, forming a straight-edge slit transverse to the rod axis. The parallel plates at the back side of the collimator and 
nearer to the detector were opened to 0.75 inch and constitute a scraper. During gamma scanning, the rod axis was located at 13.5 inches from the front end of the collimator slits and the gamma detector was 3.5 inches from the scraper aperture of the collimator. These dimensions allowed for the calculation of the rod axial section seen by the gamma detector. The same collimator setup was used in all the measurements reported here.

The gamma detector signals were processed by modular electronics and the gamma spectra were accumulated on a Nuclear Data ND-6620 system.

\subsection{MEASUREMENTS OF CLADDING INSIDE DIAMETERS}

The inside diameter of the Zircaloy cladding tubes was determined by passing a precision drill rod through the tube. The diameters of the two drill rods with a $0.5-\mathrm{mil}$ difference where one of the rods passed through the cladding tube while the other did not clear the entire length of the cladding segment, established the minimum and maximum dimensions of the cladding inside diameter.

\subsection{GROSS GAMMA SCANS}

The gross gamma scans of a rod consisted of activity traces of activity due to gamma rays in energies up to $2 \mathrm{MeV}$ and a single channel selected $54 \mathrm{Mn}$ photopeak energy region. In actual practice the rod was pulled up at a constant speed along its long axis and the single channel outputs corresponding to the two energy regions were converted to analog form using rate meters. The analog output was recorded on a dual-pen strip chart recorder. The rod pulling and strip chart paper speeds were both adjusted to one inch per minute.

\subsection{ISOTOPIC GAMMA MEASUREMENTS}

The four rod segments that were ganma scanned were examined for the radionuclide composition at three positions along the long axis of each rod. The rod was held stationary at three axial positions, 8, 15 and 22 inches from the top of the rod in front of the collimator, and a gamma spectrum was 
accumulated. The gamma spectra were analyzed and the characteristic photopeak areas were evaluated using software provided with the ND-6620 system.

The top ends of the four rods were identified with one, two and four dots and a continuous band of white paint.

\subsection{METHODOLOGY OF NEUTRON FLUENCE DETERMINATION}

The neutron fluence calculations were based on the assumption that the Zircaloy cladding experienced a constant average neutron flux during irradiation. The specific activity of ${ }^{54} \mathrm{Mn}$ produced under these conditions by the reaction ${ }^{54} \mathrm{Fe}(n, p)^{54} \mathrm{Mn}$ can be expressed by the following expression:

$$
D=n \sigma \phi\left(1-e^{-\lambda t}\right)
$$

where

$D=$ disintegration rate of ${ }^{54} \mathrm{Mn}$ at the end of irradiation (disintegrations per second)

$n=$ number of atoms of ${ }^{54} \mathrm{Fe}$ per gram of Zircaloy

$\sigma=$ reaction cross-section $\left(\mathrm{cm}^{2}\right)$

$\phi=$ average neutron flux $\left(\mathrm{n} / \mathrm{cm}^{2} / \mathrm{s}\right)$

$\lambda=$ decay constant of ${ }^{54} \mathrm{Mn}\left(\mathrm{S}^{-1}\right)$

and $t=$ irradiation time (seconds)

The value of $n$, atoms of ${ }^{54} \mathrm{Fe}$ per gram of Zircaloy, was calculated using typical iron content ${ }^{(1)}, 0.21$ w/o of Zircaloy and 5.84 atom $\%$ of ${ }^{54} \mathrm{Fe}$ in iron (2). A flux averaged reaction cross-section (3), $\sigma$, of $56.3 \mathrm{mb}$, decay constant corresponding to a half-life ${ }^{(2)}$ of 312.5 days and irradiation time of 306 days were utilized in calculating the value of $D$.

The decay rate of ${ }^{54} \mathrm{Mn}$ in irradiated Zircaloy cladding was determined from the isotopic gamma scan data at various axial positions and can be expressed as

$$
D=\frac{A}{\varepsilon \cdot M}
$$


In equation (2), A is the activity of $54 \mathrm{Mn}$ (counts per second) determined by the characteristic photopeak ( $835 \mathrm{keV})$ area decay corrected to the end of irradiation, $\varepsilon$ is the overall detection efficiency and $M$ is the mass of the cladding axial section seen by the detector.

Combining equations (1) and (2), the average neutron flux, $\bar{\phi}$, hence neutron fluence, $\bar{\phi} t$, can be evaluated by the equation

$$
\text { Neutron fluence }\left(\mathrm{n} / \mathrm{cm}^{2}\right)=\overline{\phi t}=\frac{A}{N \cdot \sigma\left(1-e^{-\lambda t}\right) \cdot \varepsilon \cdot M}
$$

In equation (3), the product, $\varepsilon \cdot M$, can be considered as a normalization constant that can be calculated by determining the absolute activity of ${ }^{54} \mathrm{Mn}$ from a portion of the cladding that was also examined by isotopic gamma scanning.

\subsubsection{Determination of Normalization Constant}

A 30-inch segment of irradiated Zircaloy cladding was positioned in front of the collimator and a gamma spectrum was accumulated to determine the activity of ${ }^{54} \mathrm{Mn}$ in an axial segment seen by the detector through the collimator system. A transverse section of 0.10 inch was taken from the same axial position and the absolute activity of ${ }^{54} \mathrm{Mn}$ was measured using a precalibrated high resolution intrinsic Ge gamma detector. The normalization constant was calculated by two different but equivalent methods in the following manner.

In one method, the mass of the transverse section was used to determine the absolute specific activity $(\mu \mathrm{Ci} / \mathrm{g})$ of $54 \mathrm{Mn}$. The normalization constant was then established as the ratio of absolute specific activity and the activity determined from isotopic gamma scan.

In the second approach, the axial section of the gamma scanned cladding, seen by the detector was calculated from the physical dimension of the counting 
setup (see section 2.0). The absolute activity of ${ }^{54} \mathrm{Mn}$ in this section was then determined based on the measurement of the 0.10 -inch section.

\subsection{RADIATION LEVELS AND RADIOISOTOPE CONTENT}

OF GAMMA SCANNED ZIRCALOY CLADDING

The gamma spectra of isotopic gamma scans all indicated the presence of $661 \mathrm{keV}$ photopeak of ${ }^{137} \mathrm{Cs}$. In order to eliminate the contribution of this fission product activity from the Hot Cell background, two representative sections, 2-3 inches in length, were taken and were gamma counted outside the Hot Cell. The gamma spectra of these samples using a precalibrated gamma spectroscopy system were used to establish the radioisotope content in the irradiated Zircaloy and their activities. The radiation levels were calculated based on this data. 
, r 


\subsection{RESULTS AND DISCUSSION}

The four specimens of irradiated Zircaloy cladding that were examined in greater detail by gamma scan method from a number of 30-inch long segments that were screened for acceptable physical dimensions. All of these segments came from two clusters (0353 and 0355). Each cluster contained a burnable poison rod and 15 prototypical, full-length, empty zircaloy cladding tubes. The preirradiation specifications of the cladding are given in Appendix $A$. The clusters were irradiated for one cycle during cycle 2 of ANO-1 reactor. The power history of the reactor during the cycle lasting for 306 days with 272 EFPD is given in Figure 1. The clusters were located in two symmetrical positions, E6 and M6, in the core as shown in Figure 2.

\subsection{INSIDE DIAMETERS OF SELECTED CLADDING SEGMENTS}

The minimum and maximum diameters of the 20 Zircaloy cladding segments that were selected are shown in Table I. A total of 22 cladding segments were screened. It can be seen that the diameters of the selected segments and the standard deviation meet the specifications of Appendix B.

Table I

INSIDE DIAMETERS OF SELECTED CLADDING SEGMENTS

No. of Tubes

2

16

2

Average

Std. Dev.
Inside Diameter (inches)

Minimum Maximum

0.3760

0.3765

0.3765

0.3770

0.3770

0.3775

0.3765

0.3770

$6.09 \times 10^{-4}$

$6.08 \times 10^{-4}$ 


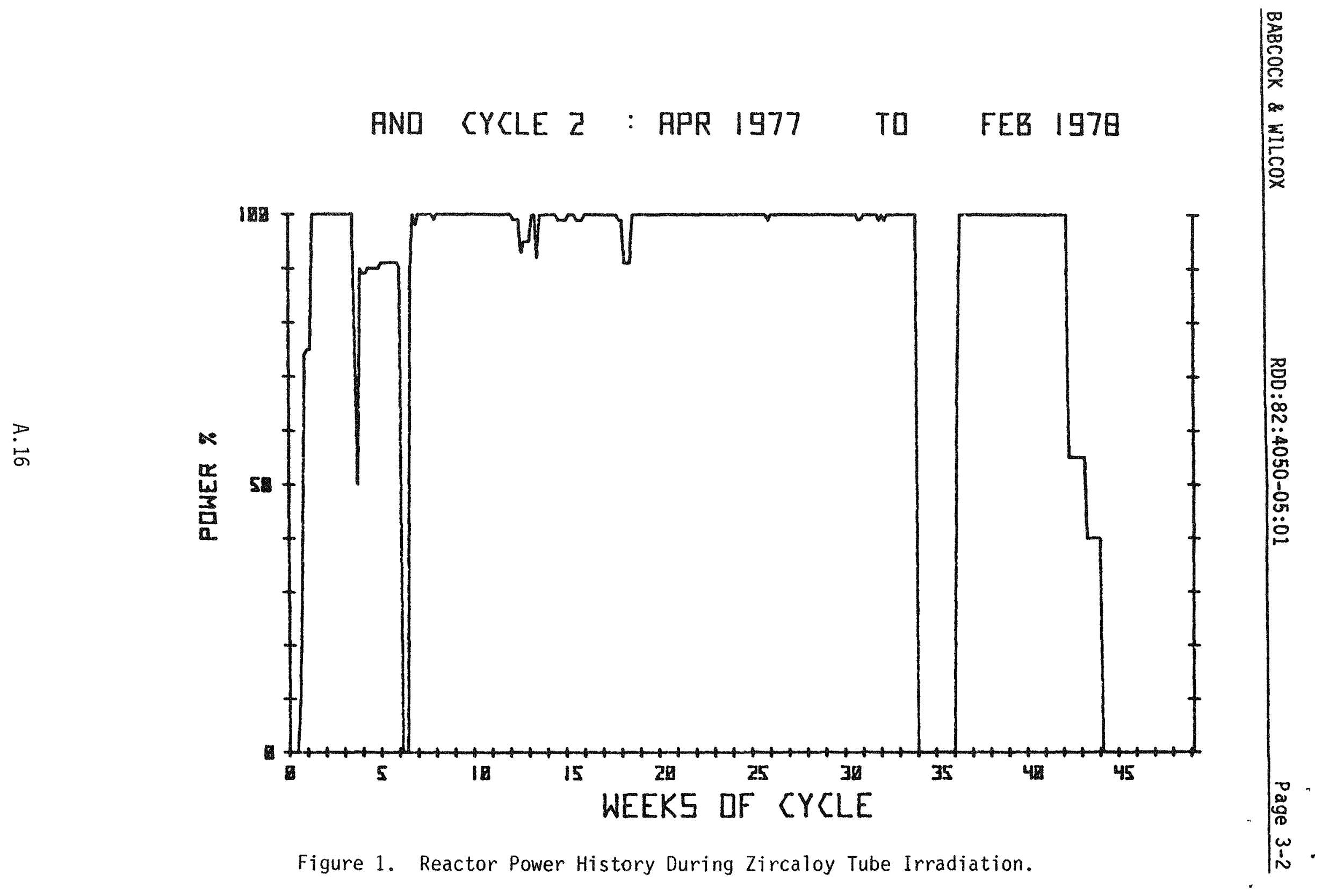




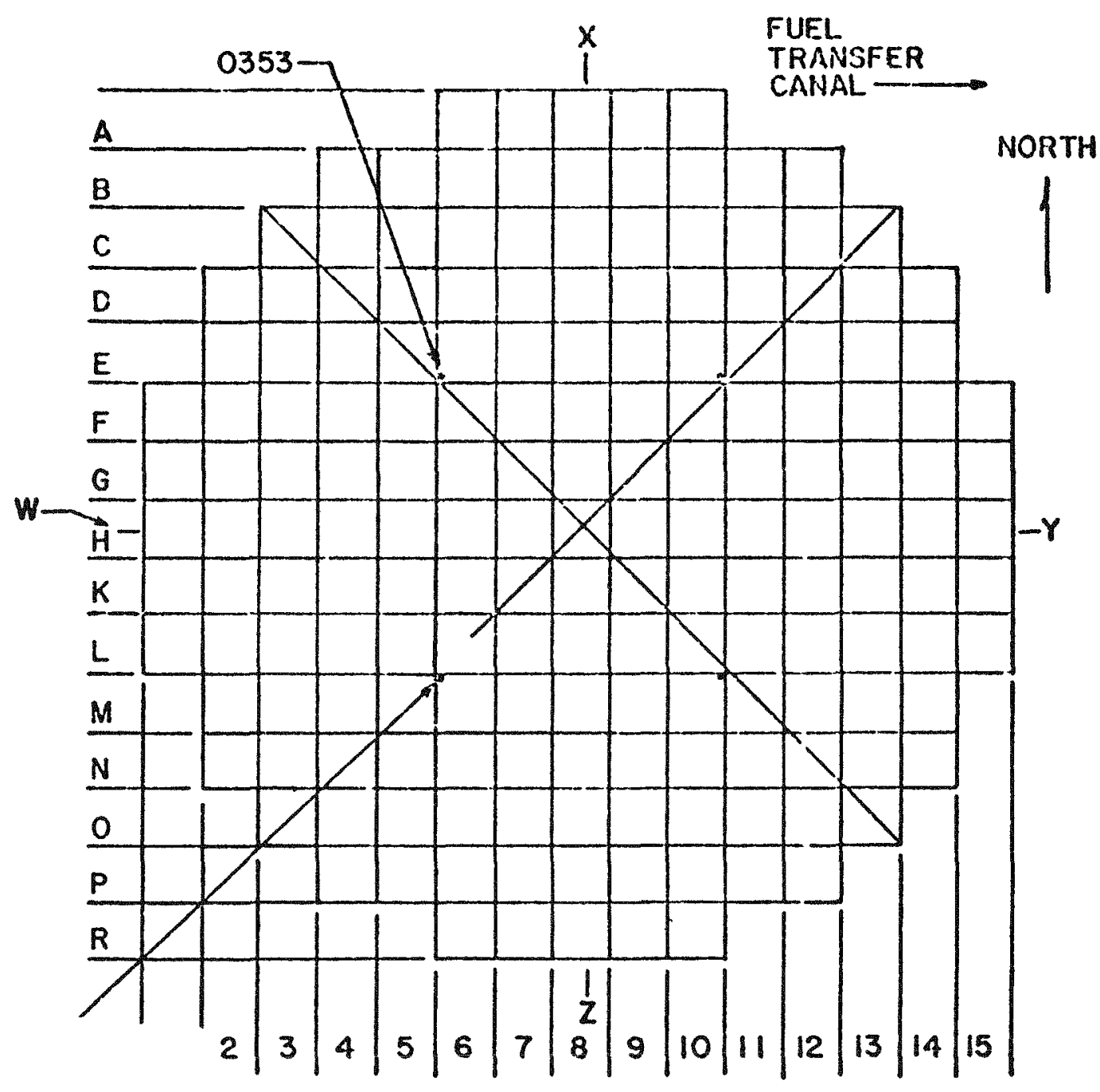

- Core Locations of Zircaloy Tube Clusters. 


\subsection{GROSS GAMMA SCANS}

The four cladding segments that were gamma scanned were identified by one, two, or four dots, and a band of white paint at the top of the rod in the gamma scan position. The activity traces of total gamma activity and, due to ${ }^{54} \mathrm{Mn}$ photopeak region, were essentially flat and did not show any axial region of excessive activity. It was determined from an examination of the activity traces that the variation in activity at any axial position was within 15 to $20 \%$ from the average. However, the activity at one end of three of the rods appeared to be higher. This type of variation is attributable to the location of these segments at the lower portions of the core where the neutron flux tends to be higher, as reported ${ }^{(4)}$ earlier in similar measurements. It can, therefore, be concluded that the neutron fluence experienced by these segments is reasonably constant at all axial positions.

\subsection{ISOTOPIC GAMMA SCAN MEASUREMENTS}

Gamma spectra were accumulated with each of the four rods positioned in front of the collimator at 8,15 and 22 inches from the top of the Zircaloy segment. One gamma spectrum of each rod and the gamma spectrum used for the evaluation of the normalization constant were taken for long counting periods ( $>15$ hours) in order to minimize random errors in counting. The activity of ${ }^{54} \mathrm{Mn}$ based on the area of the characteristic photopeak at $835 \mathrm{keV}$ was corrected for the decay to the end of irradiation.

The statistical errors (1 sigma values) in data based on two hours counting time were of the order of $15 \%$ while the errors in data based on long counts were $<4 \%$. 


\subsection{EVALUATION OF NORMALIZATION CONSTANT}

The activity of ${ }^{54} \mathrm{Mn}$ in the axial section of a rod seen by the detector using the constant collimator geometry utilized for all isotopic gamma scan measurements was $9.19 \times 10^{-5} \mathrm{mCi}$ at the end of irradiation. The absolute specific activity of ${ }^{54} \mathrm{Mn}$ in a 0.10 -inch transverse section weighing $0.3472 \mathrm{~g}$ taken from the gamma scanned position was $29.1 \mathrm{mCi}$ at the end of irradiation. It was determined from the physical dimensions of the collimating system that 0.8185 inch axial section was seen by the detector.

The nomalization constant based on measured absolute specific activity was evaluated as $9.12 \times 10^{5} \mathrm{mCi} / \mathrm{g}$ per microcurie of ${ }^{54} \mathrm{Mn}$ activity detected under isotopic gamma scan conditions and decay corrected to the end of irradiation.

A value that was $5 \%$ higher was calculated for the normalization constant using the axial section seen by the detector $(0.8185$ inch), wall thickness of the cladding (0.02675 inch) and an inside diameter of 0.3765 inch for the Zircaloy cladding.

The former value evaluated on the basis of experimental determinations was used for calculating the neutron fluences.

\subsubsection{Neutron Fluences from Isotopic Gamma Scans}

The gamma spectra recorded at three axial positions of four rods were analyzed by software provided with the Nuclear Data ND-6620 system. The activities of ${ }^{54} \mathrm{Mn}$ at the end of irradiation calculated from the spectral data are given in Table II. The neutron fluences at these axial positions were calculated using equation (3) of section 2.3 and the nomalization constant. 
Table II

FAST NEUTRON FLUENCE MEASUREMENTS OF IRRADIATED ZIRCALOY

\begin{tabular}{|c|c|c|c|c|c|c|}
\hline \multirow[b]{2}{*}{$\begin{array}{l}\text { Rod } \\
\text { No. } 2\end{array}$} & \multicolumn{2}{|c|}{ 1 Position 1} & \multicolumn{2}{|c|}{ Position 2} & \multicolumn{2}{|c|}{ Position 3} \\
\hline & $\begin{array}{l}3 \text { Activity } \\
\left(\text { mci } \times 10^{5}\right) \\
\end{array}$ & $\begin{array}{l}{ }^{4} \mathrm{Fluence} \\
\mathrm{ln} / \mathrm{cm}^{2} \times 10^{-21}\end{array}$ & $\begin{array}{l}\text { Activity } \\
\left(\mathrm{mCi} \times 10^{5}\right) \\
\end{array}$ & 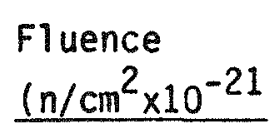 & $\begin{array}{l}\text { Activity } \\
\left(\mathrm{mCi} \times 10^{5}\right)\end{array}$ & $\begin{array}{l}\text { Fluence } \\
\left(\mathrm{n} / \mathrm{cm}^{2} \times 10^{-21}\right)\end{array}$ \\
\hline 1 & 7.61 & 1.86 & 10.3 & 2.53 & 10.8 & 2.64 \\
\hline 2 & 8.41 & 2.06 & 11.1 & 2.73 & 11.6 & 2.83 \\
\hline 3 & 11.9 & 2.92 & 8.10 & 1.98 & 7.70 & 1.89 \\
\hline 4 & 9.57 & 2.34 & 11.4 & 2.80 & 10.6 & 2.58 \\
\hline
\end{tabular}

Axial positions of 8,15 and 22 inches from top of rod.

2 Rods identified with 1,2 and 4 dots and a band of white paint.

3 Measured activity of ${ }^{54} \mathrm{Mn}$ at end of irradiation.

4 Fast neutron filuence $(\mathrm{E}>0.1 \mathrm{MeV})$.

The neutron fluence values given in Table II were based on the reaction ${ }^{54} \mathrm{Fe}(n, p){ }^{54} \mathrm{Mn}$ that has a $Q$ value of $0.085 \mathrm{MeV}$, calculated using the respective mass excess values from reference 2 . Therefore, the evaluated neutron fluence values are for neutrons with energies greater than the $Q$ value.

A reaction cross-section value of $56.3 \mathrm{mb}$ was used in calculating the neutron fluences using equation (3). This value is lower compared to a recommended value of $82.5 \mathrm{mb}$ for this reaction with fission neutrons ${ }^{(5)}$ and, therefore, needs further explanation. The lower reaction cross-section value was obtained by taking into consideration the moderation of fission neutron spectrum in a power reactor.

The Nuclear Power Generation Division (NPGD) of Babcock and Wilcox evaluated the influence of neutron moderation in a Duke type nuclear reactor and calculated ${ }^{(3)}$ the reaction cross-section for ${ }^{54} \mathrm{Fe}(n, p){ }^{54} \mathrm{Mn}$ using fission source and reactor flux distributions as weight functions and NULIF spectrum code with a lower energy limit of $0.1 \mathrm{MeV}$. The literature value ${ }^{(5)}$ of $82.5 \mathrm{mb}$ 
for $\sigma(n, p)$ was confirmed with a fission source distribution while a value of $56.3 \mathrm{mb}$ was obtained using a neutron flux distribution function. On this basis the latter value was used in the present calculations.

The neutron fluences calculated on the above basis are given in Table II. In these calculations it was assumed that the $\sigma(n, p)$ value with a neutron lower energy limit of $0.1 \mathrm{MeV}$ is the same for the reaction with a $Q$ value of $0.085 \mathrm{MeV}$.

The average value of the neutron fluence based on the 12 measurements was $(2.43 \pm 0.39) \times 10^{21}$ neutrons $/ \mathrm{cm}^{2}$ with an associated sigma value of $16 \%$. A mean value of $(2.44 \pm 0.35) \times 10^{21}$ neutrons $/ \mathrm{cm}^{2}$ with a sigma value of $14 \%$ was obtained by discarding the lowest and the highest values of calculated neutron fluences.

The neutron fluence values can be converted into fuel burnup using the physics calculations $^{(6)}$ of NPGD. These calculations provided the following relations:

$$
\phi t(E>1.0 \mathrm{MeV}) \times 10^{21}=0.17 \times \mathrm{Bu}(\mathrm{GWD} / \mathrm{MTU})
$$

and

$$
\frac{\phi t(E>0.1 \mathrm{MeV})}{\phi t(E>1.0 \mathrm{MeV})}=2.04
$$

The average fuel burnup of 7.01 GWD/MTU was calculated corresponding to the average neutron fluence of $2.43 \times 10^{\Sigma 1}$ neutrons $/ \mathrm{cm}^{2}$ of neutrons with energies $>0.1 \mathrm{MeV}$.

\subsection{RADIATION LEVELS AND RADIOISOTOPE CONTENT}

OF IRRADIATED ZIRCALOY CLADDING

The results of a gamma spectroscopic examination of two representative sections of irradiated Zircaloy cladding are given in Table III. These data were based on gamma spectra collected on 13 April 1982 of the two specimens using a precalibrated gamma detector system. They represent the true 
radioisotope composition and their activity levels in irradiated Zircaloy at the time of measurement. It can be seen that the activity due to ${ }^{125} \mathrm{Sb}$ and ${ }^{60} \mathrm{Co}$, the two activation products, constituted about $95 \%$ of the specific activity of the samples.

Table III

RADIOISOTOPE CONTENT OF IRRADIATED ZIRCALOY TUBES

\begin{tabular}{lcc} 
Nuclide & \multicolumn{2}{c}{${ }^{1} \begin{array}{c}\text { Specific Activity } \\
\text { (mCi/inch) }\end{array}$} \\
$\frac{{ }^{2} \text { Specimen 1 }}{{ }^{51} \mathrm{Cr}}$ & $\frac{57.6}{{ }^{54}}$ & $\frac{\text { Specimen 2 }}{57.6}$ \\
${ }^{54} \mathrm{Mn}$ & 11.3 & 11.7 \\
${ }^{60} \mathrm{Co}$ & 56.4 & 57.0 \\
${ }^{125} \mathrm{Sb}$ & 1517. & 1543. \\
${ }^{137} \mathrm{Cs}$ & 1.1 & 1.8
\end{tabular}

1 As measured on 13 Apri1 1982.

2 Specimen 1 of 2.33 inches: Specimen 2, 2.31 inches.

The presence of a small amount of ${ }^{137}$ Cs activity (approximately $0.1 \%$ ) was assumed to be due to the deposition on the cladding of this fission product from the reactor coolant.

The measured specific activity (mci/inch) was considered to be entirely due to ${ }^{125} \mathrm{Sb}$ and the expected radiation level was calculated $(7)$. Weighted averages of 1.9 gammas per disintegration and an energy of $1.2 \mathrm{MeV}$ were determined from the decay scheme ${ }^{(3)}$ of ${ }^{125} \mathrm{Sb}$ and were used in the calculations. A radiation level of $1.8 \mathrm{mR} / \mathrm{hr} / \mathrm{inch}$ at one meter corresponded to the measured specific activity. 


\subsection{REFERENCES}

1. J. H. Hicks and T. L. Hardt, "R\&DD Radiochemistry Manual," Rev. 1, p. 4-10, May 1980.

2. C. M. Lederer, Editor, Table of Isotopes, 7th Ed., John Wiley and Sons, 1978.

3. E. C. Toops, "Review of Results for EPRI/B\&W Contract RP-711," Babcock \& Wi lcox Document No. 32-1102761-00, June 1979.

4. V. B. Subrahmanyam, "Fast Flux Determination for Oconee 2, Cycles 1 and 2 Creep Collapse Specimens 80002 and 80021," LR:79:4733-72:01, January 1979.

5. Anon., Handbook on Nuclear Activation Cross-Sections, Technical Reports Series No. 156, p. 287, International Atomic Energy Agency, Vienna, 1974.

6. G. M. Bain, Lynchburg Research Center, Babcock \& Wilcox, Private Communication.

7. Anon., Radiological Health Handbook, p. 32, Bureau of Radiological Health, U. S. Department of Health, Education and Welfare, January 1970. 

APPENDIX A

PREIRRADIATION SPECIFICATIONS OF ZIRCALOY CLADDING 

THE BABCOCK WILCOX $C O$. NUCLEAR MATERIALS DIVISION COMMERCIAL NUCLEAR FUEL PLANT

LYNCHBURG, VIRGINIA

\section{TRANSMITTAL RECORD TR N0.: 1028}

\begin{tabular}{|c|c|}
\hline R. J. Beauregard & $660-016 B$ \\
\hline $\begin{array}{l}\text { FROM: } \\
\qquad \text { CNFP Quality Control }\end{array}$ & $\begin{array}{r}\text { NPGD SPECIFICATION } \\
\text { N/A }\end{array}$ \\
\hline $\begin{array}{l}\text { SUBJECT: } \\
\qquad 16 B / 7 C \text { Fuel Clad Data }\end{array}$ & $\begin{array}{l}\text { NPGD DRAWING } \\
\qquad / A\end{array}$ \\
\hline RIGINATOR $\frac{U^{0} \Omega_{2}}{\text { W. L. Tibbs }}$ & $\begin{array}{l}\text { OTHER REFERENCES } \\
\text { EMI } 1060 \text { and } 1068 \\
\end{array}$ \\
\hline $\begin{array}{l}\text { APPROVAL: } \\
\text { MFG.ENG. } \frac{\text { TXA }}{\text { QUAL. CONT. }} \text { DATE JieOL DATE } 19 / \mathrm{s} / 81\end{array}$ & $\begin{array}{l}\text { ATTACHMENTS } \\
\text { See Below }\end{array}$ \\
\hline $\begin{array}{l}\text { REASON FOR TRASMITTAL: } \\
9 / 28 / 81 \text { Verbal Request from C. G. Dideon to } D \text {. } \\
\text { on the Mark "B" cladding used in the } B_{4} C \text { Irradi } \\
\text { Attached for clad lot } 3 J D 53 \\
\text { 1) B\&W Inspection Results for shipment contain } \\
\text { 2) Sandvik Certification ( } \# 3 J 053 \text { ) for Lot No. } \\
\text { Certification for ingot 399488Q. }\end{array}$ & $\begin{array}{l}\text { Mayberry for clad data } \\
\text { ion test assemblies. } \\
\text { g Lot } 3 J 053 \text { (Rec. } 4796 \text { ) } \\
\text { D53 including Wah Chang }\end{array}$ \\
\hline
\end{tabular}

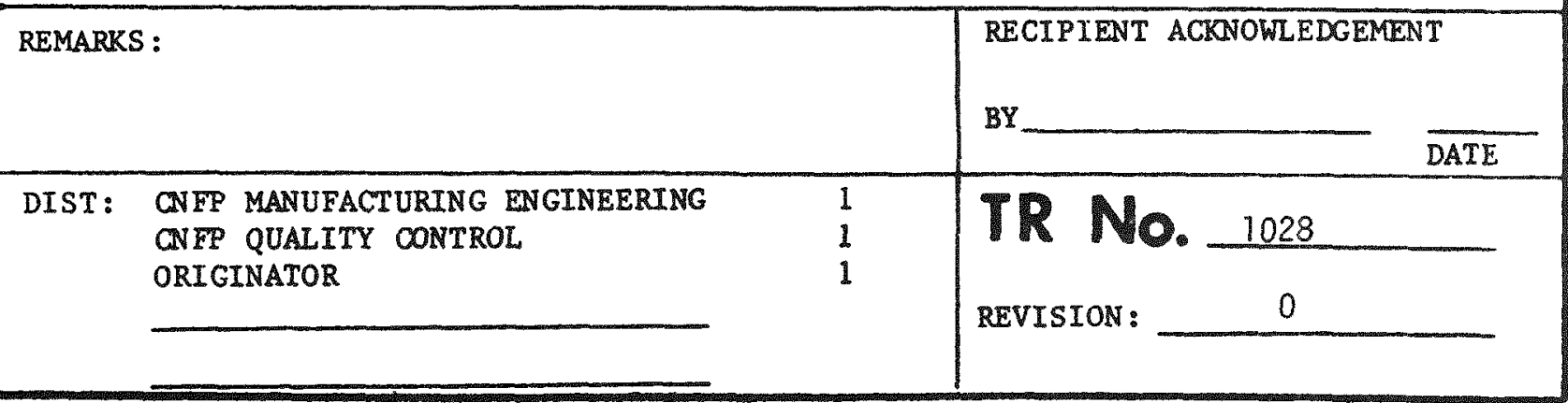



SANDVIK SPECIAL NSTALS CORP

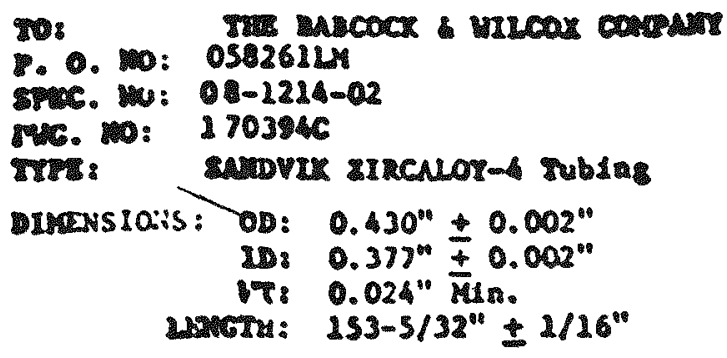

IRAS ILE PRORLILS

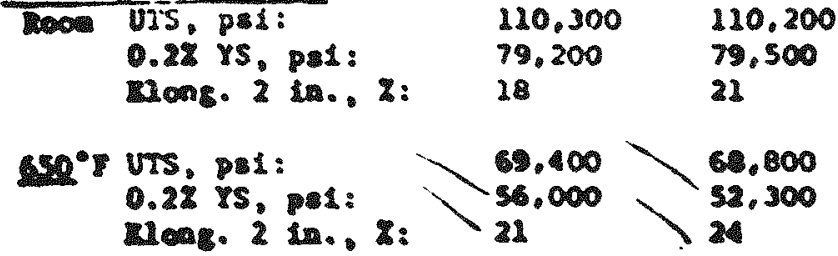

U ST rest

19.4.

Arc. Inas. :

ITLIDE ORIENTATIOA

OD:
WD:
ID:

COSIOL TEST

- Nie vitin:

5u. Calor:

1. 16:
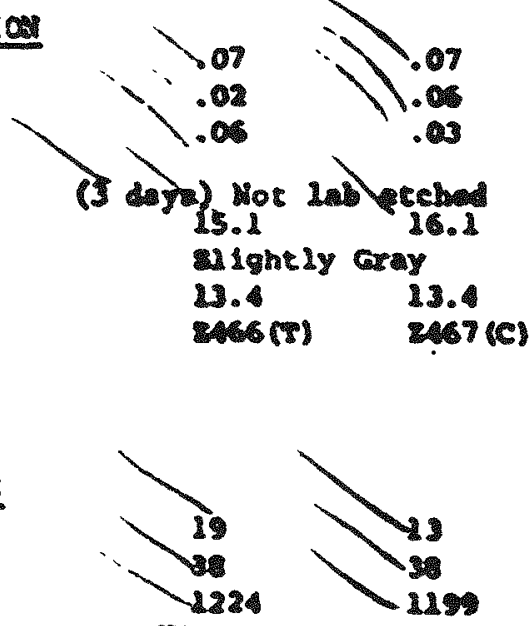

14 yroes:

4 rover:

ctrm:

Caras

1.4T. $31 \%$

Lene.

ir.

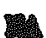

CERTIICATION OF QUALITY

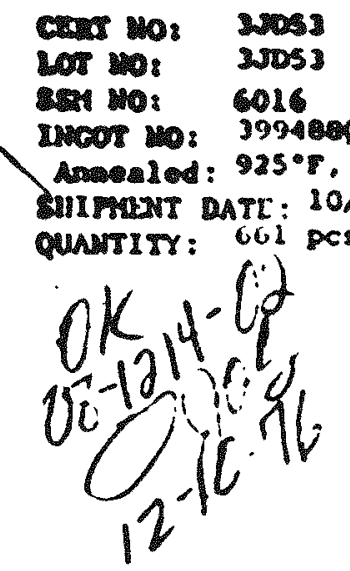

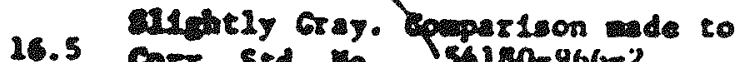
2468 (3)

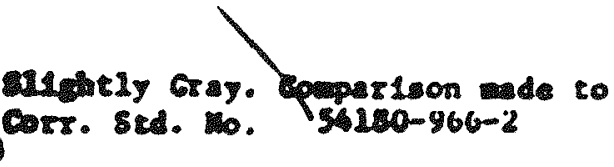

LUPACE ZCUCHESS

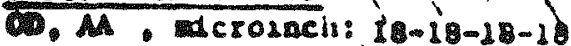

TD. Acroinch: $16-18-18-16$

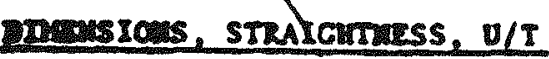

'Ll tuber approved.

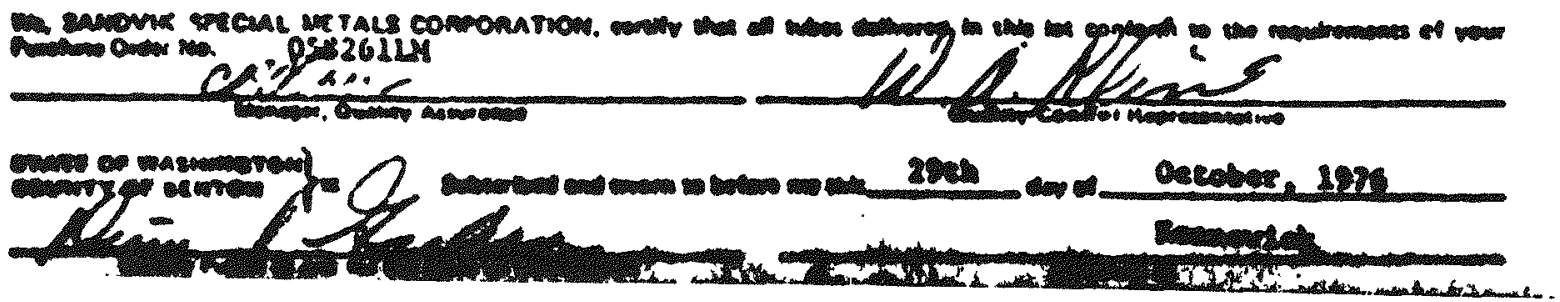




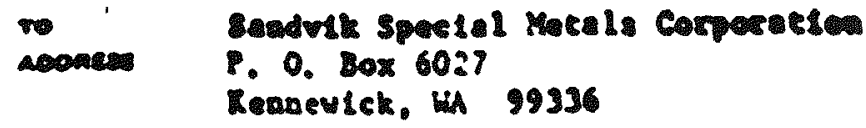

IISOT ANALISIS CasosILZOT IV PECER

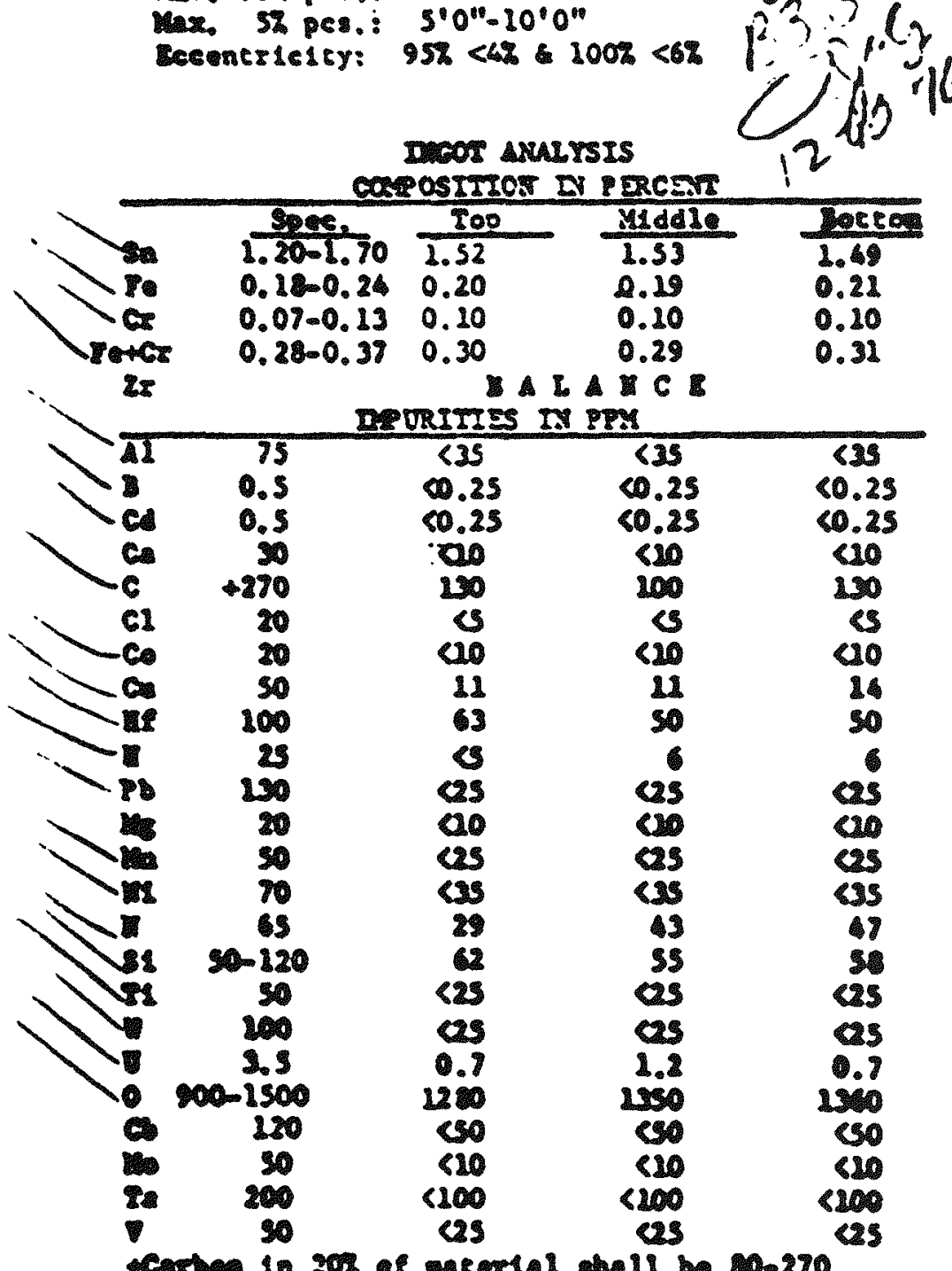

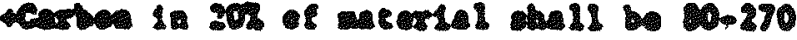

TIEOPNE WAH CHANG ALBANY

-.

1. 1212

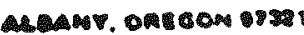

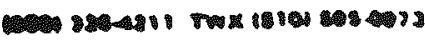

-ren

are

oumrotr 0

mocuction OM OR

-ar

47129.1976

ล. . . . . 1

100 pcs. $012.01 \mathrm{be}$

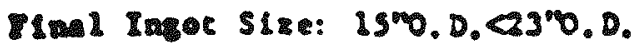
vo serlal lor isn so Noreh

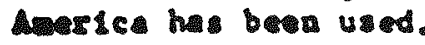

IXcot MARDTESS, BKT

(-2ase $(200) 170-178$ Average (187 176

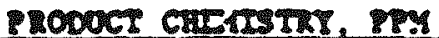

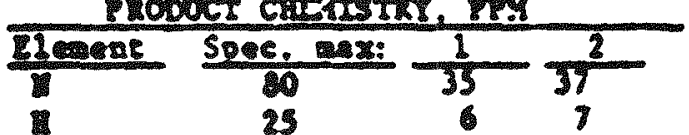

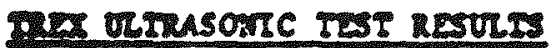

(100\% Coversere)

Heale - Acceprodo

Ex 0.D sUTACE TITST, CS Ene. Mar: 125

2aste - aceptable

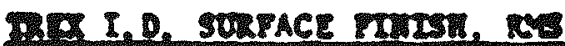
Epec. $x: 1$

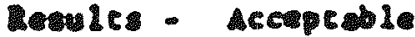

TPOT TLRASORTC TEST RESULT seceris 


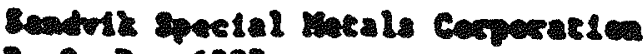
P. O. 6027

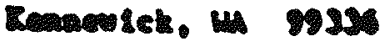

ATremion of: D. H. Darsow

\section{WTE-DONE WAH CHANG ALBANY}

6. 1. \% 1.

2a 2

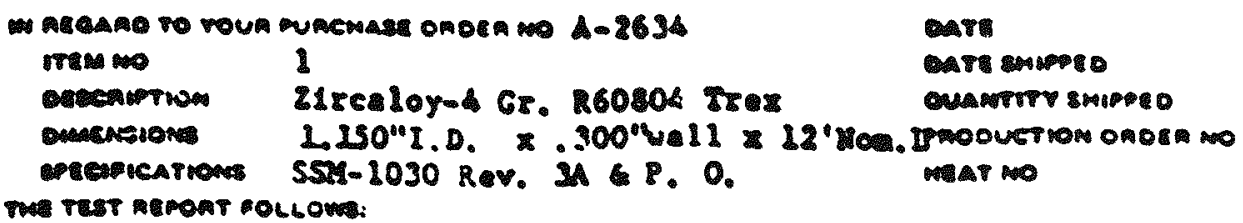

PROCOCT MARDiess, RB

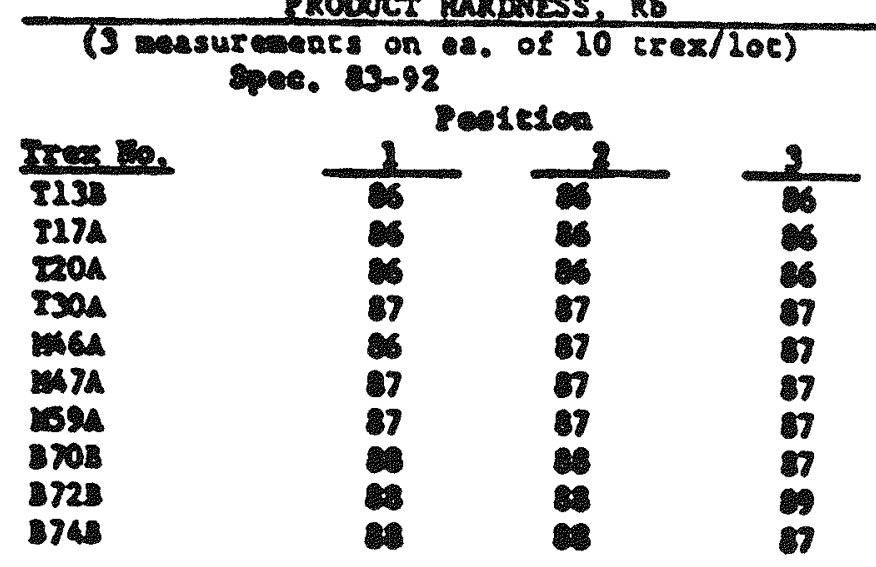

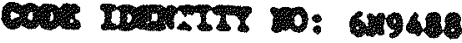

Tra remts

$105-60$ vidde -60 Botece -60

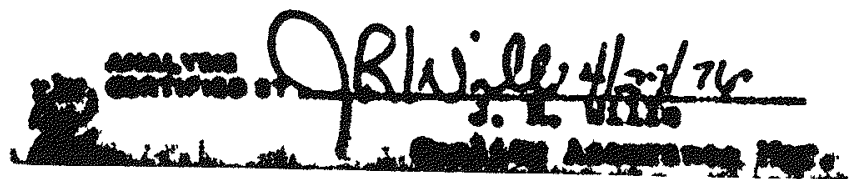




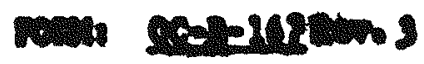

coveracial mucien nis mart

Rec. 4796

\begin{tabular}{|c|c|c|c|c|c|c|c|c|c|c|}
\hline \pm & $\begin{array}{r}1 \\
123-3 / 32^{\circ} \\
\pm 1 / 10^{\circ}\end{array}$ & 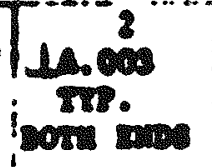 & $\begin{array}{l}.377^{3} \mathrm{DuA} \\
8.002\end{array}$ & .030 DIA & $\begin{array}{l}.005 x .005 \\
\text { Mr. } \\
\text { TrP. }\end{array}$ & $\begin{array}{c}.6 \\
\text { MIN. WALL } \\
\text { THICONESS }\end{array}$ & $\begin{array}{l}7 \\
\text { visual } \\
.0015 \\
\text { mux. }\end{array}$ & $\begin{array}{l}8 \\
\text { CLEANLI- } \\
\text { MESS }\end{array}$ & $\begin{array}{l}9 \\
\text { SURPACE } \\
\text { FISI IA } \\
45 \text { RHE }\end{array}$ & \begin{tabular}{|c|}
10 \\
Smaicurwess \\
$.010^{\circ} \mathrm{PER}$
\end{tabular} \\
\hline & of & ot & .5i6 & $\begin{array}{l}089 \\
: 48\end{array}$ & of & $025 \mathrm{~min}$ & Sh & ok & on & ot \\
\hline & & & & & & - di as & & & & \\
\hline $1-10$ & ok & $\alpha$ & $\begin{array}{r}376 \\
.3785 \\
-3985 \\
\end{array}$ & $\begin{array}{l}489 \\
-4305 \\
4305\end{array}$ & ols & $.25 \mathrm{~min}$ & on & OK & $O k$ & or \\
\hline & & & & & & - 19 ares & & & & \\
\hline $\begin{array}{l}35 e-12 \\
1 a-10\end{array}$ & of & ok & :376 & $\begin{array}{l}.589 \\
.481\end{array}$ & oks & $.0255 \mathrm{~min}$ & on & or & ok & OK \\
\hline & & 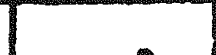 & & & & $.0 \%$ & & & & \\
\hline 31.23 & on & ok & 376 & $: y^{2}: 5$ & ok & $025 \mathrm{~min}$ & on & on & on & $a k$ \\
\hline & & & & & & 0870 & & & & \\
\hline & & & & & & & & & & \\
\hline & & & & & & & & & & \\
\hline & & & & & & & & & & \\
\hline & & & & & & & & & & \\
\hline
\end{tabular}

THE UACOC \& MILCOX CO.PAN

RULITS CONTROL DEPANTMENT

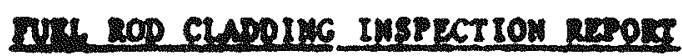

- - i

I.YNCHBURE, VIRCIMTA

DWC. :0. $\frac{170394<-1}{03-1814}$

SPEC MO. $-07-1314-03$

JOB No.

$660-021 A$
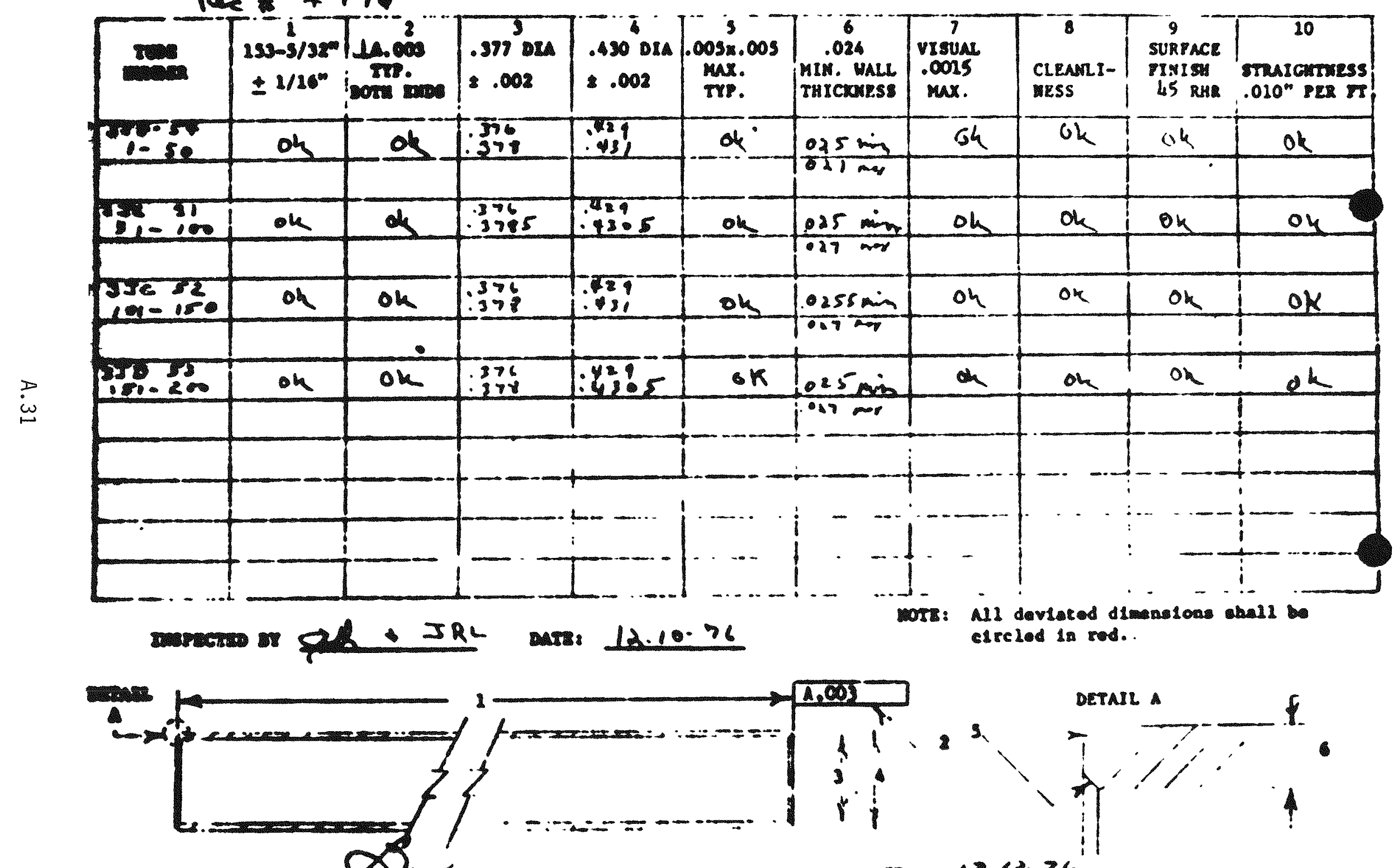

APPENDIX B

STATEMENT OF WORK 



\section{STATEMENT OF WORK}

1. Specimen Selection

The Contractor shall provide 20 specimens of irradiated Zircaloy-4 fuel rod cladding to Battelle. The specimens shall be selected from the cladding which was irradiated in a non-stressed, non-fueled condition in the ANO-1 reactor for one reactor cycle of 272 effective full power days. In addition, the 20 specimens shall meet the following requirements:

(a) Length of the fuel rod pieces shall be 27-39 inches.

(b) Local fast neutron fluence in at least 10 pieces must exceed that equivalent to 6,000 MWd/MTU local fuel burnup.

(c) Minimum inner diameter of the pieces must fall within 0.001 inch of their mutual average (minimum) inner diameter. This shall be tested by deburring the tube ends and inserting a series of drill rods (of graded diameters) to a depth of at least 26 inches into each piece. The drill rods shall be supplied by Battelle.

(d) The average minimum inner diameter for the 20 pieces shall be in the range 0.3755 to 0.3785 inches.

2. Gamma Scanning

The Contractor shall gamma scan 4 of the specimens at 3 or more axial locations. A GeLi detector will be used and a suitable standard will be prepared and analyzed. From these measurements, a fluence calculation will be made to generate an axial fluence profile for each measured rod. A suitable identification procedure shall be employed to insure that gamma scan results can be traced back to the representative tube specimens.

3. Packaging

The 20 selected specimens shall be packaged dry in a cask liner that will be inserted into a shipping cask licensed for 20 curies of special form material. The shipping cask shall be provided by the Contractor.

4. Shipping

The Contractor shall arrange for transportation of the cask to and from Battelle. Battelle shall be responsible for unloading the cask at Battelle, preparing the cask for its return and for the preparation of shipping papers required to return the cask to the Contractor's Lýnchburg Research Center. The shipment to the Contractor shall be made in accordance with the Contractor's instructions for handling the Babcock \& Wilcox Company DOT 55-12500 Shipping Cask. 
5. Documentation

The Contractor shall provide to Battelle's Technical Administrator a letter report within 30 days after the delivery of the specimens which will include the following:
(a) Tubing certifications
(b) Irradiation history
(c) Gamma scanning techniques
(d) Fluence calculations

6. Radioactive Waste

The Contractor shall be responsible for the disposal of any radioactive waste generated in the selection and preparation of the specimens.

7. Government-Furnished Property

The following government property shall be furnished to the Contractor for use in connection with the work described herein:

Nine (9) high precision centerless grind drill rods, measuring 36 "long and having diameters measuring from $.3750^{\prime \prime}$ to $.3790^{\prime \prime}$ in 0.5-mil increments. 


\section{DISTRIBUTION}

No. of

Copies

OFFSITE

U.S. Nuclear Regulatory Commission

Division of Technical

Information and Document

Control

7920 Norfolk Avenue

Bethesda, MD 20014

4 Chief, Fuel Systems Reasearch Branch

U.S. Nuclear Regulatory Commission Washington, DC 20555

2 H. H. Scott

Fuel Systems Research Branch

U.S. Nuclear Regulatory Commission Washington, DC 20555
No. of

Copies

ONSITE

50 Pacific Northwest Laboratory

W. J. Bailey

J. 0. Barner (10)

C. E. Beyer

E. R. Bradley

D. E. Fitzsimmons (2)

M. D. Freshley

E. R. Gilbert

R. L. Goodman

R. J. Guenther

C. R. Hann

D. D. Lanning (20)

F. E. Panisko

P. L. Whiting

R. E. Will iford

Publishing Coordination (2)

Technical Information (5) 